\title{
Assessing the effect of integrated water resources management on the quality of water in the Pra Basin Ghana
}

Citation for published version (APA):

Duncan, A. E. (2019). Assessing the effect of integrated water resources management on the quality of water in the Pra Basin Ghana. [Doctoral Thesis, Maastricht University]. ProefschriftMaken Maastricht. https://doi.org/10.26481/dis.20191022ad

Document status and date:

Published: 22/10/2019

DOI:

10.26481/dis.20191022ad

Document Version:

Publisher's PDF, also known as Version of record

Please check the document version of this publication:

- A submitted manuscript is the version of the article upon submission and before peer-review. There can be important differences between the submitted version and the official published version of record.

People interested in the research are advised to contact the author for the final version of the publication, or visit the DOI to the publisher's website.

- The final author version and the galley proof are versions of the publication after peer review.

- The final published version features the final layout of the paper including the volume, issue and page numbers.

Link to publication

\footnotetext{
General rights rights.

- You may freely distribute the URL identifying the publication in the public portal. please follow below link for the End User Agreement:

www.umlib.nl/taverne-license

Take down policy

If you believe that this document breaches copyright please contact us at:

repository@maastrichtuniversity.nl

providing details and we will investigate your claim.
}

Copyright and moral rights for the publications made accessible in the public portal are retained by the authors and/or other copyright owners and it is a condition of accessing publications that users recognise and abide by the legal requirements associated with these

- Users may download and print one copy of any publication from the public portal for the purpose of private study or research.

- You may not further distribute the material or use it for any profit-making activity or commercial gain

If the publication is distributed under the terms of Article $25 \mathrm{fa}$ of the Dutch Copyright Act, indicated by the "Taverne" license above, 


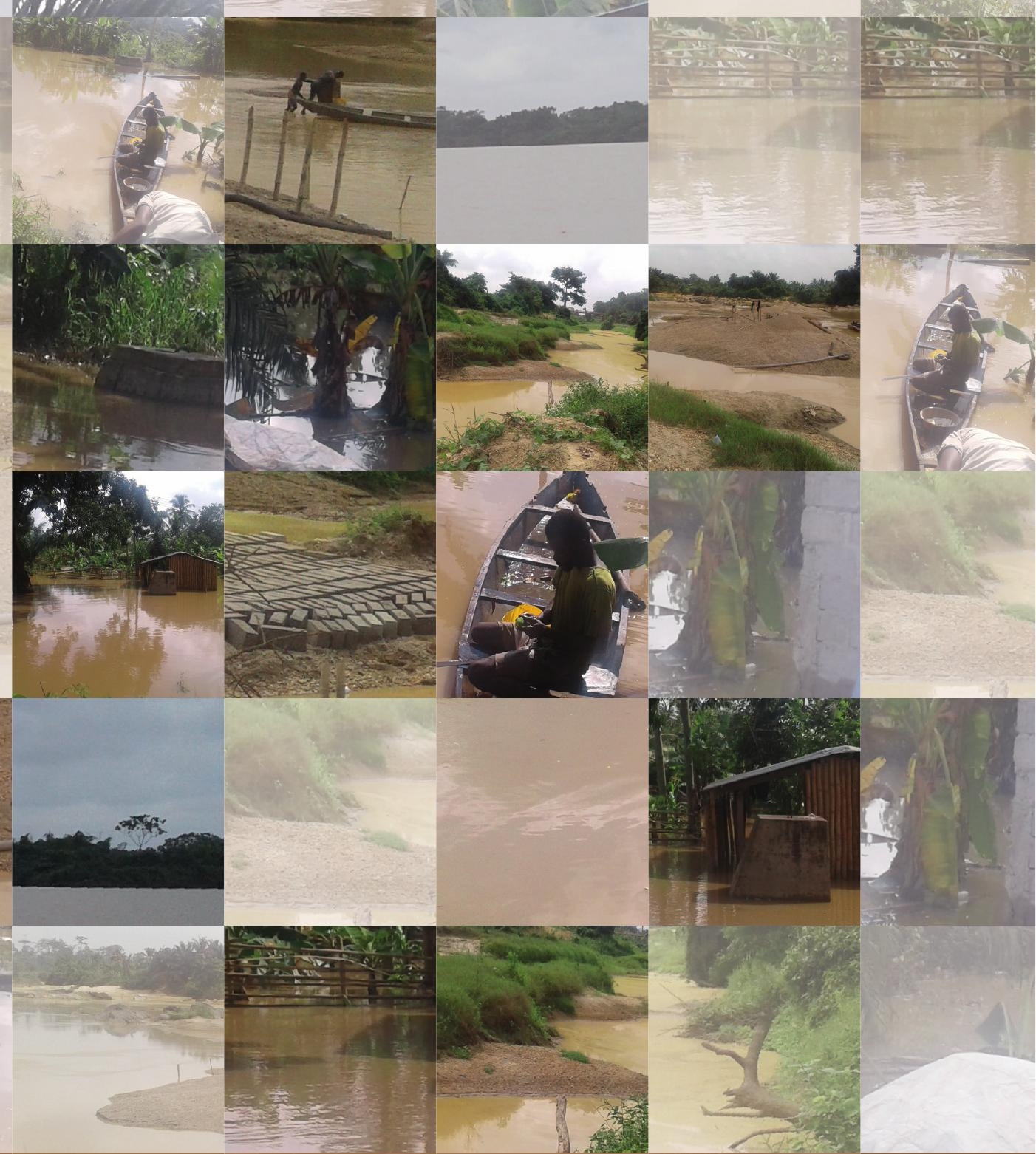

Assessing the Effect of Integrated Water Resources Management on the Quality of Water in the Pra Basin of Ghana

Albert Ebo Duncan 


\section{ASSESSING THE EFFECT OF INTEGRATED WATER RESOURCES MANAGEMENT ON THE QUALITY OF WATER IN THE PRA BASIN OF GHANA}


ISBN: 978-94-6380-565-0

Lay-out: Proefschriftmaken

Print: Proefschriftmaken | https://www.proefschriftmaken.nl

Copyright $\odot$ Albert Ebo Duncan, 2019 


\title{
Assessing the Effect of Integrated Water Resources \\ Management on the Quality of Water in the Pra Basin of Ghana
}

\author{
DISSERTATION \\ to obtain the degree of Doctor at Maastricht University, \\ on the authority of the Rector Magnificus, \\ Prof. dr. Rianne M. Letschert, \\ in accordance with the decision of the Board of Deans, \\ to be defended in public on \\ Tuesday $22^{\text {nd }}$ of October 2019 \\ at 10.00 hours
}

by

ALBERT EBO DUNCAN 


\section{SUPERVISOR}

Prof. dr. Nanne de Vries

CO-SUPERVISOR

Prof. Kwabena Biritwum Nyarko

\section{ASSESSMENT COMMITTEE}

Professor dr. R.M.M. Crutzen (Chairman)

Professor dr. H. W. van den Borne

Dr. M. Mul, Delft Institute for Water Education

Professor John Kwesi Bentum, University of Cape Coast, Ghana

Professor dr. ir. E. Nillesen

The research presented in this dissertation was conducted at the School of Public Health and Primary Care: CAPHRI, Department of Health Promotion, of the Maastricht University. CAPHRI participates in the research School Care, Netherlands School of Primary Care Research

This research presented in this dissertation was supported by the Dutch Ministry for Foreign Affairs (through NUFFIC) and University of Cape Coast (UCC) Ghana. Opinion expressed and conclusions arrived at, are those of the authors and are not necessarily to be attributed to UCC. 


\section{Table of Contents}

$\begin{array}{ll}\text { Chapter } 1 & 9\end{array}$

General Introduction

Chapter 2

The Effectiveness of Water Resources Management in Pra Basin

Chapter 3

Assessing the Effect of Integrated Water Resources Management on Water Quality in Ghana

Chapter 4

Assessment of Heavy Metal Pollution of the Main Pra River and its Tributaries in the Pra Basin of Ghana

\section{Chapter 5}

Assessment of Heavy Metal Pollution in the Sediments of the River Pra and its Tributaries

\section{Chapter 6}

An Intervention to Address Deteriorating Water Quality:

An Application of Ajzen's Theory of Planned Behavior

Chapter 7

General Discussion

References

Summary

Acknowledgements

Valorization

Curriculum Vitae

Publications 


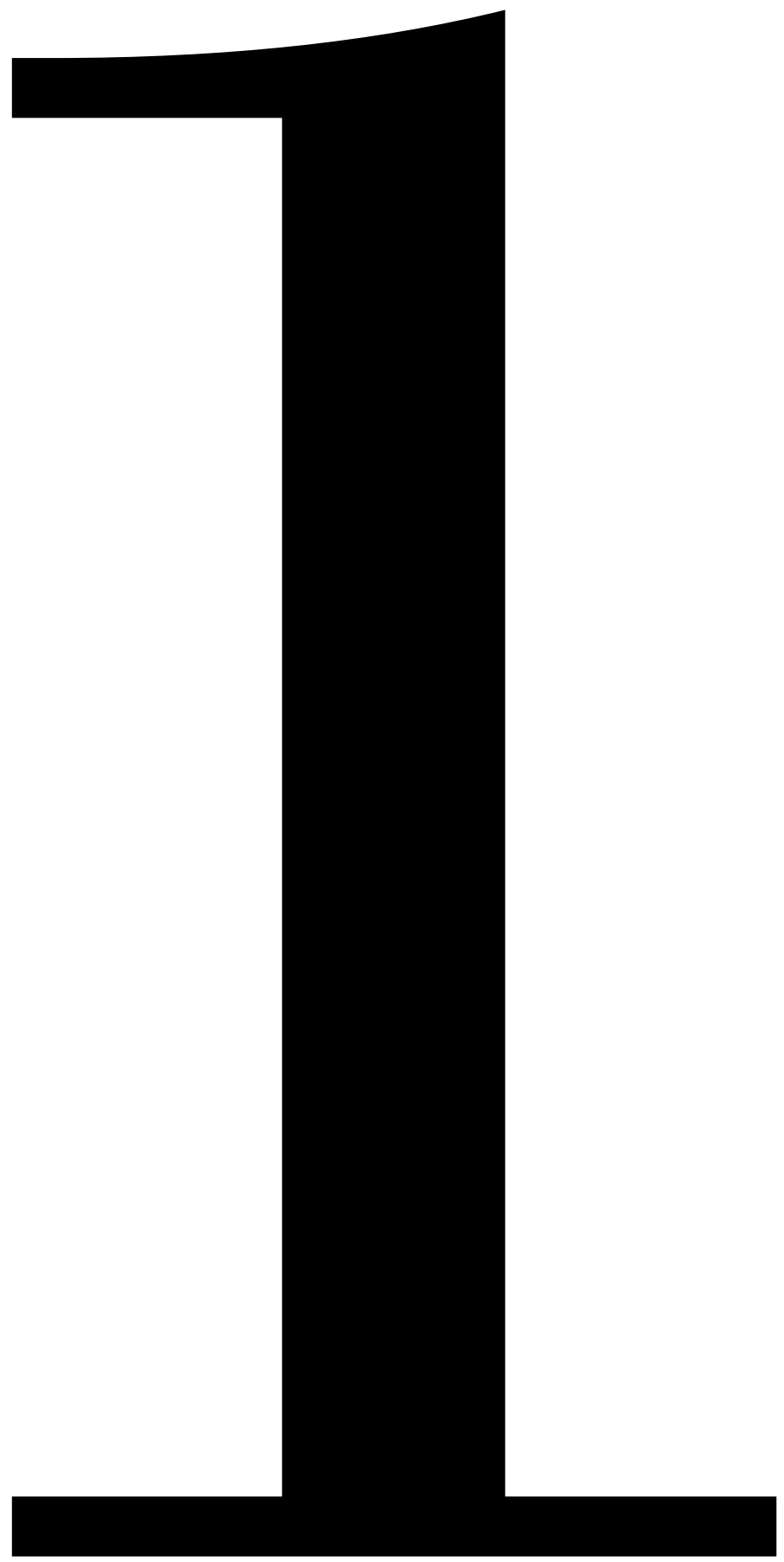


Chapter 1

General Introduction 

Effective water management is critical for water security, quality, supply and distribution. Water resources management can be defined as a process of controlling (planning, allocating, developing) and managing the optimum use of water resources (www.nrcs.usda.gov).The definition implies that any guideline for managing water resources should be practically implementable; able to optimize the use of water resources and ensure the realization of the full benefit of the water resources; and sensitive to the environment. There are two main reasons why water resources should be managed effectively. The first is natural and the second is manmade. How water occurs naturally: the quantity and quality differences and their spatial distribution call for an effective management for its sustainable use.

Concerning the quantity and the quality, about $2 / 3$ of the earth surface is covered with water. Of this, $97.5 \%$ is saline and in the oceans. Only $2.5 \%$ is fresh water. Out of this $2.5 \%$, two-thirds is locked up in glaciers and ice caps. Of the remaining $0.84 \%$, which are the rivers and lakes (the only renewable portion) about $20 \%(0.17 \%)$ is located in areas which are too remote for human access (WWC, 2000). Furthermore, three-quarters of the remaining $80 \%$ occur in monsoon and floods which are also not captured by man. This means that only about $0.13 \%$ of the $2.5 \%$ fresh water is actually available for use. This indeed requires a proper management system for its sustainability. To compound the problem, the $0.13 \%$ is also unevenly distributed. A study by Lalzad (2007) has indicated that whereas certain regions have an adequate supply of water other regions are in deficit. For example, the Amazon basin with a population of about 10 million enjoys $20 \%$ of the global annual rainfall runoff. In Africa, about $30 \%$ of the entire Africa annual runoff occurs in the Congo River basin whose population is about $10 \%$ of the entire continent. There is, therefore, the need for measures to be put in place to ensure that all mankind get access to sustainable water resources.

As for man-made reasons, the population growth, industrial development, irrigation agriculture expansion, rapid urbanization, life style improvements affect management of water resources adversely. Industrial advancement and irrigation expansion are geared towards meeting population demands and improving human life. Over the past century, the human population has tripled resulting in a six fold increase in the use of water (WWC, 2000). Whenever population increases, it produces unprecedented demands on available water complicating the consumption patterns (Radiff, 1999) with an accompanying increase in the waste generated. In the case of the industries: Industrial advancement involves the use of sophisticated machinery which uses, or whose use impact negatively on, the water resources. For example, some industries were sited close to water bodies to increase their access to such water resources and also channeled their untreated waste into them. These water bodies become polluted and are no longer useful for domestic activities. As a result, people have to migrate to other places in search of freshwater resources and a safe environment to settle. This movement adds up 
to the population of the areas they eventually settle in. As population increases the demand for food and shelter automatically increase. Demand for food can only be met through expansion and improvement in irrigation technology. Irrigation farming is known to take about $70 \%$ of the $0.13 \%$ of the available freshwater. This leaves only about $0.04 \%$ of available fresh water for all other activities including domestic, commercial and industrial (pharmaceutical, textiles, petrochemical etc.) purposes. Water abstraction and allocation for irrigation purposes has created a lot of disputes and conflicts in the management of water resources in many developing countries such as Malawi and Zimbabwe (Swatuk, 2005). The increase in population calls for expansion of infrastructure to provide shelter. The provision of shelter sometimes calls for pulling down of trees and re-diversion of rivers creating instability in the ecosystem, reducing downstream flows and changing the climatic condition of the area which will indirectly affect the rainfall pattern and the water resources as a whole. In addition, the added population will have to depend on the same limited available water resource which affects the per capita usage of water. The above factors have a high potential of influencing the quantity and quality of water resources over time especially in developing countries where infrastructural development for water management is very low and waste treatment facilities are virtually absent.

Estimates from World Commission for Water reveals that: 1) about $50 \%$ of the world's population will be under severe water stress condition by 2025 with impact being severe in Africa, the Middle East, and South Asia; 2) water use will increase by $50 \%$ in the next 30 years. These factors from the natural and anthropogenic perspective, together with the empirical estimates is enough evidence to demand that water resources all over the world be managed effectively to ensure present and future use.

\section{Historical development of Water Resources Management: global context}

Historically food shortages accounted for the ultimate reforms in water and land management among communities which settled along great rivers. This reforms led to significant transformations on the management of water from the global to the local level (Hassan, 2011) with a focus on factors such as availability, quality, and quantity to maximize their benefits (Biswas, 2004). The initial transformations focused more on water resources development (mid1920s to late 1970s) with economic focus by investing in irrigation and drainage schemes, long-distance water transport technologies and the construction of big dams at the expense of social, ecological and environment security (Hassan, 2012; Merrey, 2008; Watson, 2003). For example, Watson and Wester (2003), report on water resources development in the mid-1920s to late 1959 which focused on economic gains with an overall objective of maximizing the socio-economic benefits of the water resources through basin development. These developments, although they were environmentally 
insensitive, were believed to have served their purpose and still are. According to the World Bank (2004) water resource strategy report, there are significant direct and indirect benefits for the poor from the water development infrastructure. For instance, in Brazil, there are a large number of high-quality permanent agriculture jobs ( $40 \%$ held by women). Similarly, in India, the impact of irrigation infrastructure to education is enormous. "The return to five years of primary schooling versus no schooling in Indian districts where agricultural conditions were conducive to the adoption of Green Revolution Technologies was high (32\%) whereas in districts where the conditions were not conducive estimated returns to schooling were negative" (Briscoe, 2004 p7). Poverty in un-irrigated districts is $69 \%$ as against $26 \%$ in irrigated districts. At the world summit on sustainable development, it was recommended that developing countries invest in hydropower development as a way to reduce poverty" (Briscoe, 2004). Investing in hydropower implies new dams have to be built. These benefits notwithstanding, some concerns have been consistently raised about the environmental and human impact of these massive developments (Merrey, 2008) because of water user constrains such as unavailability and poor water quality experienced by downstream users. These transformations are also criticized for failing to recognize the interconnected (integrated) nature of water management which creates fragmenting and conflicting roles among water governing bodies. It is also criticized for being the genesis of the current global water crisis. The gaps in this un-integrated system pushed for an integrated management system. As a result, the first United Nations Water Conference was held in 1977 in Mar del Plata, Argentina, to find solutions to the challenges resulting from the unintegrated water management. The effect of the Mar del Plata conference started gaining grounds after Agenda 21 and the World Summit on Sustainable Development (WSSD) in 1992 in Rio where Integrated Water Resources Management (IWRM) became the center of discussion regarding its meaning in practice (Hassan, 2011; Hassing, 2009). The IWRM concept was settled on as the management option to deal with the un-integrated challenges in the management of water resources during the Conference on Environment and Development (Earth Summit) by nearly 500 government designated experts from 100 countries in Dublin in 1992 (Hassing, 2009). The IWRM concept is based on the four key principles from Dublin which states that:

1. Freshwater is a finite and vulnerable resource, essential to sustain life, development and the environment;

2. Water development and management should be based on a participatory approach involving users, planners and policy makers at all levels;

3. Women play a central part in the provision, management, and safeguarding of water;

4. Water has an economic value in all its competing uses and should be recognized as such.

IWRM is defined as a process, which promotes the coordinated development and 
management of water, land and related resources in order to maximize the resultant economic and social welfare in an equitable manner without compromising the sustainability of the vital ecosystem (GWP, 2000). To achieve success in IWRM is to ensure that it is fully implemented.

The IWRM implementation involves putting in place 1) appropriate policies, strategies and legislation 2) relevant organizations and institutions for implementation and 3) set up the management instrument required by these organizations and institutions to function (Hassing et al. 2009). These 3 characteristics are dynamic and flexible for innovations so should only serve as a guide to the implementation process. It is the responsibility of policy makers to determine which set of suggestions, reforms measures, management tools, and institutional arrangements are most appropriate in a particular cultural, social, political, economic or environmental context (Hassing, 2009). Furthermore, the coordination, interconnectedness, and identified needs of the various management levels must be properly addressed. For example, all infrastructural, logistical, and human resource capacity needs etc. must be addressed before the start of the implementation process. Finally, management tools developed must be as practical as possible.

One of the reasons which led to the choice of IWRM was because it seeks the balance between the three dimensions of sustainable development i.e. economic efficiency, social equity and environmental sustainability (Gallego-Ayala \& Juízo, 2011). Another reason is that it acknowledges the interdependent nature of water resources management process by bringing on board water users at all levels to address all potential trade-offs (Lenton, 2012; Pahl-Wostl, 2006). It shows the potential to integrate: 1 ) land and water management 2) surface water and groundwater management 3) quality and quantity of water resources management 4) upstream and down-stream water-related interests 5) freshwater management and coastal zone management 6) a holistic institutional framework 7) water into the national economy 8) water resources planning with poverty alleviation 9) a crosssectoral plan into the national policy development 10) water resources planning into national security and trade policies 11 ) different management levels 12) all relevant stakeholders in the planning and decision-making process (Jønch-Clausen \& Fugl, 2001). Furthermore, its flexible nature makes it possible to be tailored to address the challenges facing the multifunctional, multi-sectoral, multi-regional, degraded physical landscapes, the declining water quality and quantity, the finite, figurative and uneven distribution of water resources, all in a particular cultural, social, political, economic or environmental context across the globe (Agyenim \& Gupta, 2012; Jønch-Clausen \& Fugl, 2001; Swatuk, 2005). IWRM also offers a flexible, well designed and outlined, environmentally sensitive implementation framework. 


\section{Historical development of Water Resources Management: Ghana context}

Ghana remained a British colony until 1957. Before then, water resources management was by customary rules. Water was a free common good with ownership vested in stools and communities (Agyenim \& Gupta, 2012). As Britain gained full control over the Gold Coast in 1902, new rules and regulations were introduced to suit their system of governance. The laws introduced at the time focused more on economic gains at the expense of water and environmental security. Ghana started experiencing a pluralist legislative framework for water management during the colonial period.

Since 1902 to the present day, water resources management has evolved through different management systems, each one with its own drivers and constraints. The period after independence, from 1957-1980, has seen the government embark on various water reforms. The main areas included: 1$)$ developing water for electricity generation 2) managing water for provision, distribution, conservation and supply to the public for domestic and industrial purposes 3) establishment, operation, and control of sewerage systems and 4) developing water for irrigation farming. However, almost all reforms except that for electricity generation could not be sustained because they were state-funded: and at the time, the state was in economic shambles. From 1990 to date, water reforms in Ghana have taken the IWRM approach. The current reforms started with the creation and approval of a commission: the water resources commission (WRC) in 1996. The reforms were further strengthened by the introduction of other key regulatory documents such as the Public Utility and Regulatory Commission (PURC) Act 538 for economic regulation of Water and Electricity Utilities in 1998, and the 2007 national water policy (WRC, 2012). Other supporting institutions and legislative instruments are: The Environmental Assessment Regulation of 1999 (L. I. 1652) for regulating and granting permits for projects with impact on the environment and water resources (surface and underground); water use regulations 2001 (L. I. 1692) for water abstraction, diversion, damming and other water uses such as transportation and agriculture. The new water management uses the basin as the lowest operating unit.

\section{IWRM implementation in the Pra Basin}

Integrated water resources management has gained much popularity in the last two and a half decades. However, the practicality of the integrated approach used in the IWRM has been a controversial and much-disputed subject within the field of water resources management. The absence of practicality is said to generate more problems in developing countries (Merrey, 2008). One other aspect of IWRM which has received constant criticism has to do with the practicality of its implementation. However, the evidence against the 'integration', 'implementation' and their 'practicality' is inconclusive. This study contributes to the discussion by 
assessing the effectiveness of IWRM in addressing the quality of water in the Pra Basin of Ghana. First, we will provide an overview of the study area.

Ghana is drained by three main river systems; the Volta Basin system, South-Western Basin system, and the Coastal Basin system. The Pra Basin which is the study area forms part of the South-Western Basin which comprises of the Pra, Bia, Ankobra, and Tano rivers. Ghana has demarcated the boundaries of its water resources into six basins with a well-developed basin management plan for implementation. One of such basins is the Pra (Figure 1). The Pra Basin cut across four regions in Ghana namely the Ashanti, Eastern, Central, and the Western. There are 50 metropolitans, municipal and district assemblies within the basin. The basin is divided into three sub-basins namely the Upper Pra sub-Committee, Birim sub-Committee and Lower Pra sub-Committee for effective and efficient management.

The Pra basin is the fourth to start operation in Ghana after the Densu, the White Volta and the Ankobra. The Pra Basin is located between Latitudes $5^{\circ} \mathrm{N}$ and $7^{0}$ $30^{\prime} \mathrm{N}$, Longitudes $2^{\circ} 30^{\prime} \mathrm{W}$, and $0^{\circ} 30^{\prime} \mathrm{W}$, in south-central Ghana. The Pra Basin is the biggest among the three south-western basins (Ankobra, Tano, and Pra) of Ghana. There are five rivers in the basin, namely the Pra, the Offin, the Oda, the Anum and the Birim. Bosomtwe the only natural lake in Ghana is located in the basin. The lake serves as a tourist attraction and generates a lot of income for the government and the indigenes. The lake has a catchment area of about $106 \mathrm{~km}^{2}$. The total land area of the basin is about $23200 \mathrm{~km}^{2}$. The topography of the land is flat in the southern half with few peaks in the mid to northern sections of the basin. The vegetation of the basin is of the moist semi-deciduous forest type. The land cover types were estimated as agriculture (60\%), forest (30\%) and grassland and human settlement 10\% (Pra Basin, 2012) .

The basin has a population of about 4.2 million people and a population growth rate of 2.2\% per annum (Pra Basin, 2012). The highest population density is found upstream of the basin whereas the central part has the lowest population density. The rate of urbanization in the districts is about 32\%, however, some of the districts such as the Shama-Ahanta East, Bosomtwi and Atwima are $100 \%$ urbanized.

About $60 \%$ of those employed are in the agriculture sector. The major crop grown in the basin is cocoa and it accounts for about 70 to $100 \%$ of the household income in the basin (Pra Basin, 2012). The change in climate has greatly affected crop yield because of the unreliable rainfall pattern and farmers dependence on the rains over the past decades. Of the remaining $40 \%$ employed, an unspecified percentage are into illegal mining (Pra Basin, 2012).

The rainfall seasons are from May-July and September-November. However, the change in climate distorts the seasonal pattern sometimes. The basin has an annual 
rainfall of about $1500 \mathrm{~mm}$. Of this volume, $12 \%$ contribute to the flow of the rivers in the basin, $72 \%$ returns to the atmosphere in the form of water vapor and $16 \%$ recharges the aquifers. The annual relative humidity of the basin ranges from 70 $80 \%$. The average temperature in the basin is $26^{\circ} \mathrm{C}$ in August and $30^{\circ} \mathrm{C}$ in March (Pra Basin, 2012).

The call for IWRM implementation after the Rio conference in 1992 was accepted by the world as a step in the right direction to solve the emerging challenges in the management of water. In the Pra Basin the IWRM concept was adopted to 1) secure the available water resources through efficient water use; 2 ) improve water conservation and ecosystem health through effective protection and regulation of land and water resources; 3 ) mitigate the suffering and economic loss of communities through adaptation to climate variability and change; 4) strengthen human and institutional capacities to carry out key IWRM mandates with the aim of enhancing the full socio-economic benefit of the water resources for today and the future.

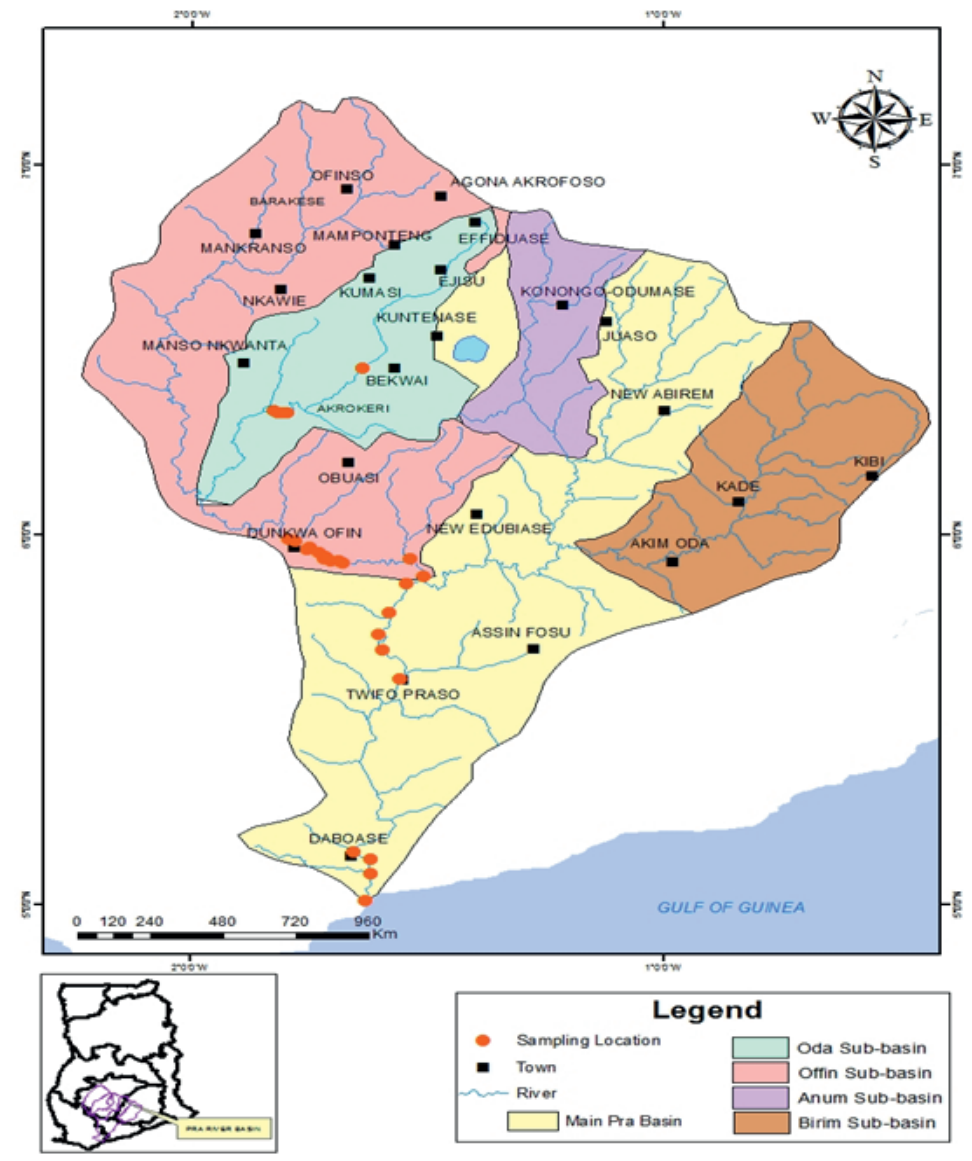

Figure 1: Pra Basin map 


\section{The outline of this thesis}

Chapter 1 provides a background to the research reported in this thesis. It highlights the natural and anthropogenic challenges such as quantity and quality differences and spatial distribution associated with water management and how this necessitated various water management reforms. It further explains why integrated water resources management (IWRM) is the (finally) adopted water management system, the challenges associated with its implementation and the proposed recommendations to ensure effective implementation. Finally, the chapter discusses the reasons/factors such as deteriorating water quality which motivated the implementation of IWRM in the Pra Basin and asks why nevertheless the water quality physically appears to be continually deteriorating.

Chapter $\mathbf{2}$ is a formative study carried out to assess the effectiveness of the IWRM implementation framework in the Pra Basin. This study was conducted to fill the knowledge gap in what is drafted on paper, what needs to be done on the ground, and what is being done, how it should have been done, and how these processes could affect the quality of water in the basin. Furthermore, a framework for ensuring effective implementation based on factors considered for effective river basin implementation is proposed.

Chapters 3, 4 and 5 each present a study conducted as an evaluation of the effectiveness of IWRM in the Pra Basin. Chapter $\mathbf{3}$ monitors the state of the water quality 4 years after implementation by comparing the baseline values to that of its present state. Basically, the study looked at the physicochemical parameters such as $\mathrm{pH}$, turbidity, conductivity, phosphates, nitrate, etc. which were the main parameters for the assessment of the water quality at the time. Information gathered from a field survey reveals the tremendous pressure on the river due to illegal mining both within and around the rivers. Unfortunately, this hasn't been fully captured with the attention it deserves in relation to the quality of water; this is clearly shown in the choice of parameters for the water quality assessment. To address this anomaly and assess the quality of the water to reflect this situation (illegal mining), studies 4 and 5 were conducted. Seasonal variation (dry and wet seasons) has a great influence on the levels and availability of certain water quality parameters such as $\mathrm{pH}$ and heavy metals, hence the inclusion in the study. Chapter 4 investigates the levels of heavy metals in the river, the pollution they cause and the potential risk they pose to inhabitants who depend directly on the river. The contribution of sediments to water quality contaminant dynamics and the use of indexes to establish the source of contaminants as natural or manmade are well established scientific facts. Chapter $\mathbf{5}$ assesses heavy metal contamination of the river sediments as a way of investigating the actual quality of the water during scouring and sharp $\mathrm{pH}$ changes which usually occur when high runoffs are discharged into rivers distorting their buffering ability. The study used the enrichment factor, the geoaccumulation index and the pollution load index to determine the source of pollution as natural or anthropogenic and the 
polluting metals.

Chapter 6 is a behavioral study conducted to address why interventions which are mapped to address environmental challenges in the basin are not working. An intervention by an NGO (A-rocha) to introduce inhabitants to non-traditional farming such as mushroom production in the Abono community in the Pra Basin was not successful. The government intervention to roll illegal miners into a planting for food program has not been successful. These interventions focused on providing alternative jobs with very rich incentives, however, the results have not been impressive. Concerns have been raised about their mode of implementation which violates the IWRM implementation principle of participation at the lowest appropriate level for effective implementation and community ownership of projects. Furthermore, information gathered on the field reveals the absence of empirical evidence in the development of the intervention. Mapping interventions requires factual information to enhance the appropriate areas and factors to consider for action. Even though there are many factors influencing an individual's decision making, since the factors considered in all these interventions (choosing an alternative job) seem to relate to "reason", the theory of planned behavior (TPB) is employed. In addition, the theory has been used to address similar environmental challenges in the past thirty years. For instance, it has been used as a study tool in addressing human behavior in environmental issues such as an enterprises' willingness to adopt/develop cleaner production technologies (Zhang, Yang, \& Bi, 2010) and to identify key behaviors underlying pro-environmental behaviors of high school students (De Leeuw, 2015). The theory which was developed by Ajzen (1991) proposes that an individual's behavior is driven by his intention (I) to execute an action which in turn is determined by his attitude (ATT), subjective norm (SN) and perceived behavioral control (PBC). This implies that an individual's behavioral action could be predicted by any one, two or all three of the above drivers. The government intervention could be classified under the driver PBC. The question is whether PBC indeed is the main predictor of the illegal miner's intention of choosing another job? The study, therefore, investigates which of the drivers is or are the predictors of the miner's behavior. This, when established, will help in the choice of the factors to consider in addressing illegal miners' decision to choose an alternative job without neglecting the recommended IWRM participatory approach.

Chapter 7 provides a general discussion of the main findings of the studies included in this thesis, the methodological issues and the implication of the findings for policy, and further research.

\section{Problem Statement}

After a series of water reforms and implementation of Integrated Water Resources Management in 2012, there are still concerns of deteriorating water quality in the Pra Basin of Ghana. This is worrying because IWRM implementation was to 
address challenges such as the absence of a national water policy, fragmented and overlapping roles and regulations among institutions and organizations in the water sector, nonexistence of cross-sector coordination and harmonization, absence of effective and total stakeholder participation, and ensuring government support and consistency in investing in the management of water resources to improve factors like the deteriorating water quality. Furthermore, it is expected that the low recognition of environmental concerns which the previous water reforms failed to addressed would be addressed by IWRM in order to help improve the quality of the water resources.

However, the continuous deteriorating water quality creates much uncertainty about whether the best water management system is being practiced; or if the system is working well; or needs improvement. This study aims to address the uncertainties by assessing the effect of IWRM on the quality of water resources in the Pra Basin of Ghana, with a particular focus on its implementation and impact on water quality. The specific objectives formulated to achieve this aim are:

1. To assess the implementation of IWRM in the Pra Basin: the effectiveness of water resources management study described in chapter 2.

2. To determine the impact of IWRM on water quality: the assessment of effects of IWRM on water quality described in chapter 3 and the assessment of heavy metal pollution described in chapter 4.

3. To assess the contribution of river sediments to the quality of water: the assessment of heavy metal pollution in sediments of river described in chapter 5.

4. To assess the intervention mapped to reduce the deteriorating water quality in the Pra Basin: the intervention study described in chapter 6 to address the deteriorating water quality in the basin. 



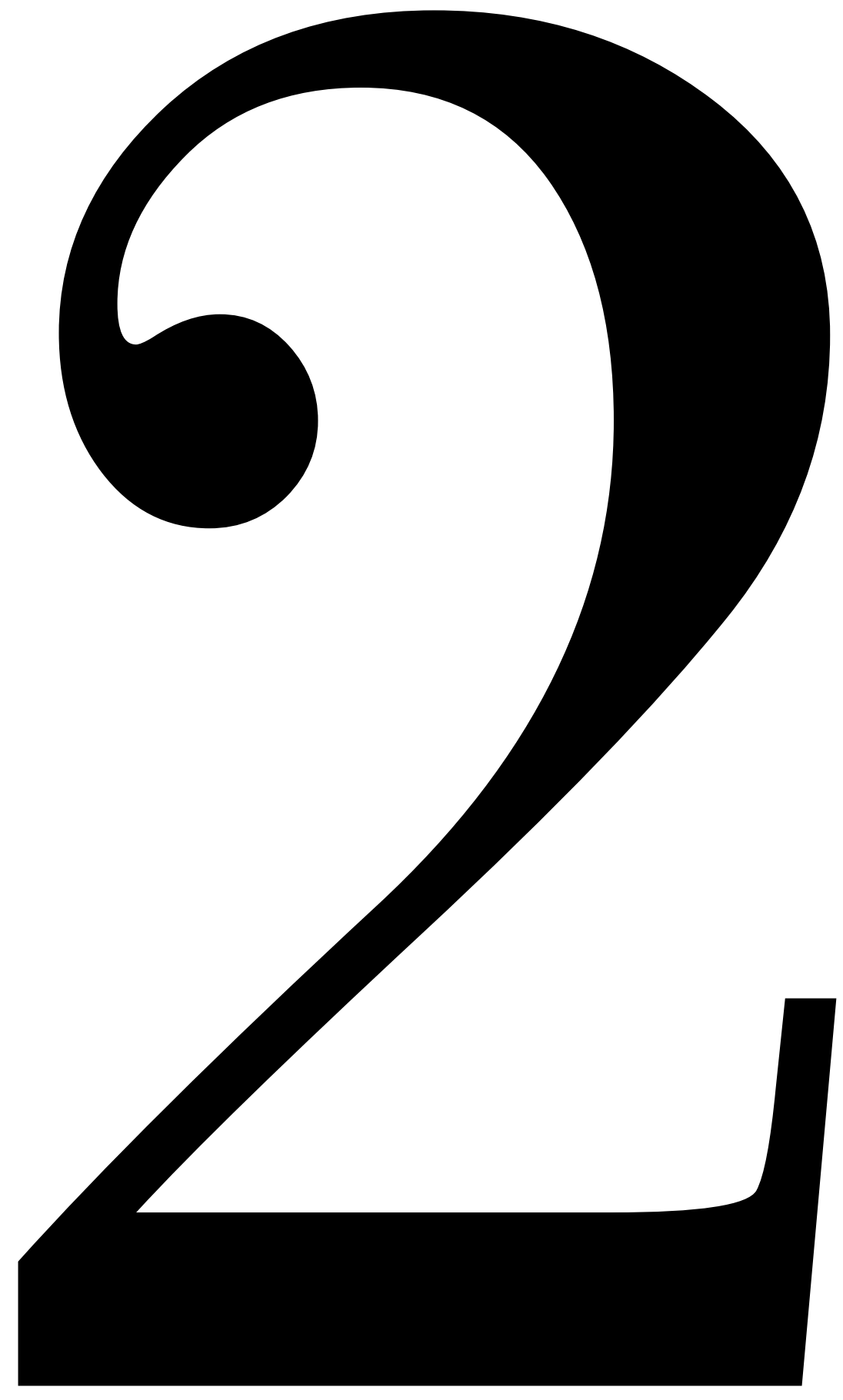




\section{Chapter 2}

\section{The Effectiveness of Water Resources Management in Pra Basin}

Published as:

Duncan, A. E., de Vries, N., \& Nyarko, K. B. (2019)

The Effectiveness of Water Resources Management in the Pra Basin

Water Policy 


\begin{abstract}
Integrated water resources management (IWRM) has been criticized yet it is the dominant approach to water resources management in developing countries. The criticism emanates from the manifold of unfounded assumptions made during implementation on issues such as availability of technology and infrastructure, privatization and sustainable financing, human resource capacity, government interference etc. The Pra Basin has been implementing IWRM since 2012. The basin houses nine out of the seventeen artificial reservoirs constructed in Ghana for drinking water supply. It is therefore prudent that the basin's water resources are given extra management care to ensure sustainable water quality and quantity for growth and development. However, much uncertainty still exists about whether the best water management system is being practiced; whether the system is working well; or needs improvement. This study used interviews, field observations, and documents such as Pra Basin IWRM plan, the National IWRM plan etc. to assess the effectiveness of IWRM in the Pra Basin. The result of the study showed that IWRM though is appropriate for the basin, there are implementation gaps. These gaps are potential contributors to the deteriorating water quality.
\end{abstract}




\section{Introduction}

Water resources management can be defined as a process of controlling (planning, allocating, developing) and managing the optimum use of water resources (www. nrcs.usda.gov). The management could be a traditional/un-integrated or an integrated approach. The un-integrated approach is associated with the building of dams and irrigation schemes without thinking about the downstream social and ecological impact (Merrey, 2008). Furthermore, the un-integrated system is fragmented and fails to recognize the interdependence (integrated) nature of water resources management. This failure leads to conflicting interest among water governing bodies as well as the development of water policies without considering the implications of such policies on other water users and without any consultation across sectors and institutional boundaries (Jønch-Clausen \& Fugl, 2001). The integrated approach is defined as a process which promotes the coordinated development and management of water, land and related resources, in order to maximize the resultant economic and social welfare in an equitable manner without compromising the sustainability of vital ecosystems (GWP, 2000). Integrated Water Resources Management (IWRM) addresses the interdependence nature of water resources management by bringing on board water users at all levels (Lenton \& Muller, 2012), to address all potential trade-offs among all relevant users and stakeholders (Pahl-Wostl, 2006). The integrated water resources management is projected with a high potential of generating resultant benefits such as water security, sustainable socioeconomic development, sound ecology, and environmental flows. Most developing countries are implementing integrated water resources management yet IWRM is criticized on the basis that that is not fully implemented and therefore the benefits are not realized. Ghana has been implementing IWRM since 2012 in the Pra Basin.

The Pra Basin cut across four out of the 10 regions in Ghana. The Pra Basin houses 9 out of the 17 constructed water supply reservoirs in Ghana but $42 \%$ of households in the basin do not have access to potable water (Pra Basin, 2012). In addition, there is a high level of illegal mining in and around the water resources. Considering the low accessibility to potable water and the high level of illegal mining in the basin, it is important to have an effective and efficient water management in the Pra Basin.

This study, therefore, examines the effectiveness of the IWRM implementation in the Pra Basin by assessing how it has addressed the needs of the basin by addressing the following questions: 1) Is the IWRM the appropriate management option? 2) What is working well? 3) What is not working well?

To address the research questions, data were drawn from interviews, field observations, Pra Basin IWRM plan, the National IWRM plan, and policy documents including annual reports of the WRC and other related government agencies. The 
field observations were carried out to get first-hand information of the developments in the basin and also to acquaint ourselves with the things which might be important for the success of the water management system but were not captured in the development framework for action in the basin. The paper draws data based on empirical evidence from a) five (5) interviews with opinion leaders and a retiree of a relevant state institution b) fourteen (14) interviews with government agencies and organizations: eight (8) Environmental Health Officers (EHOs) from the District Assemblies, two (2) Ghana Water Company Limited (GWCL) workers, and one (1) each from the Hydrological Services Department (HSD), Meteorological Services Department (MSD), Community Water and Sanitation Agency (CWSA) and the Environmental Protection Agency (EPA) . Before providing answers to the above questions, this paper first presents relevant cases of IWRM implementation, and then proposed a framework for effective IWRM implementation, before analyzing the data gathered and drawing conclusions.

\section{IWRM: implementation, benefits and challenges}

This section focuses on IWRM, the motivation behind its introduction, its benefits and challenges through the assessment of implementation in different regional backgrounds but focusing largely on the Africa region. Then finally we establish the implementation framework for assessment.

\section{Implementation}

The framework for implementing IWRM has largely been based on the definition proposed by global water partnership (GWP). As defined earlier, GWP explains that IWRM when fully implemented should promote coordination in the development and management of water, land and related resources with a resultant effect of maximizing the economic and social benefits in an equitable manner without compromising the sustainability of the vital ecosystem.

Many reasons have been assigned as to why IWRM is the best management option for the global water crisis today and for future water security; three stand out. First is its potential to integrate the natural system and human system (Jønch-Clausen \& Fugl, 2001). In this context, the natural system refers to the availability and quality of the water resources whereas the human system covers the use of the resources, waste production, resource pollution, and economic development. According to Jønch-Clausen \& Fugl ( 2001), the approach has the potential to integrate: 1) land and water management 2) surface water and groundwater management 3) quality and quantity of water resources management 4) upstream and down-stream water-related interests 5) freshwater management and coastal zone management 6) holistic institutional framework 7) water into the national economy 8) water resources planning with poverty alleviation 9) cross-sectoral plan into the national 
policy development 10) water resources planning into national security and trade policies 11) different management levels 12) all relevant stakeholders into the planning and decision-making process. The second reason is that the integration will address the water crisis. The water crisis emanates from the multifunctional, multi-sectoral, and multi-regional nature of water resources as well as the high population growth rate, continuous pollution of the water resources and the uneven distribution of the $0.04 \%$ out of the $2.5 \%$ of fresh water available for all human activities including domestic, commercial and industrial (pharmaceutical, textiles, petrochemical etc.) purposes (Agyenim \& Gupta, 2012; Jønch-Clausen \& Fugl, 2001; Swatuk, 2005)\{Swatuk, 2005 \#276;Biswas, 2008 \#192\}. Third, IWRM is decentralized to the lowest level. The decentralization ensures efficient and effective stakeholder participation at all levels. The participation at all levels, especially that at the lowest appropriate level, is anticipated to strengthen decision making, enhance local input and maximize the benefits of the water resources and ensure its security for present and future generations without compromising the sustainability of the ecosystem.

Even though IWRM has been projected to address the multiple competing and conflicting uses of water resources (Jeffrey \& Gearey, 2006), its implementation has been marred by controversies. This is not to downplay IWRM implementation benefits. IWRM has often been referred to as the Dublin-Rio principle: it is built on the recommended actions proposed from the Dublin conference to address the challenges facing water resources management and the 'solution manual' to address the identified challenges from the Earth summit (Mitchell, 2005). One of the main challenges of implementation is centered on the synchronization of the proposed solution (Dublin principles) and the outline plan/program to achieve the expected outcomes (Muller, 2010). According to Muller (2010), the Rio conference on environment and development outlined some guidelines building on these Dublin principles, including 1) integrated water resources development and management 2) water resources assessment 3) protection of water resources, water quality and aquatic ecosystem 4) drinking water supply and sanitation 5) water and sustainable urban development 6) water for sustainable production and rural development and 7) impact of climate change on water resources. The Rio United Nations Conference on Environment and Development recommended integrated (I) water (W) resources(R) management (M) and development (D) (IWRM\&D) and not IWRM as the way forward in water governance. The development component has been eliminated completely in the new management system (IWRM) (Muller, 2010) but Jønch-Clausen \& Fugl (2001) claim the M in the IWRM represents both management and development. The absence of the 'development' or the inability of implementers to discern the real meaning of " $M$ " is suggested to have negatively affected IWRM implementation especially in developing countries (Muller, 2010). From the discussions so far, it is clear that there are still unanswered questions when it comes to IWRM and its implementation. In the same way, there are definitely benefits and challenges. Concerning the benefits and challenges, we focus on 
examples from countries where implementation has taken place.

\section{The benefits}

Regarding the benefits, IWRM creates a platform for an effective, efficient and reliable network of all relevant stakeholders (Dube \& Swatuk, 2002). For example, the implementation of IWRM in Southern Africa created a global network of water resources managers such as international non-governmental organizations (INGO), international governmental organizations (IGO), private foundations and think tanks to share experience, ideas etc. (Swatuk, 2005). It decentralizes the water management system which (a) ensures proper stakeholder involvement in decision making (b) ensures efficient use of natural resources (c) ensures equitable distribution and access to the natural resources (Ribot, 2004; Saravanan, 2009); reduces fragmented management roles and decision making (Moriarty et al. 2010; Giordano \& Shah, 2014); helps in the identification of local problems for redress; reduces conflicts to the minimum and improves coordination and integration by strengthening existing laws and policies to fit into the development framework of nations/states/regions. The success of the IWRM is partly dependent on the explicit recognition of the link between development and management of water resources and the need to tailor implementation to meet the challenges of a basin. In other words, setting up the management or development scheme should be based on the pending needs of the community, basin or state at the time: making a conscious effort to ensure that the output does not negatively affect other related components of the environment. The evidence is available in Mexico, Denmark, Japan, South Africa, and Tunisia, Mozambique, Zimbabwe, Algeria etc. just to mention a few.

In Mexico, water reforms were to address the water stress and deteriorating water quality which led to the drying up of Lake Chapala. Government interventions focused more on institutional development and management innovations to support their long-term infrastructural development (Muller, 2010). Huge investments were made in the area of wastewater treatment to address the deteriorating water quality; in the end, the quality of water improved and drinking water was restored for about 16 million people. Similar reforms in Denmark also yielded fruitful results (Lenton \& Muller, 2012), however, in the Denmark situation, local administrative institutions and not river basins were involved. Japan is very susceptible to destructive typhoon and flooding. In addressing the situation, it rolled out a combination of sound institutional regulation, strong work ethics, and appropriate technology: well-managed regulation of flows and construction of a series of networked large storage reservoirs. This ensured a regular supply of water and prevented flooding (Louati \& Bucknall, 2009). A study by Lenton and Muller (2012) indicates that in Apartheid South Africa, water development was carried out at the expense of water management due to political challenges at the time. Even at the time, the water development was narrowed to support the rich farming communities to the 
detriment of broader development priorities of the water sector. However, after the Apartheid era, water reforms were linked to the countries planning framework which supported broader water sector development priorities. What resulted from the post-Apartheid innovations was a good platform and strong coordination between government and industry in the management of wastewater. Access to domestic water and industry was also improved. Tailoring IWRM to meet basin needs resulted in the trans-boundary agreement in which Mozambique willingly gave permission to Zimbabwe to draw water from the Pungwe River which passes through Mozambique (Gumbo \& Van der Zaag, 2002). A similar agreement is also reached between Tunisia and Algeria and among Tunisia, Algeria, and Libya on a common aquifer (Louati \& Bucknall, 2009). A study by Louati and Bucknall (2009) reveals that Tunisia, even though it is one of the countries in the Mediterranean basin least well-endowed with water resources and with the imbalanced spatial distribution of water resources, had never experienced drought or flooding until after 1758. Meanwhile, an effort to address this situation in the past did not yield any fruitful results. To tackle the problem, the government invested heavily in infrastructural development such as the construction of dams. This did not only reduce drought and flooding but also enhanced water storage and transfer. The experiences discussed above are all addressing specific needs: this is how IWRM should be implemented. On the contrary, certain external and internal factors such as donors, politics etc. have sometimes been allowed to be the implementation determinants instead of the needs identified in most developing countries.

\section{The challenges}

Giordano and Shah (2014), argue that IWRM implementation is mostly donor motivated instead of solving basin problem as popularly projected. Citing the case of Tanzania water resources challenges, they indicate that the main challenge at the time was water development and provision. However, because Tanzania's budget was heavily donor dependent, they rather implemented IWRM with state ownership of water resources, water-withdrawal permits, water taxes, river basin organizations, and water user associations at the expense of what their water policy identified as their need. Dube and Swatuk in 2002 reported that the selection of the Mazowe catchment in Zimbabwe for pilot projects by donors was predetermined because the choice was to secretly adopt the framework, management experience and interest of white commercial farmers at the expense of indigenous commercial farmers.

Highlighting on the importance of awareness creation in IWRM implementation, Steinich (2000) explains that low levels of public awareness impact negatively on stakeholder participation. Inguane et al (2014) narrate how lack of awareness impeded the success of the systematic processes employed by Mozambique in implementing IWRM. In their study, they explained how Mozambique created the 
enabling environment through the establishment of water law, water policy and other relevant bodies such as Regional Water Administration (RWA), Stakeholder Consultative river Basin Committees (SCRBC) and the River Basin Management Unit (RBMU) but still failed to achieve most of the outcomes. According to Inguane et al, the expectations were that the enabling environment will help increase coverage and user participation, however, most of these projections did not materialize.

There are challenges when it comes to funding and releasing of funds to the lowest appropriate levels of operation. The absence of reliable and unbiased state funding, and unsustainable funding provided by donors in developing countries (Shah, 2006), has been a major hindrance to implementation in most developing countries. In addition, the absence of skilled human resource has been identified as one of the major constraints in the implementation. Regarding funding, studies such as that conducted by Gallego-Ayala \& Juizo (2011) showed the abnormally slow pace of the water sector reforms in Mozambique due to financial constraints in the country. Swatuk (2005), showed donor funding for irrigation projects in Zimbabwe was stopped due to political instability. Operating at the basin level requires the release of money to the lowest level for efficient and effective operation, however, this is a big challenge in Africa (B. Inguane, 2010). The absence of skilled human resources is a major challenge to IWRM implementation in Africa (van der Zaag, 2005).

Another area of concern is the institutional framework. The creation of new institutions and their decentralization has generated some operational challenges. For example, Keohane et al. (1993), reports of implementation challenges due to the creation of new institutions. These challenges become more pronounced when especially the supervision over the institutions in question have a different boundary of operation (Tapela, 2002). First, even though South Africa created new institutions using the bottom-up approach, they still had serious operational difficulties (Dovers, 2001; Swatuk, 2005). Similarly, in Zimbabwe, the creation of Catchment Council (CC) and Sub Catchment Council (SCC) has done little to the devolution of authority such as stakeholder participation, institutional resilience etc. (Tapela, 2002). Second, regarding the challenges of the new institution having oversight responsibility for existing ones, the Zimbabwe scenario is a case in point. In Zimbabwe, the Catchment Council (CC) overlaps with many political and sectorial jurisdictions. As explain by Dube and Swatuk (2002), there is a great tussle between a network of government and non-governmental organizations such as the Department of Natural Resources, the mines, urban councils etc. in submitting to the directives of the CC. They explain that the tussle is further strengthened through the assigning of responsibility. Whereas the overall responsibility for CC is to manage all water resources, they are to focus on the commercial use of surface water at the catchment level whilst the Local Government Ministry takes care of rural water. What remains unanswered is what constitutes water resources as far as Zimbabwe National Water Authority is concerned? The intervention put in place to 
save the River Basins in Zimbabwe resulted in a crass scramble for authority among farming communities (Swatuk, 2005). A study by Inguane et al. (2014), shows that the transfer of power or authority from central government or state to the lowest (basin) level of operation in Mozambique followed de-concentration approach. They further explain that de-concentration is the weakest form of the decentralization process because it does not transfer full powers such as planning, management, funding, etc. to the lowest level yet that is what most developing countries adapt.

Also, of concern are the conflicting issues associated with IWRM concept. The conflicts could be internal or trans-boundary. Internal conflicts could be at the local scale with complex interactions and feedbacks among a wide array of variables from both human and natural systems (Hilemana, 2015). It may also arise from overdependence on the same volume but continuously deteriorating water resources by the growing population, industry, and urban development (Robinson, 2002). Other internal or local conflicts are linked with roles and devolution of powers. A typical example is reported by Swatuk (2005), between wetland conservationists and farmers using the wetland for farming. He also reported conflicts among upstream pastoralist, irrigators, and farmers in Tanzania.

For the purpose of streamlining the mode of assessing the IWRM implementation in the Pra Basin, we proposed a framework (Fig. 1) based on the explanation of IWRM implementation being a process. This theoretical framework (Fig. 1) can be described as an assessment and implementation framework. It can be used to assess an existing management system and based on the gaps identified; measures can be put in place to address them. It can also be followed as explained after this paragraph for implementing a new policy. It must be emphasized here that, all over the world, and in almost every country, city, town or village, water is being managed, what we are not sure of is whether the management is effective or not? In that regard, figure 1 can be used to assess systems of such nature, outline the gaps and propose solutions. Before explaining the processes taking place at each level of the framework, we first want to explain the significance of the different arrows and their role in processes.

All rectangles are labeled from $\mathrm{A}-\mathrm{N}$. There are arrows which connect the various rectangular boxes in the framework. One way of distinguishing the arrows is by their heads. There are unidirectional and bidirectional arrows. The other way to differentiate them is by their solid and broken lines. If the arrow is solid and unidirectional it signifies operational flow. The red unidirectional broken arrows indicate feedback. These feedback massages are for adjustment and improvement in operations. Unfortunately, these feedbacks are mostly underestimated by policy makers, basin officers, and engineers (Pahl-Wostl, 2006) even though they are very critical for shaping the implementation framework. The broken lines with double arrow head represent the sharing of expertise, coordination, information flow, 
awareness creation and transfer of resources. The implementation framework [Z], starts with the creation or reviewing of an existing management instrument $[A]$, institutional framework [D] and the enabling environment [G].

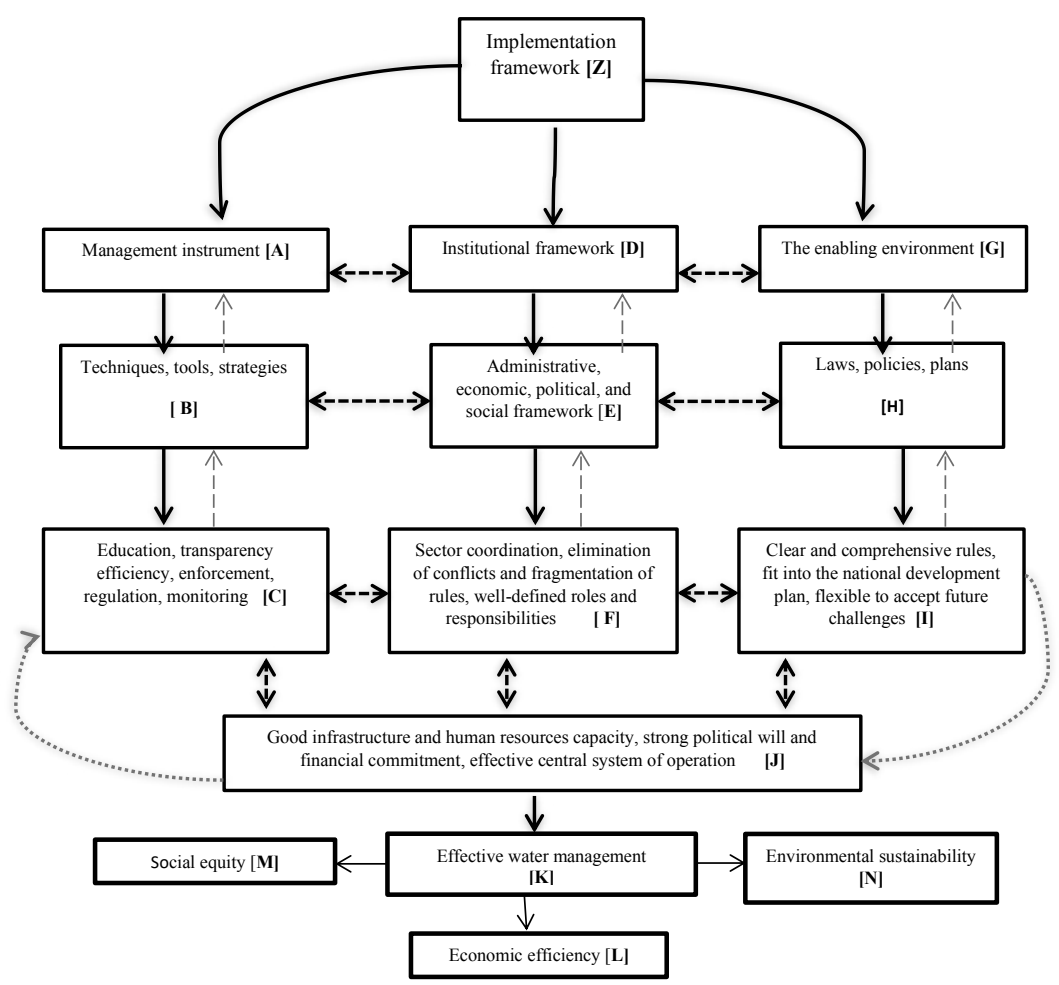

Figure 1. IWRM implementation framework

Connecting rectangles [C], [F], and [I] to [J] are broken double headed arrows which are in turn joined by a purple broken unidirectional arrow to form a loop. The bidirectional arrow at this stage indicates that for any effective and efficient actions to take place in [C], [F], and [I] the elements in [J] must be available, in good condition, and sustainable. It also implies that for an effective water management system to yield [L], [M], and [N], the bidirectional flow must be maintained.

IWRM is a process and not a one-time action. The three pillars for implementation namely the institutional framework, the management instrument, and the enabling environment must always be well established for a successful take off. In a situation where these are not present, systematic effort must be made to create them before taking off. Where they are present but weak, they must be strengthened. 
The enabling environment: The creation of a clear, comprehensive, and flexible legal framework which can accept future changes in a holistic manner is very critical in ensuring good management of water resources (Salman \& Bradlow, 2006). Where there is an existing legal framework, they should not be abandoned but rather reviewed and strengthened (Butterworth, 2010). Where new ones need to be created, efforts must be made to involve all relevant stakeholders. However, caution should be taken in the kind of consultants engaged. All stakeholders and consultants involved with the whole process should be familiar with the concerned environment in that these laws must be applicable in the local community where they are to be implemented. A situation of this kind happened in Kazakh where foreign consultants were contracted to draft their water law. Because the consultants were not familiar with the Kazakh environment they drew the laws along the European Water Directive Framework which led to implementation challenges (Warner et al., 2009). Measures must be put in place to ensure that all grievances, controversies, conflicts, etc. which arose during the formulation of the legal and regulatory framework are strategically and effectively addressed. There is also the need to reduce donor or external influence to the minimum on the legal and regulatory framework planning and decisions especially in developing countries (Shah, 2006). Finally, "the role of government in the formulation of water policy, the enactment, and enforcement of the water resources legislation, the separation of regulation from service provision functions"(Jønch-Clausen \& Fugl, 2001) must be well spelled out

Institutional framework: This deals with the setting up of the social, political, economic and administrative tools required for the management of water resources. It is at this point that a platform is created to share ideas, experiences, and expertise to facilitate the creation of a management structure (Hassing, 2009). The expectations are that because almost all relevant stakeholders are brought on board at this point, all unpredictable conflicts will be eliminated and coordination strengthened through the creation of directorates, commissions, and task forces with well-defined roles and responsibilities. The river basin authority is to link all the top and bottom relevant stakeholders by providing, receiving, and sharing information and ideas.

Management instrument: This develops the management 'toolbox' with a practical instrument to be used by water resources managers (Jønch-Clausen \& Fugl, 2001). The instrument will require some level of skills to strategically make it useful or beneficial. Attention should be paid to these factors : Information management; transparency; coherent and consensus-based planning; social change tools on public awareness creation; conflict mediation; regulatory instrument and enforcement framework; formulation of economic instruments for behavior change; water resource management (WRM) plans; assessment of water resources issues; management of water use behavior and water use efficiency (Hassing, 2009) for efficient work delivery. It is expected that adherence to the three pillars of 
implementation and their network as shown in figure 1, with good infrastructure, skilled human resource, strong political will and sustainable financing, an effective water management system which will ensure social equity, economic efficiency, and sustainable environment could be achieved. Note that the emphasis is not only on focusing on the problem as discussed earlier but also on addressing the problem from an integrated perspective.

\section{Historical perspective of water resources reforms to IWRM adoption in Ghana}

Ghana remained a British colony until 1957. Before then, water resources management was by customary rules. Water was a free common good with ownership vested in stools and communities (Agyenim \& Gupta, 2012). By tradition, customary laws were established by chiefs and elders and officially presented to the entire village or community; to determine the punishment for their violation. In that era, the people were not just obedient to these regulations but also ensured this knowledge was transferred to their children and unto the next generation; through durbars by the traditional authority which is occasionally enhanced by the family, specifically the women. Community members would monitor the behavior of their fellow community members and outsiders. Where the use of or activities around the water upstream affect other communities downstream, the different traditional boundaries necessitated leaders to sit together and resolve issues though not without a few 'ugly' conflicts (Fatawu, 2014). The customary rules were strengthened with taboos and prohibitions and backed by sanctions (Agyenim \& Gupta, 2012).

As Britain gained full control over the Gold Coast in 1902, new rules and regulations were introduced to suit their system of governance. The laws introduced at the time focused more on economic gains at the expense of water and environmental security. The laws though well-structured lacked clarity on their execution with conflicting and overlapping roles. From that time Ghana started experiencing a pluralist legislative framework for water management. Since 1902 to the present day, water resources management has evolved through different management systems, each one with its own drivers and constraints. The period after independence, from 1957-1980, has seen the government embark on various water reforms. The main areas included: 1) developing water for electricity generation 2) managing water for provision, distribution, conservation and supply to the public for domestic and industrial purposes 3 ) establishment, operation, and control of sewerage systems and 4) developing water for irrigation farming. However, almost all reforms except that for electricity generation could not be sustained because they were statefunded: and at the time, the state was in economic shambles. For example 1,879 out of 5,500 boreholes drilled in 1979 were out of order around 1990 as a result of government inability to release the subvention for their maintenance as planned. (http://www.gwcl.com.gh/gwcl_history.pdf). The argument of this paper is that introducing reforms or policies are just not enough; they must be effectively and 
sustainably implemented to achieve expected outcomes.

From 1990 to date, water reforms in Ghana have taken the IWRM approach. Ghana's IWRM plan was initiated through sub-regional agreement and national processes (WRC, 2012). At the sub-regional level, the IWRM concept was unveiled in a Ministerial conference in Ouagadougou for West Africa in 1998. The conference was to create a uniform platform for all member countries to agree on the way forward. Two areas were identified to facilitate the adoption and implementation and these are: 1 ) creation of awareness among member states on the need to change from the traditional system of managing water to IWRM 2) unconditional acceptance of the Ouagadougou proposal on IWRM by ministers in charge of water in the member state. As one of the member states at the Ouagadougou conference, Ghana fully supported the proposal.

In Ghana, the current water institutional reforms are deeply rooted in integrated water resources management. It involves the creation of a hierarchical organizational structure for water management based on the separation of regulatory and operational functions, and the delegation of operational functions to the lowest appropriate level (Inguane et al, 2014; Tapela, 2002). Unlike Mozambique and Tanzania where the water reforms followed the usual pattern of creation / amendment and approval of water law, Ghana's case was different: it started with the creation and approval of a commission: the water resources commission (WRC) in 1996.

The reforms were further strengthened by the introduction of other key regulatory documents such as the Public Utility and Regulatory Commission (PURC) Act 538 for economic regulation of Water and Electricity Utilities in 1998, and the 2007 national water policy (WRC, 2012). Other supporting institutions and legislative instruments are: The Environmental Assessment Regulation of 1999 (L. I. 1652) for regulating and granting permits for projects with impact on the environment and water resources (surface and underground); water use regulations 2001(L. I. 1692) for water abstraction, diversion, damming and other water uses such as transportation and agriculture. These regulations operate at three levels namely the policy, organizational and operational level. At the policy level, a water directorate is to guide and facilitate the implementation of Ghana's national water policy (NWP) through the Water Sector Strategic Development Plan (WSSDP). WSSDP is a framework for implementing government of Ghana's vision in the water and sanitation sector. WSSDP objectives are firmly embedded in the national development plan i.e. Ghana Shared Growth and Development Agenda (GSGDA, 2010-2013) and the National Water Policy (NWP). The NWP is structured into three sub-management categories and these are, urban water supply, rural water supply, and the national IWRM the focus of this discussion. The aim of introducing IWRM is to ensure: elimination of conflicting sector policies, elimination or reduction in 
institutional fragmentation, and broader stakeholder participation (increase user involvement in water resource management) and maximization of water benefits and security for today and the future (Inguane, 2010; Swatuk, 2005). As a policy direction to manage Ghana's water resource through the integrated approach using the river basin as the operational unit, the Water Resources Commission (WRC) has been able to define six basins with the Pra being the fourth.

\section{The findings: IWRM implementation in the Pra Basin}

Following the IWRM framework proposed, this section assesses the implementation in the Pra Basin and draws conclusion. There are many proposals for creating a robust enabling environment; the implementation in the Pra Basin followed the approach recommended by Salman \& Bradlow (2006). They recommend the following steps: 1 ) reviewing existing rules to cover all water resources management issues; 2) Developing a comprehensive legislation with a well-defined role for government agencies ; 3) Having a legislative framework which addresses the needs of the state and supports its policy implementation ; 4) Establishing clear and welldefined rules for public ownership of water projects; 5 ) Creating or strengthening the administrative and technical capacity for implementation; 6) Putting measures in place to ensure enforcement of technical and administrative provisions; and 7) Bring all relevant stakeholders to participate in the planning and decision-making process (Salman \& Bradlow, 2006) to enhance coordination and avoid conflicts. In that regard, some existing regulation such as the Environmental Protection Decree (NRCD 239) was reviewed in 1994 resulting in the Environmental Protection Agency Act (490). In areas where new acts such as the WRC Act and PURC Act were introduced, their roles were clearly defined. As discussed under historical reform of water resources above, all the new acts developed fit into the WSSDP which synchronizes with the national development plan.

In addition, the reviewed legal instruments were housed in corresponding institutions which were upgraded whereas new institutions were created for the newly created legal instrument. The Pra basin was formed as the operational unit with a River Basin Board (RBB). The complex nature of the Basin led to its categorization into three sub-basins. The first is the Upper Pra sub-Committee which has the responsibility of managing the rivers Offin, Anum and Oda, including Lake Bosomtwe. The second is the Birim sub-Committee in charge of the Birim sub-basin. The third is the Lower Pra sub-Committee charged with the management of the sub-basin between TwifoPraso and Cape Coast.

There is a Pra-Offin Basin office in Kumasi which hosts the Upper Pra sub-Committee whereas the Birim sub-Committee is being hosted by a different basin: the Densu Basin Office. However, the secretariat of the Lower Pra sub-Committee is yet to get an office space in Shama Municipal Assembly. The Pra-Offin Basin office is 
operational with a workforce of three: a basin officer, a field assistant, and a secretary. They have office accessories and a pick-up car for their day to day activities such as projects monitoring. Each basin sub-committee is to have Representation from the Municipal, Metropolitan, and District Assemblies (MMDAs); the Regional Coordinating Councils, each of the Regulatory Institutions in charge of Mining, Forest, Environment, etc.; each of the major water users (Domestic water supply, Agriculture and Mining); the Traditional Rulers; Civil Society Groups that are active in the sub-basin; Women/Youth groups. The summary of the operational framework for the basin is presented in figure 2 .

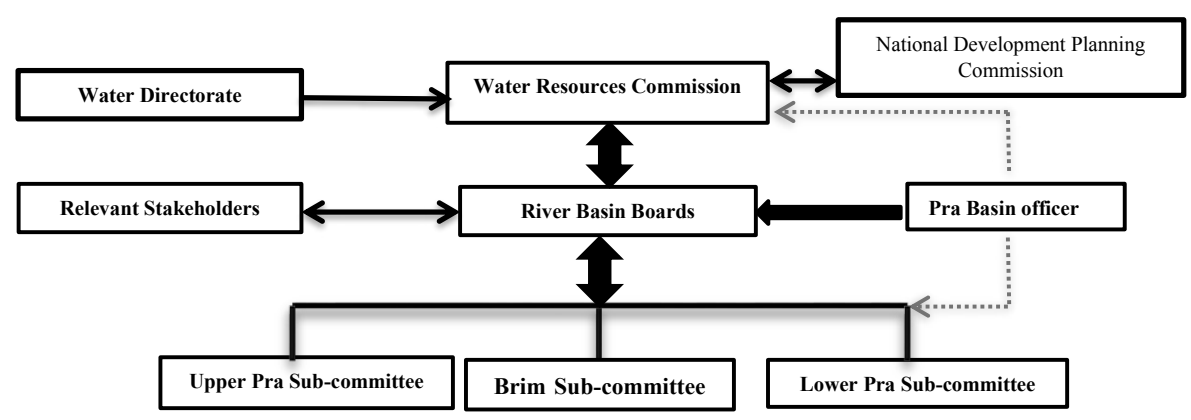

Figure 2 Pra Basin IWRM Plan

Adopted and modified from Pra Basin IWRM plan

\section{Water Resources assessment and evaluation}

The Water Evaluation and Planning (WEAP) system was used to gather data on available water resources to help demand projections and inform decision making on water resource planning in the basin. Based on the data gathered, a description of the related challenges was outlined. After this, a consultative process was carried out to involve all relevant basin-based stakeholders. The stakeholders were selected based on their specific interest/knowledge of water resources management. They included planners from the District Assemblies, Government Departments, representatives from the mining industries, representatives from major water users, NGOs, CBOs etc.(Pra Basin, 2012). The assessment and evaluation was done in the form of workshops using Strategic Environmental Assessment (SEA). SEA is a systematic process of evaluating the environmental effects of a policy, plan or program with the opportunity of proposing alternatives where there is the need and documenting the findings for use in decision-making. A total of three workshops were conducted in Kumasi in the Ashanti region of Ghana. In all the workshops the representatives from WRC played the role of facilitation and documentation. In the first workshop, stakeholders brainstormed and discussed the data gathered in relation to the challenges in the basin and categorized the identified problems into five groups. Stakeholders used the second workshop to prioritize/rank the various problems and developed their plan of action (Table 1). In the prioritization, water 
for domestic use and environmental flow were given the highest priority, followed by irrigation water demands and livestock use in that order. The action plan was subjected to a rigorous scrutiny to ascertain its sustainability and approval in the final workshop. The problem areas were identified and ranked as 1) Inadequate water supply to meet the demand for domestic, commercial, agricultural, and industrial purposes (including mining). 2) Land degradation from deforestation, agriculture, mining, settlements, and etc. 3) Water quality deterioration from household, commercial, industrial (including mining) and agricultural wastes. 4) Insufficient response to climate variability and change. 5) Weak institutional capacity in terms of human resource, funding, logistic, reliable data, information, etc. The objectives drawn to address the problems are: 1 ) To secure the available water resources through efficient water use; 2) To improve water conservation and ecosystem health through effective protection and regulation of land and water resources; 3 ) To mitigate the suffering and economic loss of communities through adaptation to climate variability and change; 4) To strengthen human and institutional capacities to carry out key IWRM mandates. The actions drafted to address the projected objectives are presented in table 1.

Table: 1. Thematic areas, objectives, key actions and implementing entities

\begin{tabular}{|c|c|c|c|}
\hline Thematic Area & Strategic Objective & Key Actions & $\begin{array}{c}\text { Implementing Entities } \\
\text { (Lead Agency + } \\
\text { Collaborators) }\end{array}$ \\
\hline $\begin{array}{l}\text { Water use } \\
\text { efficiency and } \\
\text { conservation }\end{array}$ & $\begin{array}{l}\text { 1. To improve water } \\
\text { conservation and } \\
\text { ecosystem health through } \\
\text { effective protection and } \\
\text { regulation of land and } \\
\text { water resources }\end{array}$ & $\begin{array}{l}\text { 1. Support the development and implementation of targets } \\
\text { and benchmarks for efficient water delivery by water use } \\
\text { institutions (e.g. GWCL, CWSA, and GIDA). } \\
\text { 2. Enforce and monitor the water permitting regulations. } \\
\text { 3. Promote Rainwater Harvesting and use of Underground } \\
\text { water. } \\
\text { 4. Dams for water conservation. }\end{array}$ & $\begin{array}{l}\text { PBB/WRC + } \\
\text { MWRWH, GWCL, } \\
\text { CWSA, GIDA, NGOs }\end{array}$ \\
\hline $\begin{array}{l}\text { Catchment } \\
\text { Protection and } \\
\text { Water Quality } \\
\text { Conservation }\end{array}$ & $\begin{array}{l}\text { 2. To secure the } \\
\text { availability of water } \\
\text { resources through } \\
\text { efficient water use }\end{array}$ & $\begin{array}{l}\text { 1. Create and sustain awareness of the value of water as a } \\
\text { scarce resource, and threats to water and other natural } \\
\text { resources. } \\
\text { 2. Implement the Buffer Zone Policy so as to retard silting of } \\
\text { streams and pollution of water bodies. Support MMDAs to } \\
\text { enact Bye-Laws for enforcement of regulations on water and } \\
\text { environmental management. } \\
\text { 3. Set up effective monitoring and assessment of water } \\
\text { resource availability and use, and resource quality. } \\
\text { 4. Promote integration of Tourism Development in the basin } \\
\text { IWRM work programs to boost local economies. }\end{array}$ & $\begin{array}{l}\text { PBB + MMDAs, Chiefs } \\
\text { and Communities' } \\
\text { Leaders, Forestry, EPA, } \\
\text { HSD, WRI, Media, } \\
\text { Tourist Authority, } \\
\text { MOFA, Chamber of } \\
\text { Mines, NGO }\end{array}$ \\
\hline $\begin{array}{l}\text { Adaptation to } \\
\text { Climate Change } \\
\text { Impacts }\end{array}$ & $\begin{array}{l}\text { To mitigate the suffering } \\
\text { and economic loss of } \\
\text { communities through } \\
\text { adaptation to climate } \\
\text { variability and change }\end{array}$ & $\begin{array}{l}\text { 1. Create public awareness of climate impacts (including the } \\
\text { dangers of settling in flood-prone areas). } \\
\text { 2. Improve flood management through catchment } \\
\text { conservation and protection so as to retard surface run-off. } \\
\text { 3. Support development of participatory disaster } \\
\text { preparedness and management programs. } \\
\text { 4. Strengthen basin-level information dissemination to } \\
\text { facilitate adaptation (e.g. Early Warning Systems). }\end{array}$ & $\begin{array}{l}\text { PBB/WRC + NADMO, } \\
\text { EPA, HSD, WRI, } \\
\text { MMDAs, Forestry, } \\
\text { MOFA, NGOs, Chiefs } \\
\text { and Communities' } \\
\text { Leaders }\end{array}$ \\
\hline $\begin{array}{l}\text { Institutional and } \\
\text { Human Resources } \\
\text { Capacity } \\
\text { Development }\end{array}$ & $\begin{array}{l}\text { To strengthen Human and } \\
\text { Institutional capacities to } \\
\text { carry out key IWRM } \\
\text { mandates }\end{array}$ & $\begin{array}{l}\text { 1.Set-up effective basin institutions (Pra basin Board, water } \\
\text { users' associations, a forum of Chiefs, etc.). } \\
\text { 2. Provide logistics for the efficient running of the basin } \\
\text { institutions (secretariat of PBB) and enforcement of } \\
\text { Regulations. } \\
\text { 3. Support Education and Training in IWRM at all Levels. } \\
\text { 4. Facilitate the preparation of annual basin and community } \\
\text { work programs for implementation. } \\
\text { 5.Set up Inter-sectorial collaboration mechanism and forum } \\
\text { of local actors. } \\
\text { 6. Coordinate the development of a detailed basin-level data } \\
\text { and information management system (e.g. functioning } \\
\text { website for PBB). } \\
\text { 7. Monitor and Evaluate annual basin work program }\end{array}$ & $\begin{array}{l}\text { WRC/PBB + MMDAs, } \\
\text { GES, KNUST, NGOs, } \\
\text { Chiefs and } \\
\text { Communities' Leaders }\end{array}$ \\
\hline
\end{tabular}




\section{Discussion}

\section{What is working well?}

One of the basic but most important stages in the management of water is the streamlining of roles and responsibilities (enabling environment) to reduce conflicts and enhance efficiency among different water uses and users. As part of the reforms to introduce IWRM, there was the formation of appropriate policies such as the water policy which clearly separates the management of water into the urban water supply, rural water supply, and integrated water resources management; the PURC; WRC; and EPA which was a plus for the implementation. To further avoid conflicts and overlapping roles, the well-defined laws and roles were assigned to specific responsible organizations for execution. The implementers were quick to respond to the complex nature of the basin with the creation of sub-basins to efficiently address their needs.

The composition of the basin board has almost all relevant stakeholders including traditional authority. The use of SEA at the operational level to introduce local knowledge was very innovative: it ensured the effective participation of stakeholders in the identification of the basin problems. The identified problems were strategically prioritized with specific objectives and key actions to address each of them. For administrative purpose, the Pra-Offin Basin office is currently operational and has been equipped to an extent with the necessary logistics. In the area of capacity building, the commission has made provision in its plan for the training of relevant stakeholders as well as awareness creation through public education.

\section{What is not working well?}

Despite the resources and the effort invested in the creation of new institutions and revitalization of existing ones, the new water management system suffers from several major drawbacks: One of such drawbacks is the inability of the implementing entities to translate their roles on paper into practice. For example objective 4 and key action 6 indicate that there will be detailed basin-level data and information management system. This data and information management system according to Agyenim and Gupta (2012), has been created by the commission at the national level and has resulted in collaboration between the commission and the data providers such as the Hydrological Services Department (HSD), however, interviews with the HSD and the Meteorological Services Department (MSD) revealed that though these arrangements exist on paper, they are not operational. The interviewees (MSD and HSD) blame the situation on lack of logistics; break down of their equipment and absence of trained personnel for the data collection. There is, therefore, no platform for data and information sharing among the sectors at the local level as claimed (Table 1). 
Another drawback has to do with the functioning of the basin board. Though they are well composed, they are limited by distance and logistics. The basin board and their availability for decision making during project implementation are very crucial for the success of IWRM. Unfortunately, the board is not operating and functioning as expected. The challenge is that most of the board members/implementing entities such as EPA, HSD, MSD, and WRIS operate offices either at the national or regional level which does not favor the river basin concept. The river basin by design operates more effectively at the district levels. The absence of such implementing entities at the district has affected activities like monitoring in the basin. For example, EPA is to collaborate with the minerals commission, forestry commission and the water research institute in monitoring the activities in the basin, however, they are constraint by the absence of trained staff, cars and the poor state of roads. In addition, the EPA lacks a functioning laboratory and staff at the time of interview to carry out monitoring and evaluation. Lack of funds to consistently maintain the monitoring stations and the absence of cars and the inability to employ trained persons to aid the collection of data is a major challenge to the HSD and the MSD. For example, the HSD indicated that a data monitoring personnel abandoned his work due to nonpayment of allowances. These constraints have created a big gap for illegal mining at the blind side of the River Basin Board (RBB). The opinion leaders though on the basin board feel completely stripped off their authority and role in the present IWRM set-up and regard their inclusion to the board as completely irrelevant because of the technical composition of the basin board. Furthermore, the harmonization of the working distance for the buffer zone policy is still hanging at the time of the interview. This has become a major setback to the implementation of the buffer zone policy.

In the area of awareness creation, education and training, there is more to be done especially in the training of the MMDAs (environmental health officers (EHO)) who serve as the focal point of the WRC at the district level (WRC., 2012). The OffinPra basin officer in an interview explains how they work with the EHOs and the training they offer them. However, six (6) out of the eight (8) EHO's interviewed in the basin had no idea of their capacity as representatives of the WRC at the district level let alone knowing their mandate in that capacity. The interviews revealed that even if the EHO's received the training as indicated by WRC, their staff strength will not permit them to do any effective work. The entire opinion leaders interviewed claims to have no knowledge of the IWRM in the basin. From 1998-2003, the Water Resources Information Services (WRIS) was established to handle training in data collection networks and assessment techniques (Agyenim \& Gupta, 2012). Their mandate is yet to be seen in this basin.

Even though the Pra Basin IWRM plan as indicated in table 1, have specific actions to address their problems with well outlined responsible implementing organization, there are no timelines. Timelines are among the important factors to use in 
performance assessment. For example, it will be very difficult to assess an objective such as that of thematic area 3 and key action 2 which talk about improving flood management through catchment conservation and protection to retard surface run-off without any timelines. In addition, there is not a single key action under any of the 4 objectives which indicated how such actions could be achieved. Actually, illegal mining (galamsey) is identified through field observation as an important determinant in the management of water in the basin yet the framework didn't capture it as such. In almost all areas where water resources are managed well the water policy is developed before the creation of the enabling environment, management instrument etc. however it is the opposite in the Pra Basin, therefore there are gaps in the framework. From the discussion so far, we can say that the Pra Basin framework visually (on paper) resembles the proposed framework, however, in practice there are gaps.

\section{Is the IWRM the appropriate management option?}

IWRM being an appropriate management option means it has proven practically potent to address the needs of the basin. The entire process from the national level to the Pra Basin shows government commitment and confidence in the IWRM concept. This is a good sign for implementation. The RBB in using the basin plan was able to identify almost all the problems or challenges and also categorized them in order of priority. However, the concept is appropriate cannot be ascertained by just the views expressed above but rather how such views are addressed practically. It must be emphasized here that commitment or willingness to do something does not automatically translate to the ability to it. Government commitment and confidence in the IWRM principle should translate into the funding, infrastructure, human resource capacity building. However, this has not been the case in the discussions so far. Government funding for WRC activities is unreliable (Agyenim \& Gupta, 2012), meanwhile it is common, but still strange and unacceptable as the government demonstrated such unreliability during the post-colonial water reforms. The consequences of this coupled with some inefficient management practices for example absence of training for EHO's shows that the Pra Basin needs improvement for the management system to work. The system is capital intensive and must be seriously considered in the implementation process. Since the system is not fully implemented because of the financial and management inefficiencies, the benefit of achieving water use efficiency and conservation through catchment protection and water quality conservation has not been fully realized. Addressing factors such as creation of a desk for IWRM at the district assemblies; incorporating IWRM into the training curriculum of the EHO's; conducting proper behavioural study to identify illegal miners reluctance in vacating illegal mining sites; identifying the various pollutants directly relating to illegal mining since the rivers in the basin serve as the raw water sources for drinking water treatment plants; making illegal mining a major determinant in the assessment of water quality can help improve the functioning of the system. 


\section{Conclusion}

The IWRM implementation in the Pra Basin to a large extent conforms to the selected general framework even though there are implementation gaps. Overall it can be concluded that the creation of the enabling environment, the institutional framework, the management instrument, and the problem identification in the basin was well conducted. However, there are questions when it comes to the appropriateness of the IWRM for the Pra Basin. The questions center on 1) the translation of framework on paper into practice; 2 ) some major stakeholders are not functioning appropriately at the basin level due to lack of funding, low staff strength, poor state of roads and logistical constraints; 3 ) absence of timelines in all the actions; 4) opinion leaders not counting themselves as part of the actual participation and 5) 'how' these actions will be achieved. The introduction of the water policy in the course of creating the enabling environment instead of the beginning to serve as a guide may have contributed to the ineffective functioning of the new water management system. The current framework needs improvement in the areas where questions have been raised if it needs to function well. The observations made are not enough to scientifically declare the water resources polluted; the quality of the water resource has to be assessed scientifically. 



$$
3
$$




\section{Chapter 3}

\section{Assessing the Effect of Integrated Water Resources Management on Water Quality in Ghana}

\section{Published as:}

Albert Ebo Duncan, Nanne de Vries, Kwabena Nyarko (2016). Assessing the Effect of Integrated Water Resources Management on

Water Quality in Ghana. International journal of latest research in science and technology. Volume 5, Issue 6, Pages 60-65 


\begin{abstract}
This study assesses water quality in the Pra Basin after the implementation of Integrated Water Resources Management (IWRM) using the water quality index (WQI). The study reports on changes in WQI before and after the first cycle of the implementation of IWRM. The Wilcoxon signed-rank test was used to statistically establish the significance of any difference during the implementation of IWRM. Eight (8) water sampling points from upstream to the downstream of the Basin were selected for sampling. Eight (8) physico-chemical and microbial parameters were used for the water quality measurement. Dunkwa-On-Offin (D F) recorded the lowest WQI whilst Adiambra (A $\mathrm{M})$ recorded the highest WQI. The deterioration in D F has to do with the numerous and advance system of illegal mining occurring in D F and the tributaries which feeds it. The study revealed that water quality has deteriorated as a result of the high levels of suspended solids in the rivers. For WQI, the deterioration was significantly higher during the IWRM implementation ( $\mathrm{Mdn}=40.25$ ) compared to the implementation $(\mathrm{Mdn}=72.19) \mathrm{T}=0.00, \mathrm{p}=0.012, r=0.66$. The presented results, create doubt about the practicality of the action plan and the compliance of the basin officers to the action plan.
\end{abstract}




\section{Introduction}

A flow of water of good quality in an environment, does not only sustain the environment, but it also ensures human development, economic growth and good health. Protecting, securing, maintaining and sustaining the quality of safe water in an environment is a very challenging task (Falkenmark \& Rockström, 2004). Globally an accepted principle proposed to achieve safe and sustainable water in an environment is an integrated water resource management (IWRM) system. It has however been claimed that IWRM is not effective (Biswas, 2008). That notwithstanding, the IWRM concept has gained broad adoption by many countries due to the over-popularization by the initiators (Merrey, 2008) and also its simplicity (Biswas, 2008). \{Merrey, 2008 \#250;Biswas, 2008 \#317\}According to Biswas (2008), IWRM is an old concept which failed in the past due to implementation difficulties. He explains that there are varying ideas when it comes to IWRM in operational terms even among the promoters of the principle. The challenge of the IWRM implementation is not due to the vagueness of the concept, but rather the inability of technocrats to bridge the gap between theory and practice (Rahaman, 2005). Rahaman does not see any vagueness in the IWRM concept; however, he sees the inability of technocrats to translate policy on paper onto the field as the main challenge. According to van der Zaak (2005), the challenge to IWRM implementation is the absence of the institutional capacity to bring about the integration. van der Zaak admits there are issues with IWRM concept in the area of institutional capacity but also disagrees with those who claim the concept is not practical. He see's having the right institutional capacity in place as an important step in making IWRM practical to be able to integrate all water and its related sectors and relevant stakeholders such as the water supply companies (WSC's), environmental protection agency (EPA), irrigation authority (IA), industry, community-based organization (CBO's) etc.

The IWRM concept is gradually losing credibility in some continents (like Asia) because of lack of reliable data to even prove that it is working (Asian Development Bank., 2007: cited in (Biswas, 2008)). Nevertheless, African countries like Burkina Faso, Nigeria, South Africa and Ghana started implementing the IWRM concept. It is therefore important to know the extent to which IWRM is working. In summary, there are IWRM implementation challenges, one of which is the evaluation of the expected outcomes. However, whenever or where ever IWRM is implemented, it is expected to solve an existing, emerging or anticipated problem.

The Pra Basin is located between latitude $5^{\circ} \mathrm{N}$ and $7^{\circ} 30^{\prime} \mathrm{W}$ and longitude $2^{\circ} 30^{\prime} \mathrm{W}$ in south central Ghana West Africa (figure 1). The total basin area is approximately $23,200 \mathrm{~km}^{2}$ and extends through three of the ten regions of the country. The southern part is relatively flat with the northern sections and fringes of the eastern parts showing elevations of up to 800 meters above sea level. The basin population is approximately 4.2 million with a population growth rate of $3.1 \%$, according to the 
2010 population and housing census. The basin is known for its numerous mining activities, both legal and illegal.

In Ghana and specifically the Pra Basin, one of the reasons for the implementation of the IWRM was to solve the problem of water pollution. In the sections that follow, we will go through the IWRM and its implementation framework in the Pra Basin. The next section will assess the impact of IWRM implementation on the quality of water in the basin by measuring the change in quality of water before and after the implementation using the water quality index (WQI).

\section{IWRM Implementation Framework}

According to Kennedy et al. (2009), there is a continuous four step loop which is critical in an IWRM implementation. The steps are 1) recognition and identification, 2) conceptualization, 3) coordination and planning, and 4) implementation, monitoring and evaluation. So much work has been done on these four steps in both developed and developing countries. Nonetheless, little attention has been paid to the monitoring and evaluation part of the loop. A situation which is very common in developing countries like Ghana where resources has been implemented (Merrey, 2008).

A thorough study of the surface water resource in Ghana reveals that the water bodies are seriously polluted due to discharge of untreated wastewater from industry, uncontrolled small scale mining activities and bad farming practices (Nasirudeen, 2014). IWRM was considered appropriate for putting this situation under control. As a result, a water resources commission (WRC) was established by an act of parliament to take up the responsibility of coordinating all the water related activities in Ghana. Setting up of the WRC before the implementation of the IWRM concept was very prudent as it tends to eats away a lot of time if it is setup just when implementation is to take place. The WRC, in taking a step in the implementation process, started exploring and identifying the problems and the challenges pertaining to Ghana's water environment and based on the peculiar nature of the problems identified, defined the entire surface water in Ghana into six (6) basins namely, the Volta, Ankobra, Densu, Bia, Tano and Pra. The present study focuses on the Pra Basin. Rapid socio-economic changes have impacted negatively on the water resource in the Pra Basin. Data collected in the basin identified problems in the following areas:1) water resource availability; 2) water quality and; 3) environmental and ecosystem sustainability (WRC, 2012).The collected data were harmonized with those of the sector which were not directly in water through workshops and round table discussions. The following plans :1) the creation of awareness and the sensitization of stakeholders about the negative impacts of land degradation; 2) the provision of incentives to change behavior and providing alternatives to lost livelihoods, and an implementation of a buffer zone policy; 3 ) 
strengthening the institutional capacity to enforce compliance to regulations ; 4) support the metropolitan, municipal and district assemblies (MMDAs) to enact By laws for enforcement of environmental laws; 5) support the MMDAs to rehabilitate, expand and build new waste treatment facilities to meet the increasing demand; 6) enforce regulations on waste management and pollution control of surface and groundwater resources; 7) strengthen the institutional capacity at all levels for waste management; 8) implement the Polluter Pays Principle and recover costs (WRC, 2012) were outline for action in solving the identified problems. Available data reveals that, much has been done in problem recognition and identification, and conceptualization and planning (WRC, 2012). However, little attention is paid to monitoring and evaluation.

This study is to evaluate and document the water quality changes of the various baseline sampling sites within the basin after the implementation of IWRM and classify them using the National Sanitation Foundation (NSF) water quality index (WQI). In order to statistically confirm the significance of the impacts, the Wilcoxon signed-rank test will be employed. The results from this study will provide an idea of how IWRM has performed so far in an area of remediating polluted water resources in the Pra Basin and thereby offer a platform for practical evaluation of the plan of action, for possible adjustment and improvement. The classification after the implementation of IWRM would help to locate the highly polluted areas ('hot spots'), so that special monitoring package could be mounted for further evaluation and improvement.

\section{Materials and Methodology}

The current study involved sampling and analyzing eight (8) to measure changes in the surface water quality (table $3 a$ and $3 b$ ). The eight (8) sites were chosen because they had been used in $\mathbf{2 0 1 0}$ to establish the water quality of the basin (baseline) before the implementation of IWRM. Sampling was done from April to August in 2016. Samples were collected just beneath water surface in quiescent areas with the container facing the direction of the current flow to prevent collecting larger debris at the water surface. The accuracy of the sampling process was checked using equipment blank and field blank. All sample containers, except that for the microbial analysis were pre-treated with dilute hydrochloric acid, and rinsed with double distilled water before air drying them. For the microbial analysis, sample containers were pre-treated with $70 \%$ ethanol and allowed to air dry in a dust free area. In all, a total of 40 samples were collected for the analysis. All sample containers were filled to the neck during sampling to allow aeration and mixing before sealing tightly. Parameters such as $\mathrm{pH}$, temperature, total dissolved solids, conductivity, dissolve oxygen, and salinity were measured on site using a standard water machine. The other parameters such as nitrates, total phosphates, biological oxygen demand (BOD), total suspended solids were measured as per the American 
Public Health Association (APHA) procedures.

In this study the National Sanitation Foundation (NSF) water quality indexes method was employed. In the NSF method, graphs or charts are used to convert field data into quality value (Qn) and then multiplied by their corresponding developed weighting factor $(\mathbf{W n})$ or unit.

Water Quality Index (WQI) is calculated as:

$$
W Q I=\frac{\sum \mathrm{Qn} \mathrm{Wn}}{\sum \mathrm{Wn}}
$$

Table 1 is a presentation of the drinking water standards of the parameters used in the analysis with their corresponding weighted factor whereas table 2 shows the classification status and grading use in classifying water bodies.

Table 1: The standard values and weighting factors $(\mathrm{Wn})$ of selected parameters

\begin{tabular}{llll}
\hline Serial Number & Parameters & Standards & Unit weight $(\mathrm{Wn})$ \\
\hline 1 & Ph & $6.5-8.5$ & 0.11 \\
2 & Dissolved Oxygen $(\mathrm{mg} / \mathrm{L})$ & 5 & 0.17 \\
3 & Total suspended solids $(\mathrm{mg} / \mathrm{L})$ & 500 & 0.07 \\
4 & F. Coliform $($ count $/ 100 \mathrm{ml})$ & 0 & 0.16 \\
5 & Temperature ${ }^{0} \mathrm{C}$ & 15 & 0.10 \\
6 & BOD $_{5}(\mathrm{mg} / \mathrm{L})$ & 5 & 0.11 \\
7 & Nitrates $(\mathrm{mg} / \mathrm{L})$ & 45 & 0.10 \\
8 & Phosphates $(\mathrm{mg} / \mathrm{L})$ & 0.3 & 0.10 \\
\hline & & & $\sum W n=0.92$ \\
\hline
\end{tabular}

Table 2: Water Quality Index Status and Grading

\begin{tabular}{lll}
\hline Water Quality Index & Water Quality Status & Grading \\
\hline $0-25$ & Very bad & A \\
$26-50$ & Bad & B \\
$51-75$ & Medium & C \\
$76-100$ & Good & D \\
Above 100 & Excellent & E \\
\hline
\end{tabular}




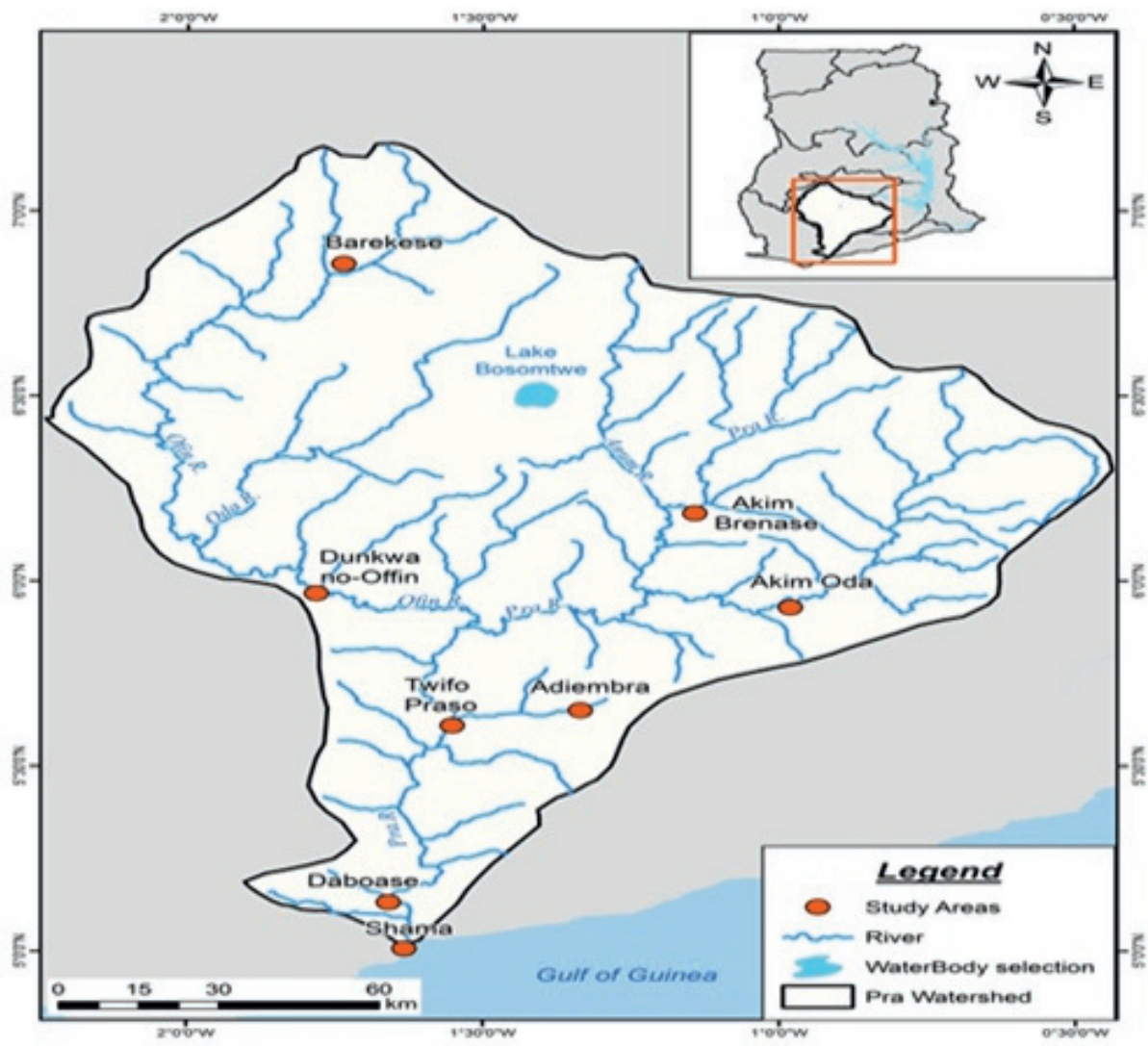

Figure 1: Map of Pra Basin

\section{Results and Discussion}

The results of the various water quality parameters are shown in table $3 \mathrm{a}$ and $3 \mathrm{~b}$. The results are for the mean current situation as well as the baseline.

Table 3a: Water Quality Values for Current and Baseline Assessment

\begin{tabular}{lllllllll}
\hline \multirow{2}{*}{ Sites } & Temperature & \multicolumn{3}{c}{$\mathrm{PO}_{4}{ }^{3-} \mathrm{mg} / \mathrm{L}$} & $\mathrm{NO}_{3}{ }^{-} \mathrm{mg} / \mathrm{L}$ & & \multicolumn{2}{c}{ F. coliform count/100 } \\
\cline { 2 - 9 } & Current & Baseline & Current & Baseline & Current & Baseline & Current & Baseline \\
\hline DF & 30.200 & 24.300 & 1.190 & 0.255 & 3.050 & 0.434 & $13 \times 10^{2}$ & 16 \\
PS & 29.640 & 26.600 & 2.010 & 0.234 & 2.450 & 0.476 & 10 & 9 \\
AO & 28.200 & 29.300 & 0.870 & 0.150 & 1.290 & 0.441 & $4 \times 10^{2}$ & 14 \\
BT & 33.050 & 26.200 & 0.990 & 0.097 & 0.410 & 0.080 & $5 \times 10^{2}$ & 30 \\
DB & 28.200 & 30.600 & 1.540 & 0.206 & 2.840 & 0.484 & 10 & 40 \\
AB & 29.630 & 29.300 & 0.470 & 0.118 & 1.905 & 0.299 & $3 \times 10^{2}$ & 80 \\
BK & 33.700 & 33.700 & 0.690 & 0.049 & 0.495 & 0.251 & 200 & 0 \\
AM & 29.100 & 29 & 1.540 & 0.094 & 0.470 & 0.245 & 10 & 2 \\
\hline
\end{tabular}

DF: Dunkwaw Offin, PS: Twifor Praso, AO: Akim Odaa, BT: Bosomtwe, DB: Deboase, Am: Adiembra, AB: Akim Breniase : BK: Berekese 
Table 3b: Water Quality Values for Current and Baseline Assessment

\begin{tabular}{lllllllll}
\hline Sites & \multicolumn{2}{l}{$\begin{array}{l}\text { Total suspended solids } \\
\mathrm{mg} / \mathrm{L}\end{array}$} & $\begin{array}{l}\text { Dissolve } \\
\text { (DO) } \mathrm{mg} / \mathrm{L}\end{array}$ & oxygen & $\mathrm{pH}$ & & \multicolumn{2}{l}{$\begin{array}{l}\text { Biological } \\
\text { demand mg/L }\end{array}$} \\
\cline { 2 - 9 } & Current & Baseline & Current & Baseline & Current & Baseline & Current & Baseline \\
\hline DF & 2371.500 & 116 & 29.870 & 84 & 8.87 & 7.960 & 27 & 3.740 \\
PS & 525 & 224 & 24.520 & 93 & 7.800 & 7.720 & 17 & 3.100 \\
AO & 564.500 & 115 & 34.020 & 93 & 7.440 & 7.660 & 10 & 3.800 \\
BT & 2.500 & 6 & 34.580 & 101 & 9.110 & 9.090 & 18 & 4.800 \\
DB & 88 & 225 & 17.270 & 103 & 7.390 & 8.100 & 22 & 3.400 \\
AB & 307.500 & 24 & 35.520 & 92 & 7.370 & 7.620 & 23.500 & 4 \\
BK & 9.500 & 5 & 45.140 & 48 & 7.110 & 7.350 & 24 & 3.500 \\
AM & 394.500 & 17 & 29.500 & 69 & 8.290 & 7.780 & 20 & 3.100 \\
\hline
\end{tabular}

DF: Dunkwaw Offin, PS: Twifor Praso, AO: Akim Odaa, BT: Bosomtwe, DB: Deboase, Am: Adiembra, AB: Akim Breniase : $B K$ : Berekese

\section{Water Quality Parameters}

Prior studies have created uncertainties about the practicality of IWRM in achieving it purpose or targets. In 2005 van der Zaak, presented IWRM as a necessary principle for all to adopt without any doubt. A study by Akpabio (2008) indicated that IWRM has failed to make a full transition from theory to practice. Despite all the uncertainties associated with IWRM, many countries especially those from developing countries are still implementing the concept. The present study, focused on assessing the impact of IWRM on the quality of water in the Pra basin. The results gathered show a decline in the quality of water in almost all study sites.

The dissolved oxygen (DO) in water is a water quality parameter which is used to assess biological changes in water as aerobic or anaerobic (Gangwar et al., 2012). DO is the main driving force for metabolic activities of aerobic organisms in water. It's level in water is therefore an important parameter to determine the safety of aerobic aquatic species. A DO saturation higher than 110 or below 90 is lethal to fishes in water (Kizha et al., 2016). The measured dissolved oxygen in the basin is not only outside the percentage saturated range of $110-90$, but it also widely deviates from the baseline measurement (table $3 \mathrm{~b}$ ). The current DO level poses a threat to the aquatic life (Kizha et al., 2016) in the basin. The level of DO in water was influenced by factors such as the temperature, the level of organic matter, and the wind blowing on the water surface or the flow of the river (Davis, 1975) . Temperature influences the speed of reaction in aquatic environments. For example, temperature can slow down or increase the rate at which algae and aquatic plants photosynthesize (Carr \& Neary, 2008). Aquatic organisms have narrow tolerance for temperature (Carr \& Neary, 2008). This means, a sharp variation in temperature over a short period as well as gradual variation over a long period are all significant to aquatic life and can result in the death of aquatic species. A temperature range 
between $28-30^{\circ} \mathrm{C}$ is good for aquatic life as it enhances photosynthesis at the surface of rivers to generate more oxygen (Mortimer, 1956). As can be seen in table $3 a$, measured temperatures for both the baseline and current values are within the range to facilitate the process of oxygen generation in the basin. However, this is not so, the observed DO saturation level in the basin currently was very low which indicated large contribution from either one or both of the remaining factors. The flow rate of a river is affected or influenced by the suspended particles it carries.

Suspended solids (SS) are the mass or concentration in $\mathrm{mgl}^{-1}$ of organic and inorganic matter, which are held in a water column of a stream, river, lake or reservoir (Bilotta $\&$ Brazier, 2008). These particles mostly come from anthropogenic activities such as soil and bank erosion, mining and farming. The SS when present in water can affect it physically, chemically and biologically (Bilotta \& Brazier, 2008). Physically, it can reduce the volume or depth of the river through siltation, reduce the penetration of light, influence temperature changes and make the water aesthetically unattractive for recreational and drinking purposes (Bilotta \& Brazier, 2008; Lloyd et al. 1987). Chemically, suspended solids can carry along pesticides, heavy metals and nutrients such as phosphates into a water body (Dawson \& Macklin, 1998; Haygarth et al., 2006). Biologically, suspended solids which contain organic matter compete with aquatic species for available oxygen. The color of the rivers as illustrated photographically in figure 2 is an indication of high levels of suspended solids in the basin.

It can be observed (Table 3b) that apart from Bosomtwe (B T) and Barekese (B K) which saw a reduction in the level of the suspended solids, five of the remaining six sites saw between $100-200 \%$ increase in levels of the suspended solids. Site B T and $B K$ unlike the other sites are located upstream the basin where there are no mining activities. In addition to the rise in suspended solids in the five sites, a difference of more than $1000 \%$ was observed in Dunkwa-On-Offin (D F). This striking difference might have been caused by the numerous and uncontrolled illegal mining activities occurring in that part of the basin and the close upstream tributaries. In addition, the advanced technology in mining in site D F employs the use of sophisticated equipment. As a result, the rivers are dredged and the soil is left at the banks of the rivers without caring about its future consequences. Currently the route of the river in site $D F$ has been diverted for illegal mining activities.

Suspended solids may contain high levels of organic matter (OM) depending on their sources. Most often suspended organic matter get into rivers or streams through run-offs from upstream forest, farm lands and wastewater from anthropogenic activities.OM, when in water compete with living species for available oxygen which limit the level of oxygen in the water.OM, like any other suspended solid does affect the water physically, chemically and biologically (Lloyd et al., 1987). The physical effect has been well explained in paragraph 3 of this discussion. Chemically the 
OM carries along nutrients in the form of phosphates and nitrates into the water bodies (Smith, 2003). In the right concentration, phosphates are useful because they catalyze the growth of aquatic plants which serve as a source of food for fish (Smaya, 2008). However, an excess of phosphate and nitrate will cause algae, and aquatic plants to grow wildly, choke up the waterway and use up large amounts of the oxygen (Brian Oram, 2014) creating eutrophic conditions. Under a eutrophic condition, the living organisms compete for the available oxygen for survival and this creates high biological oxygen demand (BOD) levels in the rivers. Studies have shown that once eutrophication occurs in a river, it would take about 1000 years for the water to be restored under the best circumstances (Carpenter \& Lathrop, 2008), a condition the basin officers must try and avoid considering the high accumulation of the nutrients in the basin currently. Although the temperatures were favorable, the effect from the suspended particles completely nullifies that of the temperature, hence the observed DO values.

The BOD is the mass of the oxygen required by bacteria in decomposing an organic matter under aerobic conditions. Low BOD in a water body is an indication of the good quality of the water because it implies less decomposable organic matter in the water and less oxygen needed to break it down. The current results not only show excess of the permissible limit but also a sharp rise of about 3 to 5 times the baseline values confirming the influence of the high levels of the suspended solids in the basin rivers. Apart from the miners mining directly in the rivers, large volumes of soils dredged from the river beds are left at the bank of the river: these soils get washed by run offs from heavy downpours into the streams and rivers carrying along nutrients and other contaminants (Bilotta \& Brazier, 2008). Usually the less dense organic fraction of the soil is removed during run off and this adds up to the organic fraction of the suspended solids to make it rich (Debyle 1976).When BOD increases and nothing is done to restore the oxygen levels, many aerobic aquatic species are lost through death as anaerobic conditions set in.

In a water environment, water molecules dissociate and establish equilibrium with its $\mathrm{H}^{+}$and $\mathrm{OH}^{-}$ions $\left(\mathrm{H}_{2} \mathrm{O} \leftrightarrow \mathrm{H}^{+}+\mathrm{OH}^{-}\right)$. Anytime $\mathrm{H}^{+}$concentration exceeds that of $\mathrm{OH}^{-}$, the water is said to be acidic and when the opposite occurs the water is said to be basic. The negative logarithm of the dissociated $\mathrm{H}^{+}$ions from a water molecule is known as the $\mathrm{pH}$. The $\mathrm{pH}$ is an important indicator of the solubility and the biological availability of chemical constituents such as heavy metals and nutrients such as phosphates and nitrates in water (Robertson-Bryan, 2004). It also has a link with the biological productivity in water. Though there are fluctuations in all the sites for the $\mathrm{pH}$ that of the site B T should be of much concern because it is gradually increasing to 10 which could be very dangerous for the aquatic life. According to Alabaster (1980), pH values between 9 and 10 can result in the partial mortality of certain fish; as such there is the need to safeguard the $\mathrm{pH}$ from getting to that point to reverse complaints of the low fish harvest in the lake. The generally found $\mathrm{pH}$ 
range of 7-9 in the basin is in the range which is known to reduce the solubility of heavy metals in water and make it less toxic whilst ensuring smooth exchange of the gases between the aquatic species with the water (Alabaster, 1980).

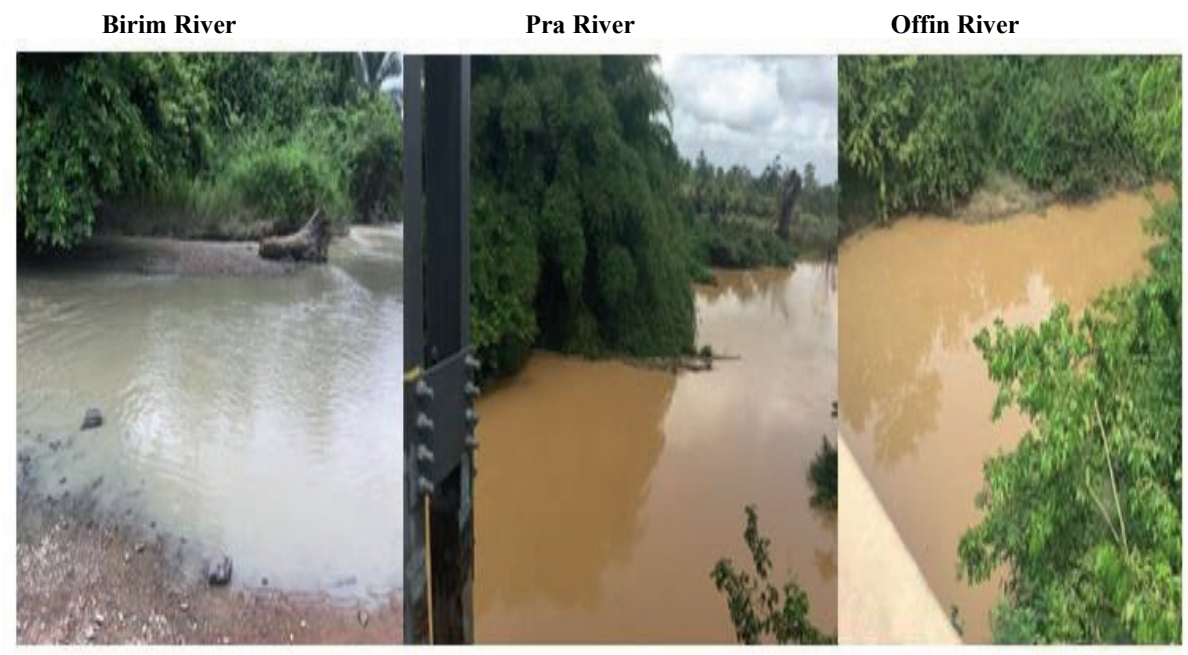

Figure 2: Colored Basin Rivers

\section{Water Quality Classification}

In the classification of the basin water quality, the water quality parameters were converted into quality values (Qn) and then multiplied by their corresponding developed weighting factor $(\mathrm{Wn})$ as shown in the case for site D F in table 3c.

Table 3c: NSF Water Quality index for Dunkwa-on- Offin Site (D F)

\begin{tabular}{|c|c|c|c|c|c|c|}
\hline \multirow[t]{2}{*}{ Parameter } & \multicolumn{3}{|c|}{ Sample site DF Baseline } & \multicolumn{3}{|c|}{ Sample site DF current } \\
\hline & $\mathrm{Wn}$ & Qn & WnQn & $\mathrm{Wn}$ & Qn & WnQn \\
\hline Temperature & 0.10 & 14 & 1.40 & 0.10 & 10 & 1.35 \\
\hline PO43- & 0.10 & 91.87 & 9.19 & 0.10 & 35 & 3.50 \\
\hline NO3- & 0.10 & 94.5 & 9.45 & 0.10 & 84 & 8.4 \\
\hline $\mathrm{FC}(\mathrm{C} / 100)$ & 0.16 & 66 & 10.56 & 0.16 & 21.50 & 3.44 \\
\hline TSS (mg/L) & 0.07 & 81 & 5.67 & 0.07 & 20 & 1.40 \\
\hline $\mathrm{DO}(\mathrm{mg} / \mathrm{L})$ & 0.17 & 90 & 15.30 & 0.17 & 20 & 3.40 \\
\hline $\mathrm{Ph}$ & 0.11 & 80 & 8.8 & 0.11 & 55 & 6.05 \\
\hline \multirow[t]{2}{*}{ BOD } & 0.11 & 59.33 & $\sum^{6.53} W n$ & 0.11 & 4.50 & $\sum^{0.50} W n Q n=280.4$ \\
\hline & \multicolumn{3}{|c|}{$\sum \frac{W n Q n}{W n}=\frac{57.38}{0.92}=62.36$} & \multicolumn{3}{|c|}{$\sum \frac{W n Q n}{W n}=\frac{28.04}{0.92}=30.47$} \\
\hline
\end{tabular}

The above procedure is used to calculate for WQI for the remaining seven sites. The WQI values of the sites are classified using the water quality status (Table 2). The results are also compared to the baseline results to establish the level of impact (Table 3d). 
Table 3d: Water Quality Index and Classification

\begin{tabular}{lllllll}
\hline Sampling site & \multicolumn{2}{l}{ Summary of water quality index classification } & & & \\
\cline { 2 - 6 } & Current WQI & classification & Baseline WQI & classification & Difference & Difference \% \\
\hline DF & 30.47 & Bad & 62.36 & Medium & -31.89 & 51.13 \\
PS & 43.23 & Bad & 78.38 & Good & -35.15 & 44.84 \\
AO & 43.39 & Bad & 75.78 & Good & -32.39 & 42.74 \\
BT & 43.46 & Bad & 72.54 & medium & -29.08 & 40.09 \\
DB & 38.75 & Bad & 69.20 & Medium & -30.45 & 44 \\
AB & 45.47 & Bad & 71.84 & medium & -26.37 & 36.70 \\
BK & 51.02 & Medium & 71.13 & Medium & -18.08 & 24.87 \\
AM & 54.61 & Medium & 72.69 & Medium & -20.11 & 28.27 \\
\hline
\end{tabular}

The calculated water quality index for the baseline and current values are summarized in table $3 \mathrm{~d}$. There is a large decrease of WQI values from the baseline to the current. The decrease is the sign of an increasing pollution load which is caused by the high level of suspended particles released into the water bodies through mostly illegal mining. The intensity of an illegal mining activity and the proximity of sampling sites to such areas is a major contributing factor to the variation in the measured suspended solids. The lowest water quality index was found in Dunkwa On - Offin (D F) whilst Adiembra (A M) had the highest. The deterioration difference in WQI between these two sites can be linked to three reasons: 1) the number of mining sites, 2) the level or scale and the intensity of mining, 3) the nature of soil and its iron content. In classifying the eight (8) sampling sites, as many as $50 \%$ of the sites moved from medium to bad, $25 \%$ moved from good to bad, and only $25 \%$ maintained their medium state. Even the $25 \%$ which maintained their classification status show a decline in WQI. Wilcoxon signed-rank test shows that there is a significant change in the deterioration of the water quality in the basin. For WQI, the deterioration is significantly high after IWRM implementation ( $M d n .=40.25$ ) than before implementation (Mdn. $=72.19$ ) $\mathrm{T}=0, \mathrm{p}=0.012, \mathrm{r}=0.66$.

\section{Conclusion}

The suspended solid is a major problem for the Pra basin, Ghana. In this study, the suspended solids were far higher than the permissible levels which indicated that the Pra basin is polluted by suspended solids which pose a serious threat to the health of the river. The overall water quality index shows a deterioration in the quality of water in the basin which has been statistically proven to be significant. The presented results create doubt about the practicality of the action plan and the compliance of the basin officers to the action plan. The study therefore proposes that illegal mining activities which contributes heavily to the suspended solids should be monitored and regulated, especially in site D F and its surrounding areas. The existing environmental laws should be enforced to reduce the activities of illegal miners. An educational model on IWRM should be developed for all schools from the primary to the secondary level to widen the awareness and sensitization 
creation. Considering the $\mathrm{pH}$ range of 7-9 in the basin, there is the need for heavy metal analysis to be conducted on the river and its soil sediment from upstream to downstream. Interventions should be mapped to create jobs for the youth to keep them away from illegal mining. 


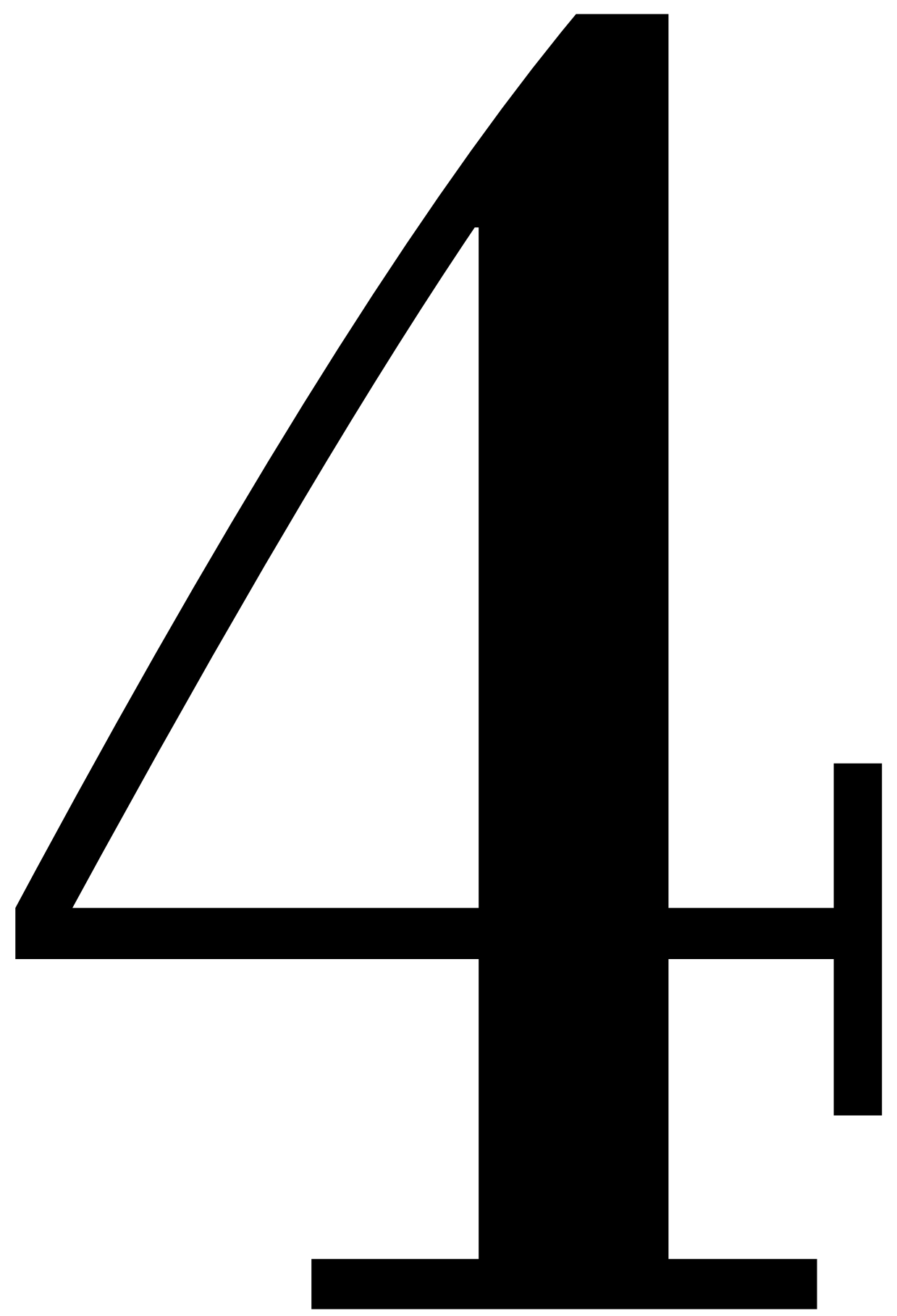




\section{Chapter 4}

\section{Assessment of Heavy Metal Pollution of the Main Pra River and its Tributaries in the Pra Basin of Ghana}

Published as:

Albert Ebo Duncan, Nanne de Vries, Kwabena Biritwum Nyarko (2018) Assessment of heavy metal pollution in the main Pra River and its tributaries in the Pra Basin of Ghana

Environmental nanotechnology, monitoring \& management, 10, 264-271 


\begin{abstract}
The Pra Basin is one of the Basins in Ghana with a high level of illegal mining activities. Heavy metal pollution in water bodies is common in areas where illegal mining is practiced. This study focused on the assessment of heavy metal pollution in the Pra Basin. The study was based on 216 water samples collected from 27 sampling points from the Pra River and two of its tributaries during the dry and wet seasons in 2017. Nine heavy metals namely arsenic (As), chromium ( $\mathrm{Cr}$ ), cadmium (Cd), copper (Cu), lead $(\mathrm{Pb})$, manganese $(\mathrm{Mn})$, nickel $(\mathrm{Ni})$, zinc $(\mathrm{Zn})$, and iron (Fe) were assessed in this study. The metal concentrations (mgL-1) in the wet season were as follows: $\mathrm{Fe}>\mathrm{Pb}>$ $\mathrm{Ni}>\mathrm{Cu}>\mathrm{Cr}>\mathrm{Cd}>\mathrm{Zn}>\mathrm{Mn}>\mathrm{As}$ and in the dry season as $\mathrm{Fe}>\mathrm{Zn}>\mathrm{Cu}>\mathrm{Cr}>\mathrm{Pb}>\mathrm{Mn}$ $>\mathrm{Ni}>\mathrm{Cd}>$ As. Five metals exceed the safe drinking water guidelines making the water generally not safe for domestic activities like drinking and cooking. According to the Nemerow's Pollution Index (NPI) results, six metals namely $\mathrm{Pb}, \mathrm{Cd}, \mathrm{Cr}, \mathrm{Ni}, \mathrm{Fe}, \mathrm{Zn}$ were the principal metal pollutants in both the dry and wet seasons whereas $\mathrm{Mn}, \mathrm{As}$, and $\mathrm{Cu}$, were found not to contribute to the pollution effect. The water quality index confirms that the water quality is marginal to fair in the dry season and poor for 26 out of the 27 sites in the wet season. Generally, the studied rivers (Pra, Offin and Oda) are polluted which is a serious threat to the health of inhabitants in villages which still use the water for cooking activities. The study recommends continuous monitoring of the polluting metals and the assessment of the river sediments to inform effective remediation measures.
\end{abstract}




\section{Introduction}

The suitability of water for any purpose defines its quality. Globally, the quality of water is under serious threat due to anthropogenic activities such as urbanization, industrialization and unregulated mining (Jung, 2001; Sekabira, 2010). The threat could either affect the water physically, biologically or chemically (Carr \& Neary, 2008). The United States Environmental Protection Agency (2000) defined heavy metals as metals with a specific gravity of 5 or greater or metallic element with high atomic weight which have the potential to damage living things at low concentrations. Heavy metal contamination of rivers, mostly from unregulated mining, is now a major concern in most developing countries such as India, Peru, Ghana etc. (Ali et al., 2016).

They are of great concern because of their public health consequences and their stress on ecology (Montuelle \& Graillot, 2017). Exposure to heavy metals over a long period can cause memory impairment and damage to the nervous system (Rajendran, 2003). High accumulation of the metals can cause irreversible brain damage (Afrasiab, 2014). They are a threat to the environment because they are indestructible and can enter the food chain (Ololade, 2008). They can also affect invertebrates and fishes in the aquatic environment (Yi, 2011).

The alarming rate at which rivers in Ghana are getting polluted with heavy metals from untreated industrial waste is still a pending problem that has not been solved. The heavy metal pollution from industry has been compounded by that of unregulated/illegal mining. The Pra Basin has been experiencing unregulated mining in and around most of its major rivers for more than 30 years (WRC., 2012). The expansion of the illegal mining happened so fast that almost all the rivers in the basin which in the past 35 to 50 years were very useful to the riparian communities have become esthetically unattractive and unhealthy for consumption (Attuaquayefio \& Folib, 2005; Donkor et al. 2006; Afum \& Owusu, 2016). The unattractive nature notwithstanding, some riparian communities when faced with water supply crises depend on the rivers for domestic activities such as cooking and washing. In recent years major steps have been taken to improve water management in the Pra Basin (Pra Basin, 2012). Incorporated in the new management set-up is a river monitoring and evaluation unit with a task to conduct regular assessment of the rivers to see if there is any improvement or deterioration. Monitoring stations have been established along the Basin River since 2011. However, monitoring is not functioning effectively (WRC, 2011). Illegal mining is prevalence in the basin but heavy metal concentration is not used in classifying water quality. There has not been any scientific study of the heavy metal which pollutes the main Pra River from the upstream to the downstream of the basin. Therefore, the objective of the study is to identify the heavy metals with a pollution threat and the extent of their threat using Nemerow's Water Pollution Index (NPI). We also assess the overall 
water quality with reference to the metals under study by employing the Canadian Council of Ministers of the Environment (CCME) Water Quality Index (WQI). The study will contribute in developing the right strategies and remediation measures in solving the threat posed by these metals in the basin and other comparable areas.

\section{Materials and Methods}

\section{Study area and sampling}

Ghana is drained by three main river systems; the Volta Basin system, SouthWestern Basin system, and the Coastal Basin system. The Pra Basin which is the study area forms part of the South-Western Basin which comprises of the Pra, Bia, Ankobra, and Tano rivers. A total of 17 artificial reservoirs are constructed nationwide along the three main river systems for hydropower generation, irrigation, and water supply (Pra Basin, 2012). Nine (9) out of the 17 reservoirs are located in the study area which is why the quality of the water in the area is very important. Illegal mining sites are scattered all over the Pra Basin. All sampling sites were either within or around the illegal mining sites. Site 'LAK' was a control site located in the northern part of all the sites with no form of mining going on in the area. Kriging was used to develop a heat map for the polluting metals in all sampling sites. In this method, the field data was loaded in arcmap and the comma separated values (csv) file format converted into points. The Inverse distance weighted (IWD) interpolation tool was then used to run the interpolation for each element and displayed in figure 2. The study area is the largest among the three South-Western River Systems and occupies an area of $23000 \mathrm{~km}^{2}$ which is about $9.64 \%$ of the area of Ghana (Pra Basin, 2012). Studies conducted in the basin by the water resources commission of Ghana and that by Duncan (2016) reveals similar illegal mining activities in the entire basin. Due to the similar characteristics pertaining in the basin and accessibility difficulties, the main Pra River, and two of its tributaries (Offin and Oda) was considered for this study. The main Pra River takes it source from the Kwahu plateau from the eastern part of Ghana and flows through a distance of about $240 \mathrm{~km}$ before joining the Gulf of Guinea. There are 43 administrative districts with about $42 \%$ of the households not having access to potable water i.e. tap water or approved wells (Pra Basin, 2012). Figure 1 presents the study area map. Eight (8) samples were collected from each sampling point and in a total of 27 sampling points, 216 water samples were collected in laboratory cleaned and rinsed 1.5-liter polyethylene bottles. Water samples were collected from January to April 2017 for the dry season and May to August 2017 for the wet season. Samples were acidified with $0.24 \mathrm{M}$ nitric acid (analytical grade) and kept at $4^{\circ} \mathrm{C}$ in the dark before analysis. 

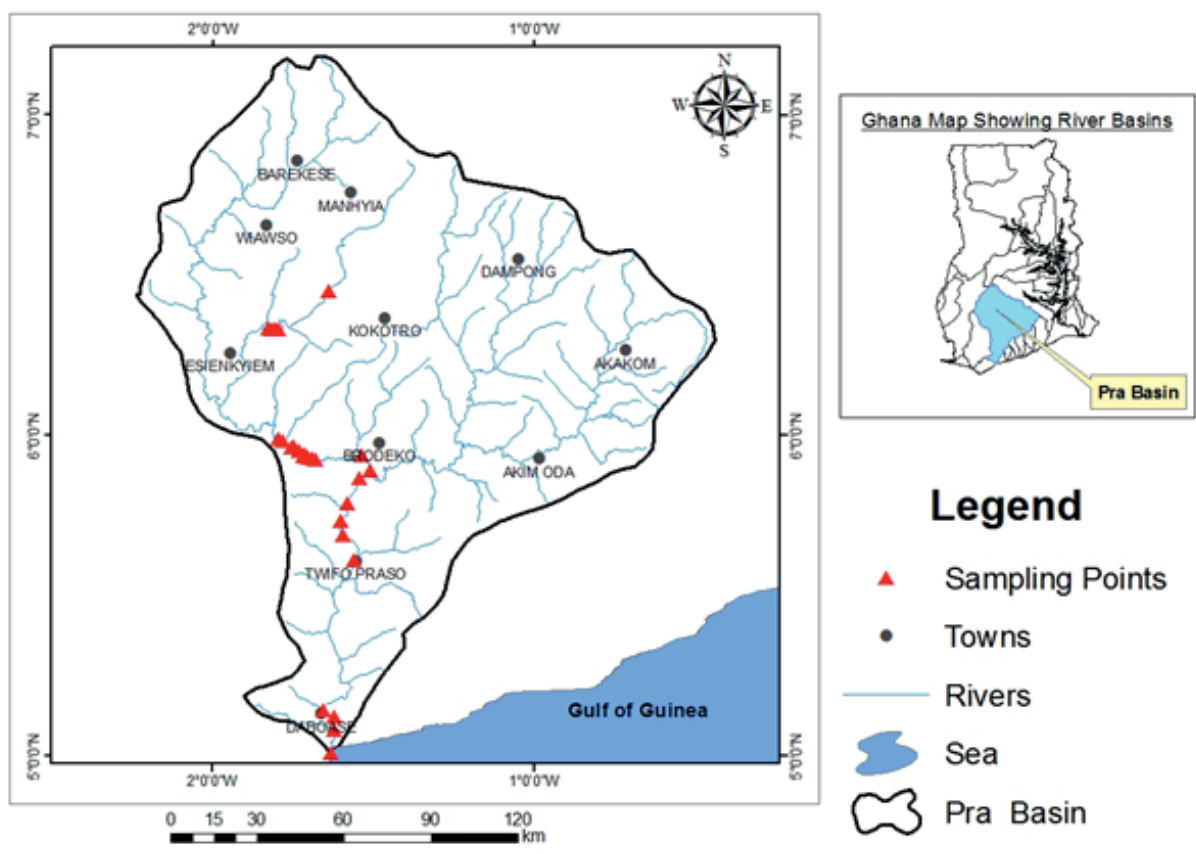

\section{Legend}

4 Sampling Points

- Towns

Rivers

Sea

Ora Basin

Figure 1: Map of Pra Basin

\section{Water quality parameter}

Physico-chemical parameters such as $\mathrm{pH}$, electrical conductivity, turbidity, and temperature were measured on the field. Temperature and $\mathrm{pH}$ were measured using a pH meter (model No. PHSB-320, BOQU instruments China). Conductivity was determined with the pen-type conductivity meter (model No. LH- P1318). Turbidity was measured by the portable $2100 \mathrm{Q}$ turbidity meter of the HACH United States of America.

\section{Chemical and sample digestion}

Deionized water supplied by University of Cape Coast Technology village was used in all the analysis. All standard solutions used were of the highest purity supplied by MES Equipment Limited Ghana. The nitric and hydrochloric acids used for the digestion were all analytical grades and supplied by MES equipment. Water samples were filtered using a $0.45 \mu \mathrm{m}$ cellulose membrane filter and acidified to $\mathrm{pH}<2$ using analytical grade nitric acid. $50 \mathrm{ml}$ of a well-mixed acid preserved sample was transferred to a boiling tube and $5 \mathrm{ml} \mathrm{HNO}_{3}$ added. The mixture was heated at $130^{\circ} \mathrm{C}$ in a graphite block digester till the volume reduced to about $25-20 \mathrm{ml}$. Addition of nitric acid and heating was repeated until the solution became light colored or clear. The solution was cooled and made to the desired volume using deionized water and filtering through Whatman no. 41 filter paper. 


\section{Analytical technique and accuracy check}

Nine (9) heavy metals namely arsenic (As), total chromium ( $\mathrm{Cr}$ ), cadmium (Cd), copper $(\mathrm{Cu})$, lead $(\mathrm{Pb})$, manganese $(\mathrm{Mn})$, nickel $(\mathrm{Ni})$, zinc $(\mathrm{Zn})$, and iron (Fe) were measured using dual atomizer and hydride generator atomic absorption spectrophotometer (model ASC-7000 No A309654, Shimadzu, Japan). All reagents used were of the analytical grade from MES Equipment Ghana. Ultrapure metal free deionized water was used for all analysis. All glassware and plastic were cleaned by soaking them in warm 5\% (V/V) aqueous nitric acid for 6-7 hours and rinsed with ultrapure deionized water. The standard for the ASS calibration was prepared by diluting standard (1000 ppm) supplied by MES Equipment Ghana. All the results were expressed in $\mathrm{mg} / \mathrm{L}$. Matrix Spike recovery was in the range of $85 \%-100 \%$. The precision was estimated from the relative percentage difference (RPD) of the spiked concentration and the recovered concentration using the relation:

$$
R P D=C 1-C 2 / 0.5(C 1+C 2) \times 100
$$

Where $\mathrm{C} 1$ is the spiked concentration and $\mathrm{C} 2$ is the recovered concentration. The calculated percentage of $12 \%$ was within the acceptable range of $\pm 15 \%$.

\section{Assessment of heavy metals in water}

In assessing the water quality in terms of the heavy metal load, two indices, the Canadian Council of Ministers of the Environment (CCME) Water Quality Index (WQI) and Nemerow's Pollution Index (NPI) were applied. These indices use the permissible levels of the parameters concerned as a reference point for assessment.

\section{Canadian Council of Ministers of the Environment (WQI)}

This index summarizes the overall quality of water by considering the number of variables not meeting the water quality objectives (scope); the number of times these objectives are not met (frequency) and the amount by which the objectives are not met (amplitude). The scope, frequency, and the amplitude together can provide a single value $(0-100)$ that describes the quality of the water. Once the CCME WQI value has been determined, the water quality can be classified as Excellent (95100), good (80-94), fair (65-79), marginal (45-64) and poor (0-44). The CCME WQI provides a mathematical framework for assessing ambient water quality conditions relative to water quality objectives. In the mathematical framework, there should be at least a minimum of four sampling times with at least four variables; however, there is no limitation to the maximum numbers in the areas specified.

$F_{1}$ (Scope) represents the percentage of variables that do not meet their objectives at least once during the time period under consideration ("failed variables"), relative to the total number of variables measured. $F_{1}$ is mathematically expressed as: 


$$
F 1=\frac{\text { Number of failed variable }}{\text { Total number of variables }} \times 100
$$

$F_{2}$ (Frequency) represents the percentage of individual tests that do not meet objectives ("failed tests"). It is mathematically expressed as:

$$
F 2=\frac{\text { Number of failed tests }}{\text { Total number of tests }} \times 100
$$

$F_{3}$ (Amplitude) represents the difference in amount between the failed test values and their objectives. The $F_{3}$ calculation involves three steps. The first step is to estimate the number of times the individual concentrations are greater than (or less than, when the objective is a minimum) the objectives (excursion). This is mathematically expressed as:

$$
\text { excursion }=\frac{\text { Failed test value }}{\text { objective }}-1
$$

For the cases in which the test value must not fall below the objectives, the excursion is calculated as:

$$
\text { excursion }=\frac{\text { objective }}{\text { Failed test value }}-1
$$

The ratio of the sum of excursions to the total test is referred to as the normalized test of excursion or nse.

$$
\text { nse }=\frac{\sum_{i=1}^{n} \text { excursion }}{\text { number of tests }}
$$

$\mathrm{F}_{3}$ is then calculated by an asymptotic function that scales the normalized summed of the excursions from the objectives (nse) to yield a range between 0 and 100 .

$$
F 3=\frac{n s e}{0.01 n s e+0.01}
$$

After calculating for the three F's, CCME WQI can be calculated as:

$$
\text { CCME WQI }=100-\frac{\sqrt{F 1^{2}+F 2^{2}+F 3^{2}}}{1.732}
$$

\section{Nemerows Pollution Index (NPI)}

Nemerow's pollution index provides information on the extent of pollution of individual pollutants in a sampled area with reference to its standard value (Rathod et al., 2011). Whereas the WQI provides the general quality of the water, Nemerow's index identifies and establishes the extent of pollution of individual parameters at each sampling site. It is mathematically expressed as: 


$$
N P I=C i / L i
$$

Where $C_{i}$ is the observed concentration of $i^{\text {th }}$ parameter; $L_{i}$ is the permissible limit of $\mathrm{i}^{\text {th }}$ parameter. Each value of the calculated NPI represents the relative pollution contribution by a single parameter. The calculated NPI when is less than or equal to 1 indicates the absence of pollution and any value above 1 indicate pollution.

\section{Statistical analysis}

Microsoft Excel 2010 was used to calculate the mean and standard deviations of the heavy metal concentration in the water samples. An independent t-test was used to assess the significance of the seasonal contribution to the variations in metal concentration and physicochemical parameters.

\section{Results and Discussion}

\section{Water quality parameters}

The mean values of the physico-chemical parameters are presented in table 1 . The physical and chemical components of water are very important because they influence the stability of the water ecosystem as well as the chemical reactions which takes place in the water (Deborah, 1996). The $\mathrm{pH}$ of water is very important because it has a strong influence on the biological productivity (Carr \& Neary, 2008) as well as the solubility of heavy metals in the water. The dry season $\mathrm{pH}(\mathrm{M}=7.22$, $\mathrm{SE}=0.08)$ was significantly different from that of the wet season $(\mathrm{M}=6.85, \mathrm{SE}=$ 0.01). The mean pH range of 5.08 to 8.94 and 5.5 to 9.67 recorded for both dry and wet seasons were all outside the WHO permissible limits (Table 1). The recorded pH ranges are not favorable for aquatic life (Carr \& Neary, 2008). However, the mean $\mathrm{pH}$ of 6.86 and 7.22 was within the WHO permissible limits. Aquatic organisms have very narrow temperature tolerance; as a result, small changes in temperature can affect species such as algae, invertebrates, fishes etc. (Carr and Neary, 2008; Yi, 2011). The temperatures measured ranged from $27^{\circ} \mathrm{C}$ to $32^{\circ} \mathrm{C}$ and $27^{\circ} \mathrm{C}$ to $30^{\circ} \mathrm{C}$ for the dry and wet seasons respectively. The mean temperatures of the two seasons though were within the WHO standards were significantly different (table 1\&5). The dry season showed a higher temperature $(M=29.10, S E=0.24)$ than the wet season $(\mathrm{M}=27.97, \mathrm{SE}=0.12)$. The significant temperature difference can have serious influences on aquatic species as well as some form of chemical reactions in the basin (Haiyan L., 2013). The mineral content of water which is usually made of the total dissolved solids is an important feature in the quality of the water (Deborah, 1996). Electrical conductivity is a measure of the dissolved salts and inorganic materials like sulfides and carbonates. Most water bodies have fairly constant conductivity; as a result, a sharp change in conductivity could be an indication of 
a possible pollution. The values of conductivity ranged from 97.2 to $948 \mu \mathrm{s} / \mathrm{cm}$ and 1.05 to $609 \mu \mathrm{s} / \mathrm{cm}$ for dry and wet seasons respectively. The mean conductivities of the two seasons were all within the WHO guideline value of $1000 \mu \mathrm{scm}^{-1}$. Turbidity is a measure of the number of suspended solids in the water. It is very important because biodegradable suspended organic materials deplete available dissolved oxygen in water creating anaerobic conditions. The measured turbidity was ranged from 1.05 to $609 \mathrm{NTU}$ and 2.14 to $910 \mathrm{NTU}$ for the dry and wet seasons. There is a significant difference in the dry season turbidity $(M=285.33, \mathrm{SE}=29.7)$ and wet season turbidity $(M=535.01, S E=39.02)$. The higher turbidity value recorded for the wet season could be attributed to the high runoffs from the excavated fields and scouring of rivers during heavy downpours (Carr \& Neary, 2008). High turbidity means more chemical usage for drinking water treatment plants in the basin.

Table 1. Water quality parameters of the Pra River and its tributaries in the Pra Basin of Ghana

\begin{tabular}{|c|c|c|c|c|c|c|c|c|}
\hline \multirow[t]{2}{*}{ Sites } & \multicolumn{2}{|c|}{ Temperature ${ }^{\circ} \mathrm{C}$} & \multicolumn{2}{|l|}{$\mathrm{pH}$} & \multicolumn{2}{|c|}{$\begin{array}{l}\text { Electrical Conductivity } \\
\left(\mu \mathrm{s} \mathrm{cm}^{-1}\right)\end{array}$} & \multicolumn{2}{|c|}{ Turbidity (NTU) } \\
\hline & Dry & Wet & Dry & Wet & Dry & Wet & Dry & Wet \\
\hline Lake (LAK) & 29.58 & 27.85 & 8.82 & 8.96 & 9.38 & 131.28 & 1.42 & 171.87 \\
\hline Oda (OD1) & 28.00 & 27.00 & 7.39 & 7.20 & 252.00 & 178.15 & 74.95 & 303.75 \\
\hline Oda (OD2) & 28.20 & 28.08 & 7.76 & 7.30 & 255.75 & 187.30 & 80.93 & 346.75 \\
\hline Oda (OD3) & 28.13 & 27.63 & 7.37 & 7.52 & 282.00 & 168.40 & 93.15 & 358.50 \\
\hline Oda (OD4) & 27.75 & 27.45 & 7.24 & 7.36 & 261.25 & 168.15 & 73.48 & 132.75 \\
\hline Praso Town (PT) & 27.75 & 27.13 & 7.06 & 6.36 & 165.08 & 123.83 & 347 & 788 \\
\hline Praso Subinso (PS) & 27.63 & 27.63 & 7.20 & 6.41 & 174.35 & 124.15 & 358.75 & 639.75 \\
\hline Twifo Agona (TAG) & 30.70 & 28.33 & 7.16 & 6.41 & 180.30 & 128.38 & 278.50 & 740.50 \\
\hline Twifo Kotokyire (TK) & 31.20 & 28.68 & 7.05 & 6.54 & 210.20 & 106.75 & 339.25 & 623.50 \\
\hline Assin Awisam (TAW) & 31.13 & 28.13 & 6.93 & 6.46 & 226.00 & 111.58 & 407.25 & 666.50 \\
\hline Assin asaman (AAS) & 31.10 & 28.88 & 7.06 & 6.44 & 281.75 & 229.50 & 376.25 & 603.00 \\
\hline Assin Nyardom (ANY) & 29.93 & 28.43 & 7.09 & 6.80 & 252.75 & 144.78 & 364.50 & 622.75 \\
\hline Dunkwa Town (DT) & 28.13 & 27.48 & 6.92 & 6.73 & 248.50 & 138.70 & 297.75 & 693.25 \\
\hline Dunkwa Upstream (DU) & 28.20 & 27.48 & 7.24 & 6.73 & 169.50 & 149.46 & 490 & 704.00 \\
\hline Dunkwa Breman (DBR) & 27.63 & 27.25 & 7.38 & 6.62 & 293.50 & 142.58 & 509.5 & 584.25 \\
\hline $\begin{array}{l}\text { Dunkwa Downstream } \\
\text { (DDO) }\end{array}$ & 29.30 & 28.55 & 7.39 & 6.89 & 274.75 & 133.98 & 401.75 & 490.75 \\
\hline Dunkwa Ankaase (DAN) & 29.13 & 28.20 & 7.08 & 6.49 & 313.00 & 135.88 & 231.25 & 407.25 \\
\hline Dunkwa Kojokrom (DKO) & 30.53 & 29.25 & 7.10 & 6.88 & 278.75 & 137.05 & 498.5 & 803 \\
\hline Appiah Nkwanta (ANK) & 30.48 & 28.50 & 7.40 & 7.13 & 252.00 & 127.93 & 366.8 & 657.75 \\
\hline Dunkwa Edwuma (DED) & 29.68 & 28.50 & 7.34 & 6.47 & 241.25 & 115.48 & 342 & 779.25 \\
\hline Dunkwa Akropong (DAK) & 29.85 & 28.48 & 6.10 & 6.78 & 223.65 & 124.93 & 473 & 631.00 \\
\hline Dunkwa Kyekyere (DKY) & 30.63 & 28.63 & 7.01 & 6.54 & 224.75 & 134.10 & 366.75 & 692.75 \\
\hline Anhwia Nkwanta (AAN) & 28.75 & 27.68 & 7.27 & 7.19 & 344.75 & 245.50 & 50.53 & 71.83 \\
\hline Beposo (BEP) & 28.10 & 27.55 & 6.68 & 6.88 & 162.10 & 150.50 & 325.50 & 589 \\
\hline Daboase (DAB) & 28.13 & 27.60 & 7.48 & 6.68 & 154.50 & 157.25 & 304.50 & 544 \\
\hline Atwereboanda (ATW) & 28.75 & 27.90 & 7.21 & 6.61 & 917.50 & 531.50 & 213.75 & 373.25 \\
\hline Shama (SHA) & 27.50 & 27.05 & 7.30 & 6.79 & 361.25 & 363.50 & 36.78 & 426.25 \\
\hline Average \pm SD & $\begin{array}{l}29.10 \pm 0.2 \\
0\end{array}$ & $\begin{array}{l}27.97 \pm 0.2 \\
7\end{array}$ & $\begin{array}{l}7.22 \pm \\
0.19\end{array}$ & $6.86 \pm 0.22$ & $\begin{array}{l}259.65 \pm 1 \\
3.96\end{array}$ & $\begin{array}{l}170.02 \pm 8 \\
1.23\end{array}$ & $\begin{array}{l}285.33 \pm 4 \\
0.79\end{array}$ & $\begin{array}{l}535.01 \pm \\
78.00\end{array}$ \\
\hline Average Max & 32 & 30 & 8.94 & 9.67 & 950 & 948 & 609 & 910 \\
\hline Average Min & 27 & 27 & 5.08 & 5.5 & 3.7 & 97.2 & 1.05 & 2.14 \\
\hline WHO (2011) & \multicolumn{2}{|c|}{$25-30$} & & $6.5-8.5$ & \multicolumn{2}{|c|}{1000} & \multicolumn{2}{|r|}{5} \\
\hline
\end{tabular}

Bolded figures are above WHO standards.

\section{Metal concentration in water}

The result of the heavy metal concentration in the water is shown in table 2 . The concentration of the metals varied between the two seasons (figure 2). The metal concentrations $\left(\mathrm{mgL}^{-1}\right)$ in the water were as follows: $\mathrm{Fe}>\mathrm{Pb}>\mathrm{Ni}>\mathrm{Cu}>\mathrm{Cr}>\mathrm{Cd}>$ $\mathrm{Zn}>\mathrm{Mn}>\mathrm{As}$ and in the dry season as $\mathrm{Fe}>\mathrm{Zn}>\mathrm{Cu}>\mathrm{Cr}>\mathrm{Pb}>\mathrm{Mn}>\mathrm{Ni}>\mathrm{Cd}>\mathrm{As}$. The 
concentration of the metals $\mathrm{Mn}$, As, and Cu was below the WHO permissible levels during the dry and wet season. An independent t-test was used to test the level of seasonal influence on the measured $\mathrm{Pb}$ concentration, $\mathrm{t}(52)=-12.21, \mathrm{p}=0.00$, with the wet season showing higher $\mathrm{Pb}$ concentrations than the dry season (wet season $M=1.03$; dry season $M=0.18$ ). The mean concentration of $\mathrm{Pb}$ was 0.175 and $1.03 \mathrm{mg} / \mathrm{L}$ for dry and wet season respectively. The values are far above the WHO permissible levels for drinking water. There was a significant seasonal variation in the Ni concentration. The wet season showed a higher Ni concentration ( $\mathrm{M}=$ $0.33, \mathrm{SE}=0.08)$ than the dry season $(\mathrm{M}=0.08, \mathrm{SE}=0.00)$. However, the observed mean concentrations of $\mathrm{Ni}$ for the dry and wet season were higher than the WHO guideline for drinking water (Table $2 \& 3$ ). The higher levels of $\mathrm{Pb}$ and $\mathrm{Ni}$ in the wet season could be due to high turbidity and low pH (Table 1). Turbid water which contains suspended solids from a mining environment mostly carries heavy metals which dissolve under low pH. The concentrations of $\mathrm{Pb}$ and $\mathrm{Ni}$ (Table 3 ) in the wet season can also be attributed to the washing of the excavated sediments by runoff and scouring of river sediments during heavy rainfall into the river (Carr, 2008). The metals $\mathrm{Cr}, \mathrm{Fe}, \mathrm{Cd}$, and $\mathrm{Zn}$ all recorded higher values in the dry season and vice versa (Figure 2). All the four metals had concentrations above the WHO guideline for drinking water. However, unlike Fe and $\mathrm{Zn}$, there was no significant difference in the seasonal concentrations for the metals $\mathrm{Cr}$ and $\mathrm{Cd}$ (Table 4). Two reasons could account for the different concentrations in the two seasons. First, in the dry season, there was an increase in illegal mining hours and coverage due to the government order to stop all illegal mining by the end of March 2017. This catalyzed a lot of the miners to spend long periods working at the site to make enough money before the deadline. Second, dilution of rivers (Carr \& Neary, 2008) during the wet season could account for the low concentration observed in $\mathrm{Cr}, \mathrm{Fe}, \mathrm{Cd}$, and $\mathrm{Zn}$. Reduction in the illegal mining in most part of the basin after March 2017 could also account for the low concentrations in the four metals during the wet season. 
Table 2. Mean metal concentration $(\mathrm{mg} / \mathrm{L}$ ) in water sample in the Pra Basin and maximum permitted concentration in water $(\mathrm{mg} / \mathrm{L})$ during dry season

\begin{tabular}{|c|c|c|c|c|c|c|c|c|c|}
\hline \multirow{2}{*}{ Sites } & \multicolumn{9}{|c|}{ Dry Season } \\
\hline & As exp -3 & $\mathrm{Zn}$ & $\mathrm{Pb}$ & $\mathrm{Cu}$ & $\mathrm{Cd}$ & $\mathrm{Fe}$ & $\mathrm{Mn}$ & $\mathrm{Cr}$ & $\mathrm{Ni}$ \\
\hline LAK & 0.745 & 1.141 & 0.016 & 0.031 & 0.004 & 1.916 & 0.051 & 0.045 & 0.014 \\
\hline OD1 & 1.746 & 4.430 & 0.489 & 0.340 & 0.016 & 5.660 & 0.163 & 0.146 & 0.068 \\
\hline OD2 & 1.734 & 4.097 & 0.050 & 0.368 & 0.047 & 5.718 & 0.173 & 0.149 & 0.073 \\
\hline OD3 & 0.674 & 3.246 & 0.467 & 0.333 & 0.028 & 5.045 & 0.168 & 0.243 & 0.073 \\
\hline OD4 & 0.994 & 1.263 & 0.245 & 0.367 & 0.047 & 5.518 & 0.267 & 0.212 & 0.090 \\
\hline PT & 2.164 & 6.215 & 0.057 & 0.595 & 0.084 & 3.446 & 0.095 & 0.199 & 0.131 \\
\hline PS & 1.603 & 6.545 & 0.099 & 0.213 & 0.036 & 3.928 & 0.028 & 0.244 & 0.119 \\
\hline TAG & 3.736 & 3.647 & 0.164 & 0.295 & 0.035 & 2.998 & 0.033 & 0.217 & 0.114 \\
\hline TK & 1.168 & 4.065 & 0.114 & 0.188 & 0.049 & 4.118 & 0.021 & 0.039 & 0.136 \\
\hline TAW & 1.861 & 1.811 & 0.108 & 0.257 & 0.056 & 5.219 & 0.101 & 0.071 & 0.057 \\
\hline AAS & 2.750 & 2.745 & 0.058 & 0.091 & 0.035 & 5.254 & 0.062 & 0.137 & 0.119 \\
\hline ANY & 1.094 & 4.963 & 0.190 & 0.229 & 0.035 & 4.131 & 0.124 & 0.290 & 0.074 \\
\hline DT & 1.023 & 4.324 & 0.502 & 0.079 & BDL & 6.226 & 0.115 & 0.127 & 0.131 \\
\hline DU & 3.197 & 5.487 & 0.021 & 0.071 & 0.028 & 4.007 & 0.007 & 0.269 & 0.142 \\
\hline DBR & 2.246 & 7.435 & 0.086 & 0.657 & 0.036 & 4.563 & 0.197 & 0.204 & 0.000 \\
\hline DDO & 2.762 & 0.234 & 0.048 & 0.054 & 0.042 & 5.012 & 0.157 & 0.019 & 0.063 \\
\hline DAN & 2.235 & 6.081 & 0.579 & 0.183 & 0.028 & 5.825 & 0.094 & 0.126 & 0.091 \\
\hline DKO & 0.603 & 5.199 & 0.026 & 0.230 & 0.017 & 5.458 & 0.041 & 0.326 & 0.015 \\
\hline ANK & 1.939 & 4.573 & 0.077 & 1.676 & 0.027 & 3.716 & 0.061 & 0.076 & 0.052 \\
\hline DED & 1.612 & 3.842 & 0.106 & 0.317 & 0.029 & 4.951 & 0.057 & 0.151 & 0.009 \\
\hline DAK & 2.254 & 1.890 & 0.013 & 1.636 & 0.040 & 4.569 & 0.018 & 0.102 & 0.083 \\
\hline DKY & 2.118 & 1.994 & 0.018 & 0.340 & 0.043 & 5.361 & 0.047 & 0.100 & 0.069 \\
\hline AAN & 1.883 & 2.272 & 0.047 & 0.292 & 0.041 & 6.037 & 0.297 & 0.154 & 0.086 \\
\hline BEP & 1.849 & 3.188 & 0.105 & 0.474 & 0.048 & 4.835 & 0.306 & 0.169 & 0.068 \\
\hline DAB & 2.314 & 2.907 & 0.697 & 0.422 & 0.046 & 4.431 & 0.177 & 0.285 & 0.198 \\
\hline ATW & 1.108 & 2.155 & 0.122 & 0.428 & 0.045 & 5.467 & 0.327 & 0.475 & 0.083 \\
\hline SHA & 1.647 & 1.623 & 0.162 & 0.218 & 0.048 & 5.768 & 0.295 & 0.468 & 0.083 \\
\hline $\begin{array}{c}\text { Average } \\
\pm \mathrm{SD}\end{array}$ & $\begin{array}{c}1.893 \\
\pm 0.756\end{array}$ & $\begin{array}{c}3.703 \pm 1.77 \\
1\end{array}$ & $0.175 \pm 0.192$ & $0.394 \pm 0.392$ & $0.037 \pm 0.017$ & $4.784 \pm 0.897$ & $0.129 \pm 0.099$ & $0.187 \pm 0.115$ & $0.08 \pm 0.048$ \\
\hline Max & 7.930 & 9.252 & 0.894 & 3.824 & 0.161 & 7.768 & 0.520 & 0.820 & 0.541 \\
\hline Min & 0.051 & 0.000 & 0.000 & 0.000 & 0 & 1.124 & 0.000 & 0 & 0 \\
\hline $\begin{array}{l}\text { WHO } \\
(2011)\end{array}$ & 0.01 & 3 & 0.01 & 2 & 0.003 & 2 & 0.4 & 0.05 & 0.07 \\
\hline
\end{tabular}

Bolded figures are above $W H O$ standards; $B D L=$ below detection limit

Table 3. Mean metal concentration $(\mathrm{mg} / \mathrm{L})$ in water sample in the Pra Basin and maximum permitted concentration in water $(\mathrm{mg} / \mathrm{L})$ during wet season

\begin{tabular}{|c|c|c|c|c|c|c|c|c|c|}
\hline \multirow{2}{*}{ Sites } & \multicolumn{9}{|c|}{ Wet Season } \\
\hline & As exp -3 & $\mathrm{Zn}$ & $\mathrm{Pb}$ & $\mathrm{Cu}$ & $\mathrm{Cd}$ & $\mathrm{Fe}$ & $\mathrm{Mn}$ & $\mathrm{Cr}$ & $\mathrm{Ni}$ \\
\hline LAK & 0.076 & BDL & 0.032 & 0.037 & BDL & 1.725 & BDL & 0.020 & 0.025 \\
\hline OD1 & 1.431 & BDL & 1.492 & 0.118 & 0.007 & 6.905 & BDL & 0.164 & 1.514 \\
\hline OD2 & 1.407 & BDL & 1.200 & 0.458 & BDL & 1.197 & 0.166 & 0.275 & 0.176 \\
\hline OD3 & 0.798 & BDL & 1.170 & 0.222 & BDL & 1.601 & BDL & 0.252 & 0.201 \\
\hline OD4 & 2.438 & BDL & 1.135 & 0.178 & 0.499 & 1.729 & 0.021 & 0.110 & 0.246 \\
\hline PT & 1.414 & BDL & 1.098 & 0.334 & BDL & 2.265 & BDL & 0.072 & 0.128 \\
\hline PS & 0.997 & BDL & 1.189 & 0.346 & BDL & 1.634 & BDL & 0.040 & 0.133 \\
\hline TAG & 1.585 & BDL & 1.454 & 0.310 & BDL & 1.883 & BDL & 0.094 & 0.120 \\
\hline TK & 0.663 & BDL & 0.770 & 0.201 & BDL & 1.841 & BDL & 0.070 & 0.106 \\
\hline TAW & 0.595 & BDL & 0.870 & 0.326 & BDL & 2.086 & BDL & 0.016 & 0.146 \\
\hline AAS & 0.948 & BDL & 0.568 & 0.155 & 0.771 & 2.197 & BDL & 0.493 & 0.221 \\
\hline ANY & 1.620 & BDL & 0.677 & 0.341 & BDL & 1.426 & BDL & 0.460 & 1.935 \\
\hline DT & 1.025 & BDL & 0.810 & 0.305 & BDL & 1.132 & BDL & 0.019 & 0.128 \\
\hline DU & 1.065 & BDL & 0.926 & 0.151 & BDL & 3.984 & BDL & 0.039 & 0.118 \\
\hline DBR & 0.803 & BDL & 0.994 & 0.487 & BDL & 2.339 & BDL & 0.018 & 0.335 \\
\hline DDO & 1.591 & BDL & 0.900 & 0.019 & BDL & 9.847 & BDL & 0.033 & 0.166 \\
\hline DAN & 2.171 & BDL & 1.139 & 0.306 & BDL & 2.826 & BDL & 0.030 & 0.268 \\
\hline DKO & 1.351 & 0.722 & 0.830 & 0.196 & BDL & 2.283 & BDL & 0.043 & 0.198 \\
\hline ANK & 1.484 & BDL & 1.123 & 1.385 & BDL & 0.792 & BDL & 0.029 & 0.232 \\
\hline DED & 1.205 & BDL & 1.223 & 0.152 & 0.370 & 1.505 & BDL & 0.048 & 0.158 \\
\hline DAK & 1.438 & BDL & 1.335 & 0.751 & BDL & 0.443 & BDL & 0.126 & 0.243 \\
\hline DKY & 1.321 & BDL & 1.186 & 0.132 & BDL & 2.338 & BDL & 0.260 & 0.200 \\
\hline AAN & 0.969 & BDL & 1.215 & 0.383 & BDL & 3.257 & BDL & 0.150 & 0.257 \\
\hline BEP & 1.494 & BDL & 0.993 & 0.382 & BDL & 5.150 & BDL & 0.077 & 0.191 \\
\hline DAB & 0.856 & BDL & 1.470 & 0.195 & BDL & 1.690 & BDL & 0.134 & 0.316 \\
\hline ATW & 0.817 & BDL & 0.916 & 0.370 & BDL & 0.762 & BDL & 0.146 & 0.902 \\
\hline SHA & 0.878 & BDL & 0.971 & 0.179 & BDL & 1.735 & BDL & 0.113 & 0.206 \\
\hline $\begin{array}{l}\text { Average } \\
\pm \mathrm{SD}\end{array}$ & $1.201 \pm 0.483$ & $0.027 \pm 0.139$ & $1.025 \pm 0.307$ & $0.312 \pm 0.263$ & $0.061 \pm 0.184$ & $2.493 \pm 1.998$ & $0.007 \pm 0.032$ & $0.123 \pm 0.126$ & $\begin{array}{c}0.329 \\
\pm 0.434\end{array}$ \\
\hline $\operatorname{Max}$ & 5.435 & 1.166 & 3.752 & 1.978 & 0.148 & 4.019 & 0.5846 & 1.473 & 0.537 \\
\hline Min & 0.00 & 0.000 & 0.000 & 0.008 & 0 & 1.341 & 0 & 0 & 0 \\
\hline $\begin{array}{l}\text { WHO } \\
(2011)\end{array}$ & 0.01 & 3 & 0.01 & 2 & 0.003 & 2 & & 0.05 & 0.07 \\
\hline
\end{tabular}

Bolded figures are above $W H O$ standards; $B D L=$ below detection limit 
Table 4. Independence t-test for heavy metals and physicochemical parameters

\begin{tabular}{|c|c|c|c|c|c|c|c|c|}
\hline Parameter & Season & mean & SD & SE & MD & DF & $\begin{array}{l}\text { Sig (2- } \\
\text { tailed) }\end{array}$ & $\mathrm{t}$ \\
\hline Temperature & $\begin{array}{l}1 \\
2\end{array}$ & $\begin{array}{l}29.10 \\
27.97\end{array}$ & $\begin{array}{l}1.25 \\
0.60\end{array}$ & $\begin{array}{l}0.24 \\
0.12\end{array}$ & 1.13 & 52 & 0.00 & 4.24 \\
\hline $\mathrm{pH}$ & $\begin{array}{l}1 \\
2\end{array}$ & $\begin{array}{l}7.22 \\
6.85\end{array}$ & $\begin{array}{l}0.44 \\
0.53\end{array}$ & $\begin{array}{l}0.08 \\
0.01\end{array}$ & 0.37 & 52 & 0.01 & 2.76 \\
\hline $\mathrm{EC}$ & $\begin{array}{l}1 \\
2\end{array}$ & $\begin{array}{l}259.65 \\
170.02\end{array}$ & $\begin{array}{l}148.91 \\
89.34\end{array}$ & $\begin{array}{l}28.66 \\
17.19\end{array}$ & 89.62 & 52 & 0.01 & 2.68 \\
\hline Turbidity & $\begin{array}{l}1 \\
2\end{array}$ & $\begin{array}{l}285.32 \\
535.01\end{array}$ & $\begin{array}{l}154.41 \\
203.70\end{array}$ & $\begin{array}{l}29.7 \\
39.02\end{array}$ & -249.68 & 52 & 0.00 & -5.07 \\
\hline Zinc & $\begin{array}{l}1 \\
2\end{array}$ & $\begin{array}{l}3.61 \\
0.03\end{array}$ & $\begin{array}{l}1.84 \\
0.14\end{array}$ & $\begin{array}{l}0.35 \\
0.03\end{array}$ & 3.58 & 52 & 0.00 & 10.09 \\
\hline Lead & 1 & $\begin{array}{l}0.17 \\
1.03\end{array}$ & $\begin{array}{l}0.19 \\
0.31\end{array}$ & $\begin{array}{l}0.04 \\
0.06\end{array}$ & -0.85 & 52 & 0.00 & -12.21 \\
\hline Cadmium & $\begin{array}{l}1 \\
2\end{array}$ & $\begin{array}{l}0.04 \\
0.06\end{array}$ & $\begin{array}{l}0.02 \\
0.18\end{array}$ & $\begin{array}{l}0.00 \\
0.04\end{array}$ & -0.02 & 52 & 0.50 & -0.68 \\
\hline Iron & $\begin{array}{l}1 \\
2\end{array}$ & $\begin{array}{l}4.78 \\
2.47\end{array}$ & $\begin{array}{l}1.01 \\
2.00\end{array}$ & $\begin{array}{l}0.19 \\
0.39\end{array}$ & 2.32 & 52 & 0.00 & 5.37 \\
\hline Chromium & $\begin{array}{l}1 \\
2\end{array}$ & $\begin{array}{l}0.19 \\
0.12\end{array}$ & $\begin{array}{l}0.11 \\
0.13\end{array}$ & $\begin{array}{l}0.02 \\
0.02\end{array}$ & 0.06 & 52 & 0.06 & 1.92 \\
\hline Nickel & $\begin{array}{l}1 \\
2\end{array}$ & $\begin{array}{l}0.08 \\
0.33\end{array}$ & $\begin{array}{l}0.04 \\
0.43\end{array}$ & $\begin{array}{l}0.00 \\
0.08\end{array}$ & -0.24 & 26.22 & 0.01 & -2.92 \\
\hline
\end{tabular}

$S D=$ standard deviation; $S E=$ standard error; $M D=$ mean difference; $D F=$ degree of freedom; $S E D=$ standard error difference; $E C=$ Electrical Conductivity; Season $1=$ dry season; Season 2 = wet season; $P<0.05$

\section{Assessment of metal pollution}

The summary of the Numerow's pollution index (NPI) and Canadian council of ministers of the environment water quality Index (CCMEWQI) is presented in table 5. The NPI values ranged from 0 to 99.6 and 0 to 257 during the dry and the wet seasons respectively, confirming that some of the metals did not contribute to the overall pollution effect in the study area $(0 \leq \mathrm{NPI}>1)$. Even though $\mathrm{Cd}$ did not pollute all the sites in both dry and wet season, it was the metal with the highest pollution index at site ANK and ANY during the dry and wet season respectively (Table 5). However, $\mathrm{Pb}$ polluted every site in both seasons indicating the persistence of the metal in the mining environment. On the general polluting effects of the basin by the metals, NPI results indicate that 11 of the sites were polluted by six metals whereas 12 sites were polluted by five metals, 3 sites were polluted by four metals and only 1 site was polluted by two metals during the dry season (Fig. 2). In the wet season, two sites were polluted with 5 metals, five sites polluted with four metals, sixteen sites polluted with 3 metals, three sites polluted with 2 metals and one site polluted with 1 metal (Fig. 2). The observed NPI values will serve as a guide in the choice of remediation measure to adopt at each study site. There wasn't much difference in the dry and wet season water quality index. The observed water quality index showed poor water quality for all the sites during the dry season except sites DDO and LAK which showed marginal (45-64) and fair (65-79) water quality respectively. Apart from site LAK which showed good (80-94) water quality in the wet season, all other sites observed poor (0-44) water quality. The observed water quality index for the study sites confirms the polluting effects of the study metals. 
Table 5. Pollution index and water quality index for dry and wet seasons

\begin{tabular}{|c|c|c|c|c|c|c|c|c|c|c|c|c|c|}
\hline \multirow[t]{2}{*}{ Sites } & \multicolumn{6}{|c|}{ NPI dry season } & \multirow[t]{2}{*}{ WQI } & \multicolumn{5}{|c|}{ NPL wet season } & \multirow[t]{2}{*}{ WQI } \\
\hline & $\mathrm{Zn}$ & $\mathrm{Pb}$ & $\mathrm{Cd}$ & $\mathrm{Fe}$ & $\mathrm{Cr}$ & $\mathrm{Ni}$ & & $\mathrm{Pb}$ & $\mathrm{Cd}$ & $\mathrm{Fe}$ & $\mathrm{Cr}$ & $\mathrm{Ni}$ & \\
\hline LAK & 0.38 & 1.6 & 1.33 & 0.95 & 0.9 & 0.2 & 68 & 3.2 & 0 & 0.88 & 0.4 & 0.36 & 85 \\
\hline OD1 & 1.48 & 48.9 & 5.33 & 2.83 & 2.92 & 0.97 & 31 & 149 & 2.33 & 3.48 & 3.28 & 21.6 & 31 \\
\hline OD2 & 1.37 & 5.0 & 15.7 & 2.86 & 2.98 & 1.04 & 35 & 120 & 0 & 0.59 & 5.5 & 2.51 & 37 \\
\hline OD3 & 1.08 & 46.7 & 9.33 & 2.52 & 4.86 & 1.04 & 30 & 117 & 0 & 0.80 & 5.04 & 2.87 & 38 \\
\hline OD4 & 0.42 & 24.5 & 15.6 & 2.76 & 4.24 & 1.3 & 31 & 113 & 166 & 0.86 & 2.2 & 3.51 & 31 \\
\hline PT & 2.07 & 5.7 & 28 & 1.72 & 3.98 & 1.87 & 42 & 109 & 0 & 1.13 & 1.44 & 1.83 & 37 \\
\hline PS & 2.18 & 9.9 & 12 & 1.96 & 4.88 & 1.7 & 32 & 118 & 0 & 0.82 & 0.8 & 1.90 & 38 \\
\hline TAG & 1.22 & 16.4 & 11.667 & 1.49 & 4.34 & 1.63 & 35 & 145 & 0 & 0.94 & 1.88 & 1.71 & 37 \\
\hline TK & 1.36 & 11.4 & 16.3 & 2.06 & 0.78 & 1.94 & 36 & 77 & 0 & 0.92 & 1.4 & 1.51 & 40 \\
\hline TAW & 0.60 & 10.8 & 18.6 & 2.61 & 1.42 & 0.81 & 37 & 87 & 0 & 1.04 & 0.32 & 2.09 & 40 \\
\hline AAS & 0.92 & 5.8 & 11.7 & 2.63 & 2.74 & 1.7 & 38 & 56.8 & 257 & 1.10 & 9.86 & 3.16 & 32 \\
\hline ANY & 1.65 & 19 & 11.7 & 2.06 & 0.73 & 1.05 & 34 & 67.7 & 0 & 0.71 & 9.2 & 27.6 & 39 \\
\hline DT & 1.44 & 50.2 & 0.00 & 3.11 & 2.54 & 1.87 & 37 & 81 & 0 & 0.57 & 0.38 & 1.83 & 40 \\
\hline DU & 1.83 & 2.1 & 9.33 & 2.00 & 5.38 & 2.02 & 39 & 92.6 & 0 & 1.99 & 0.78 & 1.69 & 38 \\
\hline DBR & 2.48 & 8.6 & 12 & 2.28 & 4.08 & 0 & 36 & 99.4 & 0 & 1.17 & 0.36 & 4.79 & 37 \\
\hline DDO & 0.08 & 4.8 & 14 & 2.51 & 0.38 & 0.9 & 55 & 90 & 0 & 4.92 & 0.66 & 2.37 & 38 \\
\hline DAN & 2.03 & 57.9 & 9.33 & 2.91 & 2.52 & 1.3 & 29 & 113 & 0 & 1.43 & 0.6 & 3.83 & 37 \\
\hline DKO & 1.73 & 2.6 & 5.66 & 2.73 & 6.52 & 0.21 & 41 & 83 & 0 & 1.14 & 0.86 & 2.83 & 39 \\
\hline ANK & 1.52 & 7.7 & 99.6 & 1.86 & 1.52 & 0.74 & 45 & 112 & 0 & 0.40 & 0.58 & 3.31 & 41 \\
\hline DED & 1.28 & 10.6 & 9.66 & 2.48 & 3.02 & 0.13 & 36 & 122 & 123 & 0.75 & 0.96 & 2.26 & 33 \\
\hline DAK & 0.63 & 1.3 & 13.3 & 2.28 & 2.04 & 1.19 & 44 & 133 & 0 & 0.22 & 2.52 & 3.47 & 44 \\
\hline DKY & 0.67 & 1.8 & 14.3 & 2.68 & 2 & 0.98 & 42 & 118 & 0 & 1.17 & 5.2 & 2.86 & 36 \\
\hline AAN & 0.76 & 4.7 & 13.6 & 3.02 & 3.08 & 1.23 & 41 & 121 & 0 & 1.63 & 3 & 3.67 & 36 \\
\hline BEP & 1.06 & 10.5 & 16 & 2.41 & 3.38 & 0.97 & 33 & 99.3 & 0 & 2.58 & 1.54 & 2.73 & 37 \\
\hline DAB & 0.97 & 69.7 & 15.3 & 2.22 & 5.7 & 2.83 & 28 & 147 & 0 & 0.85 & 2.68 & 4.51 & 37 \\
\hline ATW & 0.72 & 12.2 & 15 & 2.73 & 9.5 & 1.19 & 32 & 91.6 & 0 & 0.38 & 2.92 & 12.8 & 41 \\
\hline SHA & 0.54 & 16.2 & 16 & 2.88 & 9.36 & 1.17 & 28 & 97.1 & 0 & 0.87 & 2.26 & 2.94 & 39. \\
\hline Mean & 1.203 & 17.281 & 15.568 & 2.391 & 3.548 & 1.184 & 37.593 & 102.322 & 20.309 & 1.235 & 2.467 & 4.687 & 39.185 \\
\hline Standard & $1 \leq$ & & & & & & 100 & $1 \leq$ & & & & & 100 \\
\hline
\end{tabular}

Bolded figures are above WHO standards 

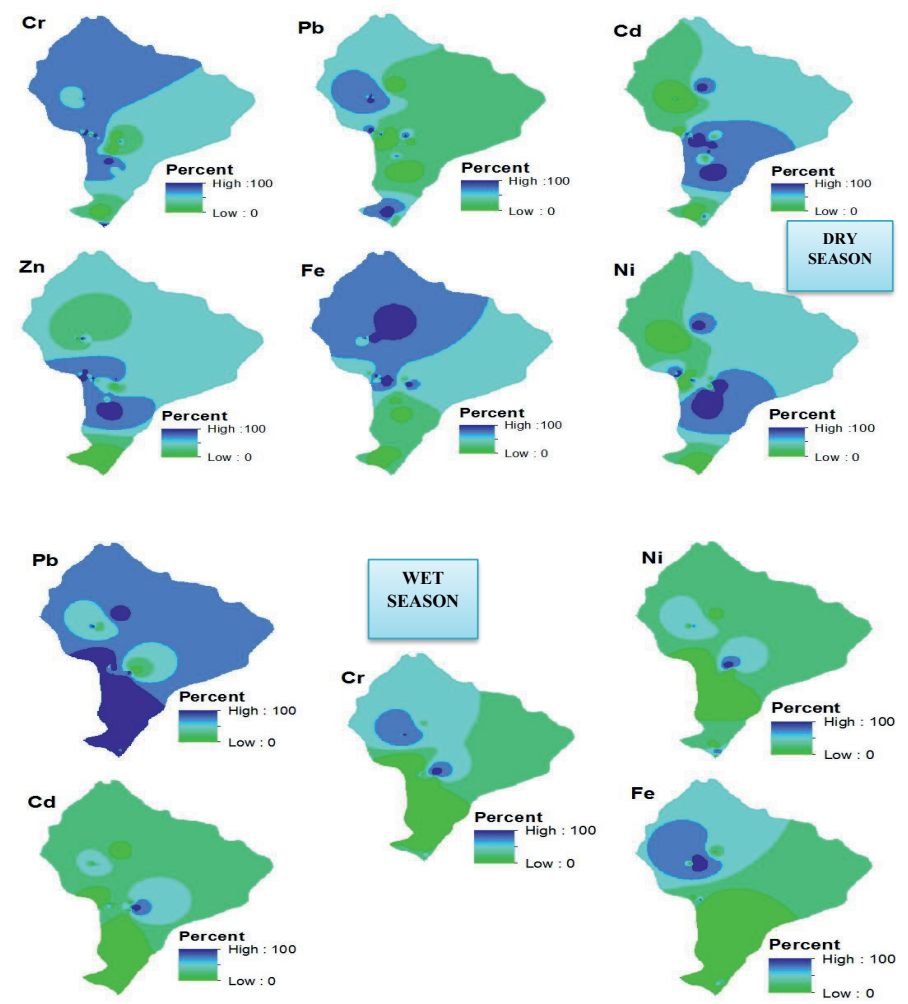

Figure 2. Percentage distribution of polluting metals in the Pra Basin Rivers

\section{Conclusions}

The results identified $\mathrm{Pb}>\mathrm{Cd}>\mathrm{Cr}>\mathrm{Ni}>\mathrm{Fe}>\mathrm{Zn}$ as the mean polluting order of the individual metals in the study sites for the dry and wet season (Fig. 2). The concentrations of the polluting metals were higher in the wet season than the dry season. The concentrations of the polluting metals were far higher than the permissible limit which is an indication that the Pra Basin is polluted by the studied metals. Among the six polluting metals, $\mathrm{Cd}$ showed the highest pollution index at site ANK and ANY during the dry and wet season. Metal pollution at the sites for the dry and wet season do not follow any pattern. $\mathrm{Pb}$ is the only metal among the six polluting metals identified to have polluted all the 27 sites during the dry and wet season. The water quality index confirms that the water quality is marginal to fair in the dry season and poor for the 26 out of the 27 sites in the wet season. Even though the contribution of unplanned urbanization and industrialization to heavy metal pollution of rivers in developing countries is a known phenomenon (Ali et al., 2016), the main cause of heavy metal pollution in the Pra Basin stems from the unregulated illegal mining activities. The pollution is a public health concern for the communities which still depend on these rivers for domestic activities such as 
cooking during water crises and those who feed on fishes from these rivers. The study results lead us to propose intensification of the monitoring in the basin to sustain the fear of arrest which has kept most of the illegal miners out of their sites. It further suggests the study of the levels of these metals in the river sediments to help in the choice of a holistic remediation process. 


$$
5
$$




\section{Chapter 5}

\section{Assessment of Heavy Metal Pollution in the Sediments of the River Pra and its Tributaries}

Published as:

Duncan, A. E., de Vries, N., \& Nyarko, K. B. (2018). Assessment of Heavy Metal Pollution in the Sediments of the River Pra and Its Tributaries. Water, Air, \& Soil Pollution, 229(8), 272. 


\section{Abstract}

An investigative study was conducted to determine the heavy metal pollution in the sediment in the Pra Basin of Ghana from 27 sampling points during the dry and wet seasons using the geo- accumulation index (Igeo), enrichment factor (EF) and pollution load index (PLI). Sediments were acid digested and analyzed for the following selected metals: arsenic (As), lead (Pb), cadmium (Cd), zinc ( $\mathrm{Zn})$, manganese (Mn), total chromium $(\mathrm{Cr})$, nickel $(\mathrm{Ni})$ and iron $(\mathrm{Fe})$ using the dual atomizer and hydride generator atomic absorption spectrophotometer (model ASC-7000 No A309654, Shimadzu, Japan). The metal concentrations $\left(\mathrm{mgkg}^{-1}\right)$ in the sediments were as following : $\operatorname{As}(0.175)<$ $\mathrm{Cd}(3.206)<\mathrm{Ni}(79.927)<\mathrm{Zn}(118.323)<\mathrm{Cr}(216.708)<\mathrm{Mn}(234.742)<\mathrm{Pb}(335.381)<$ Fe $(1354.513)$ in the dry season and $\mathrm{As}(0.002)<\mathrm{Cd}(7.279)<\mathrm{Ni}(72.663)<\mathrm{Zn}(35.622)$ $<\mathrm{Pb}(135.863)<\mathrm{Cr}(167.604)<\mathrm{Mn}(183.904)<\mathrm{Fe}(1138.551)$ for the wet season. The $\mathrm{EF}$ which is an indication of whether metal concentrations are due to anthropogenic activities shows enrichment at all site for the metals $\mathrm{Cr}, \mathrm{Pb}$, and $\mathrm{Cd}$ in the wet seasons. However, only 4 out of the 27 sites showed $\mathrm{Ni}$ enrichment in the wet season. Contrary to the wet season, only $\mathrm{Pb}$ and $\mathrm{Cr}$ recorded enrichment at all sites during the dry season. Fifteen (15) out of the 27 sites recorded Cd enrichment and 24 out of the 27 sites recorded $\mathrm{Ni}$ enriched during the dry season. None of the sites were enriched with $\mathrm{Fe}, \mathrm{As}, \mathrm{Zn}$, and $\mathrm{Mn}$ in either the dry or wet seasons. For both dry and wet seasons, the pollution load index for all the sites except one was at the background levels which is a sign of non-deterioration of the sites studied. In the wet season, the calculated Igeo reveals that the study area is not contaminated with respect to $\mathrm{As}, \mathrm{Zn}, \mathrm{Fe}$, and $\mathrm{Mn}$; uncontaminated to moderately contaminated with $\mathrm{Cd}$; moderately contaminated with $\mathrm{Cr}$; uncontaminated to moderately to heavily contaminated with $\mathrm{Ni}$; and moderately to heavily contaminated with $\mathrm{Pb}$. The dry season Igeo results reveal non-contamination of the study area with respect to As, Fe, and $\mathrm{Mn}$; uncontaminated to moderately contamination with $\mathrm{Zn}$; moderately contaminated with $\mathrm{Cr}$; uncontaminated to heavily contaminated with $\mathrm{Cd}$; uncontaminated to extremely contaminated with $\mathrm{Ni}$; and moderately to extremely contaminated with $\mathrm{Pb}$. The high levels of $\mathrm{Cd}, \mathrm{Pb}$, and $\mathrm{Cr}$ in all the sites are due to unregulated illegal mining activities occurring in and around the study area. It is hoped that this study will prompt the basin management board to improve their management strategies in controlling unregulated illegal mining in the basin sediments. 


\section{Introduction}

Accumulation of heavy metals in the sediments of rivers which are exposed to mining and industrial waste is a common phenomenon in most developing countries (Islam, 2015). Such river sediments have become sinks for heavy metals, just like wetlands. The sediments sometimes act as carriers and sources for the heavy metals in the environment (Haiyan L., 2013). The study of heavy metals in river sediments is very important because sediments serve as habitat for many benthic organisms like the mudfish. Unfortunately, most of the time, the rivers are monitored without paying any attention to the sediments which are in constant interaction with the river. Studies have shown that rivers have been severely contaminated with heavy metals due to historic and modern mining and industrial operations (Miller, 2004). Heavy metals in river sediments enter through different pathways, either from point or non-point sources (Shazili, 2006). Examples of point sources could be the discharges of industrial waste such as metal mine wastes through pipes or drains, into rivers. Non-point sources such as silt-laden runoff from excavated lands and leachate from landfills also contribute to the levels of heavy metals usually discharged into water resources. The fate of heavy metals in an aquatic environment is affected by processes such as precipitation, sorption, and dissolution (Abdel-Ghani, 2007). These processes are also affected by factors such as $\mathrm{pH}$, temperature, dissolve oxygen concentration and the disturbance of the water (Atkinson, 2007; Simpson, 2004). At higher $\mathrm{pH}$, heavy metals precipitate and get adsorbed onto sediment surfaces. Metals are also released more easily into the water at lower $\mathrm{pH}$ and higher temperatures. When the dissolved oxygen concentration is low i.e. less than $7 \mathrm{mg} / \mathrm{L}$, heavy metals especially those bound to organic matter sediments are released into the overlying water and vice versa (Haiyan L., 2013). A study by Atkinson (2007) shows that physical disturbance of water releases metals more rapidly into water than biological disturbance. The study of heavy metals in sediments can serve as a guide in predicting the extent of pollution of the overlying water under different environmental conditions.

The present study assesses the heavy metal pollution level in the main Pra River and two of its tributaries in the Pra Basin of Ghana. The study area is the largest among the three South-Western River Systems in Ghana and occupies an area of $23000 \mathrm{~km}^{2}$ which is about $9.64 \%$ of the area of Ghana. Sediments pollution by heavy metals in the study area is now graduating into a major problem with the increased illegal mining activities in and around the rivers in the basin which are increasing the turbidity and the heavy metal levels, making the rivers physically unstable, and chemically and biologically toxic. The present state of the rivers poses serious problems to the environment and the health of those villages which still depend on the rivers for cooking and bathing during water crises. To date, no detailed upstream to the downstream scientific analysis of the River sediments have been conducted concurrently. The aim of this study is to assess the concentrations of lead 
$(\mathrm{Pb})$, cadmium $(\mathrm{Cd})$, arsenic $(\mathrm{As})$, chromium $(\mathrm{Cr})$, iron $(\mathrm{Fe})$, manganese $(\mathrm{Mn})$, zinc $(\mathrm{Zn})$, and nickel (Ni) using the enrichment factor (EF), pollution load index (PLI), and the geo-accumulation index (Igeo). Geo-accumulation index determines the metal levels of contamination or accumulation with reference to background levels of the same element in the environment. EF which is also an indication of enrichment of a selected metal with reference to a background metal such as iron complements the Igeo. by indicating the source of enrichment as either natural or anthropogenic. The pollution load index assesses the cumulative pollution effect of the metals at each site by making reference to the EF of all the metals measured at each site.

\section{Materials and Methods}

This study was conducted in the Pra Basin of Ghana. The hydrogeology of the Pra Basin is dominated by aquifers of the crystalline basement rocks and the Birimian Province. Sediment texture from the sampling site spans from sand, sandy loam, loamy sand, silty clay loam, and sandy clay loam. The Basin is located between latitudes $5^{\circ} \mathrm{N}$ and $7^{\circ} 30^{\prime} \mathrm{N}$, and longitudes $2^{\circ} 30^{\prime} \mathrm{W}$, and $0^{\circ} 30^{\prime} \mathrm{W}$, in south-central Ghana. It is the largest among the three south-western basins in Ghana (Ankobra, Tano, and Pra) and covers an area of 238,540sq. km. The Basin enjoys sub-equatorial wet climate with two raining seasons (May-June and September - November). The relative humidity in the basin is around $70 \%$ to $80 \%$ throughout the year. The annual rainfall range is between $1300 \mathrm{~mm}$ and $1900 \mathrm{~mm}$ with an annual mean value of $1500 \mathrm{~mm}$. The only natural lake in Ghana, Bosomtwe which is a major tourist attraction is located in the basin. The land area is largely dominated by Agriculture (60\%) with the remaining $40 \%$ being covered by human settlement $(10 \%)$ and forest (30\%). Towns like Twifo Praso and Kade in the basin are known for their large palm plantations. Gold mining both regulated and unregulated is the most prominent and highly patronized job in the basin. Figure 1 presents the study area map. The sampling order of the sites and their names from upstream to downstream in figure 1 is presented in table 1 . All sampling sites were either within or around an illegal mining site. A control site which has no such activities going on was also selected. From a total of 27 sampling points, 108 sediment samples were collected from January to April 2017 for the dry season and 108 from May to August 2017 for the wet season making a total of 216 . For each sampling point, 8 samples were collected. The sediments were sampled(grab) from the river bank by manual dredging using plastic scoop into polyethylene bags and air dried at room temperature and sieved through a $2 \mathrm{~mm}$ sieve for further analysis. 


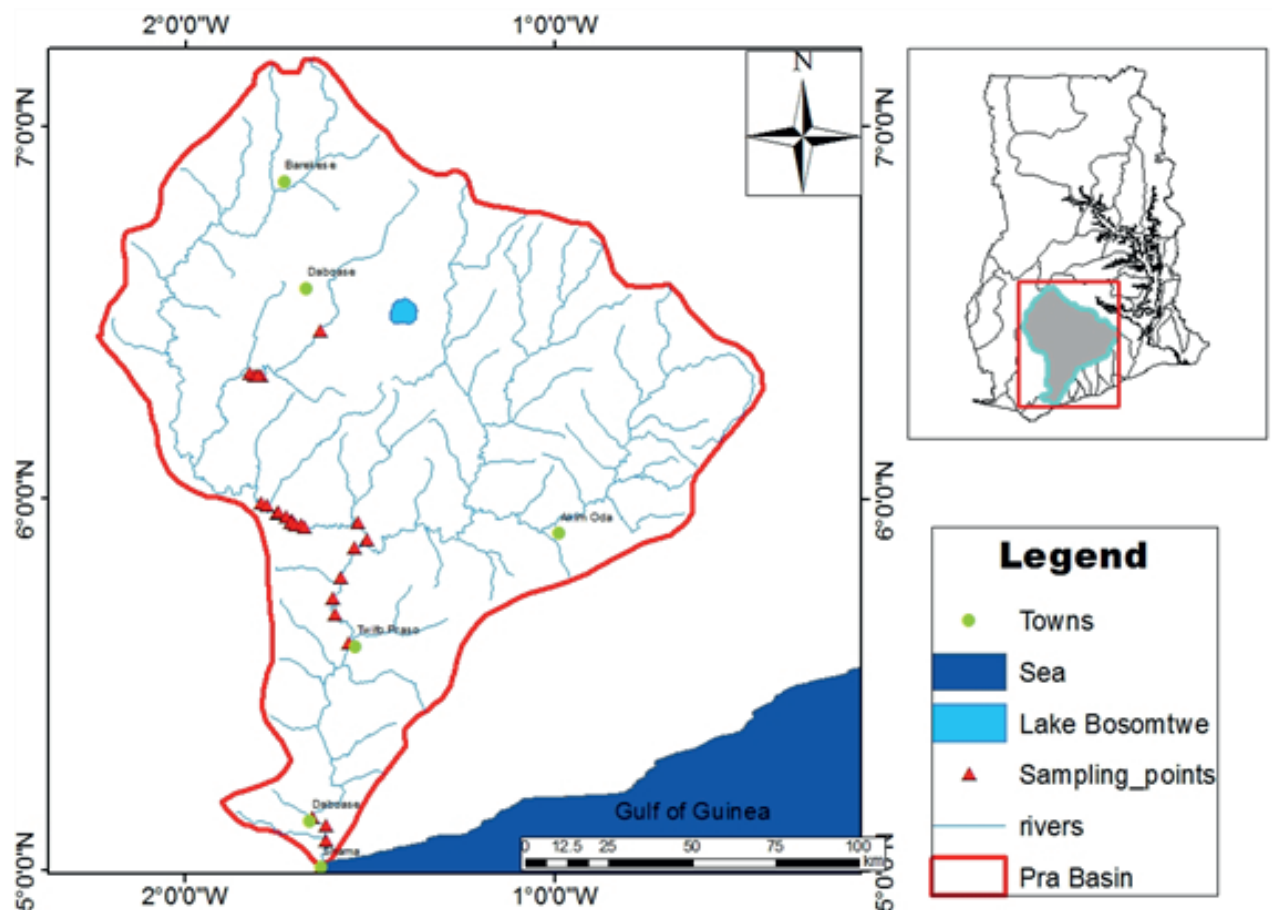

Figure 1: Map of Pra Basin

\section{Chemicals and sample digestion}

Deionized water supplied by University of Cape Coast Technology village was used in all the analyses. All standard solutions used were of the highest purity supplied by MES Equipment Limited Ghana. The nitric and hydrochloric acids used for the digestion were all of the analytical grades and supplied by MES Equipment. The sieved sediment was further ground with mortar and pestle until fine particles $(<200 \mu \mathrm{m})$ were obtained (Ismaeel \& Kusag, 2015). About $2 \mathrm{~g}$ of the ground sediment was taken in a $100 \mathrm{ml}$ beaker and $15 \mathrm{~mL}$ of concentrated $\mathrm{HNO}_{3}$ was added. The content was heated at $130^{\circ} \mathrm{C}$ for $5 \mathrm{~h}$ until $2-3 \mathrm{~mL}$ remaining in the beaker. The digested sediment was then passed through Whatman no. 41 filter paper and washed with a $0.1 \mathrm{M}$ $\mathrm{HNO}_{3}$ solution and made up to the $100 \mathrm{~mL}$ volume using deionized water (Ali, 2016).

\section{Analytical technique and accuracy check}

The heavy metal determination was conducted using a dual atomizer and hydride generator atomic absorption spectrophotometer (model ASC-7000 No A309654, Shimadzu, Japan). All the samples were analyzed for arsenic (As), chromium ( $\mathrm{Cr}$ ), cadmium (Cd), lead $(\mathrm{Pb})$, manganese $(\mathrm{Mn})$, nickel $(\mathrm{Ni})$, zinc $(\mathrm{Zn})$, and iron (Fe). All reagents used were of the analytical grade from MES Equipment Ghana. Ultrapure 
metal free deionized water was used for all analyses. All glass and plastic wares were cleaned by soaking them in warm $5 \%(\mathrm{~V} / \mathrm{V})$ aqueous nitric acid for 6-7 hours and rinsed with ultrapure deionized water. The standard for the ASS calibration was prepared by diluting standard (1000 ppm) supplied by MES Equipment Limited Ghana. All measured results were converted from $\mathrm{mg} / \mathrm{L}$ and $\mu \mathrm{g} / \mathrm{L}$ to $\mathrm{mg} /$ $\mathrm{kg}$. Matrix Spike recovery was in the range of $85 \%-100 \%$. The performance of the AAS was checked daily to ensure that the instrument is working according to the specifications.

\section{Assessment of heavy metal pollution}

The choice of background values plays important roles in geochemical data interpretation (Ali, 2016). The background value is the natural content of a substance in the soil which is completely dependent on the composition and mineralogical characteristics of the parent/source geological material (Maurizio, 2016). The contribution of human activities to the levels of heavy metals in sediments and their pollution can be estimated using geo-accumulation (Igeo), enrichment factor (EF) and pollution load index (PLI).

\section{Geo-accumulation index}

This index was first proposed for metal concentration determination in 2-micron fraction and later developed to the present form (Müller, 1979). The method is used to determine the levels of contamination or accumulation of metals in soil. The formula is mathematically expressed as:

$$
\text { Igeo }=\log 2 \frac{[\mathrm{Cn}]}{1.5 \mathrm{Bn}}
$$

Where $\mathrm{Cn}$ is the measured concentration of metal $\mathrm{n}$ in the sediment, $\mathrm{Bn}$ is the geochemical background value of element $\mathrm{n}$ in the background sample (Yu, 2011), 1.5 is the background matrix correction factor due to lithogenic effects. Müller (1979) gave seven classes for interpreting the geo-accumulation index which ranged from: Igeo $\leq 0$ - uncontaminated, $0<$ Igeo $<1$ - uncontaminated to moderately contaminated, $1<$ Igeo $<2$ - moderately contaminated, $2<$ Igeo $<3$ - moderately to heavily contaminated, $3<$ Igeo $<4$ - heavily contaminated, $4<$ Igeo $<5$ - heavily to extremely contaminated and Igeo $\geq 5$ - extremely contaminated.

\section{Enrichment factor (EF) and pollution load index (PLI)}

The enrichment factor as proposed by Zoller (1974) is given by:

$$
E F=\frac{[\mathrm{Ai}]}{[\mathrm{Ao}]} / \frac{[\mathrm{Bi}]}{[\mathrm{Bo}]}
$$


[Ai] and [Bi] are the concentrations of elements $A$ and $B$ at sampling station $\mathrm{i},[\mathrm{Ao}]$ and $[\mathrm{Bo}]$ are the background concentrations of elements $A$ and $B$. Values estimated for $E F$ from equation (1) provide the pollution state of the sediment. Values of $0.5 \leq$ $\mathrm{EF} \leq 1.5$ are an indication that the metal concentration is a natural weathering process (J. Zhang, Liu, C. L. , 2002). A value above 1.5 indicates the influence of anthropogenic activity (Klerks, 1989; Taylor, 2010; J. Zhang, Liu, C. L. , 2002). There are five classes of contamination with reference to $E F$ : $E F<2$ - depletion to minimal enrichment, $E F=2-5$ - moderate enrichment, $E F=5-20$ - significant enrichment, $E F=$ 20-40 - very high enrichment, EF > 40 - extremely high enrichment. The pollution load index is defined as the nth root of the multiplication of the enrichment factor (EF) of metals involved

$$
\mathrm{PLI}=\left(\mathrm{EF}_{1} \times \mathrm{EF}_{2} \times \mathrm{EF}_{3} \times \mathrm{EF}_{4} \times \mathrm{EF}_{\mathrm{n}}\right)^{1 / \mathrm{n}}
$$

According to Tomilson (1980), a PLI of zero indicates excellence; a value of one indicates baseline levels of the concerned metals, whereas values above one are signs of progressive deterioration. Whereas EF gives the individual effects of the metals at a site, the PLI gives the overall effect of all metals studied at a site.

\section{Results and discussion}

The mean heavy metal concentrations for sediments in the study sites during the dry and wet seasons are presented in tables 1 . Praso Town (PT) recorded the highest average metal concentration during the period under study. Dunkwa Akropong (DAK) and Atweneboanda (ATW) recorded the lowest metal concentrations during the dry and wet seasons respectively (tables 1 ). The observed high metal concentrations in PT can be attributed to the uncontrolled and scattered illegal mining activities occurring in and around the area. The lowest metal concentration found in ATW river sediments may be due to dilution in the area as the town is the last point after which the river joins the sea. The river is a major source of water for domestic activities in ATW; the frequent visitation of the river banks and domestic activities such as washing and playing along the banks of the river as compared to other areas sampled may have contributed to the washing away of the top sediments and thereby reduce accumulation of metals. Generally, there is a significant difference in the dry season metal concentration $(M=293.12, S E=18.31)$ and wet season metal concentration ( $M=217.31, \mathrm{SE}=11.93)$; the difference in concentration in the dry season may be attributed to the intensification of illegal mining activities which occurred as a result of a government order to halt illegal mining after the dry season of 2017. Excessive washing of the surface soil during the wet season could also account for the lower concentrations in the wet season.

The iron (Fe) and arsenic (As) concentrations in the wet and dry seasons were lower than WHO standards. Regarding manganese (Mn), apart from site PT which 
recorded concentrations of about 5 and 3 times the background levels for both dry and wet seasons, all other sites recorded values or concentrations below the background levels. The high values of manganese recorded at PT may be due to the sloppy nature of the land which turns to experience high level of siltation from turbid water flowing from nearby illegal mining sites. Zinc (Zn) concentrations in sediments were above the background values for 9 out of 27 of the sites in the dry seasons and only 3 out of 27 of the sites in the wet season. In the case of nickel (Ni), only 2 sites recorded values below the background values (table 1 ). Concerning chromium $(\mathrm{Cr})$ all the sites recorded values above the background levels. $\mathrm{Cr}$ Values as high as 5 and 4 times the background values were recorded for the dry and wet seasons (table 1). Cadmium ( $\mathrm{Cd}$ ) recorded concentrations as high as 8 times the background values. Unlike the wet season, 8 out of the 27 sites in the dry season recorded $\mathrm{Cd}$ values below the background values. Lead $(\mathrm{Pb})$ is the only metal whose concentration is above the background level for all the sites in both dry and wet seasons. The identified metals $(\mathrm{Ni}, \mathrm{Cr}, \mathrm{Cd}, \mathrm{Pb})$ are major components of the soil from which the gold is mined. Furthermore, the metal, mercury, which is usually part of the soil sediment because of its use in the gold extraction, was absent. The absence of mercury in the soil is expected because miners now carry out the extraction of the gold far away from the mining location due to the threat posed by arm robbers. The most striking result to emerge from the data is the abnormally high value of $\mathrm{Pb}$ concentration at BEP during the dry season. The measured $\mathrm{Pb}$ concentration (table 1) is about 54 times the background value. Metal concentrations exceeding the background level is an indication that their presence in the sediments is due to human activities. The BEP environment is highly dominated by illegal mining activities. Exposure to high level of illegal mining activities especially through the use of sophisticated machines recorded the high metal concentrations or values (table 1). The mean concentration of metals exceeding background level in the wet season is in the order: $\mathrm{Cr}>\mathrm{Pb}>\mathrm{Ni}>\mathrm{Cd}>\mathrm{Zn}$ and in the dry season as $\mathrm{Pb}>\mathrm{Cr}>\mathrm{Ni}$ $>$ Cd. 


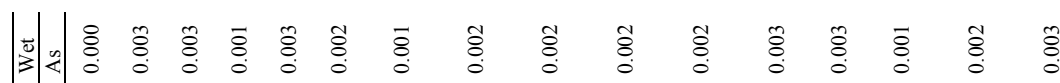

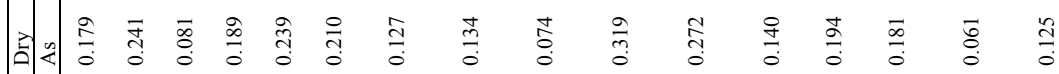

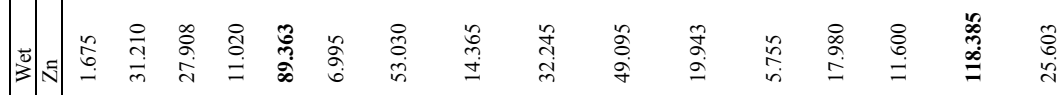

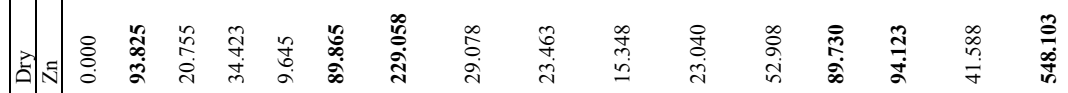

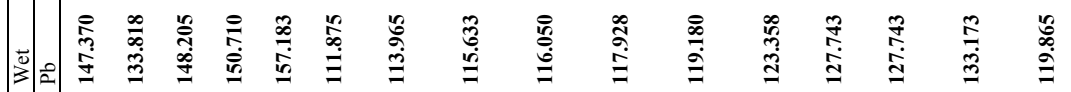

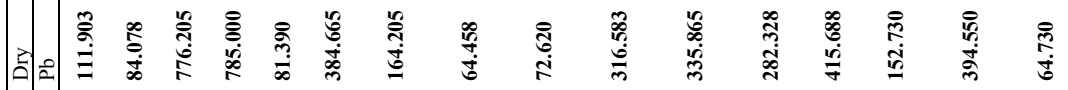

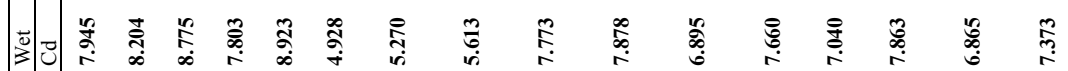

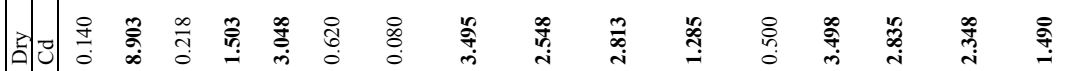

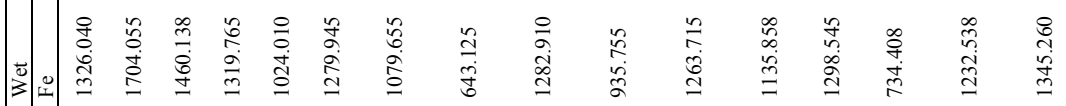

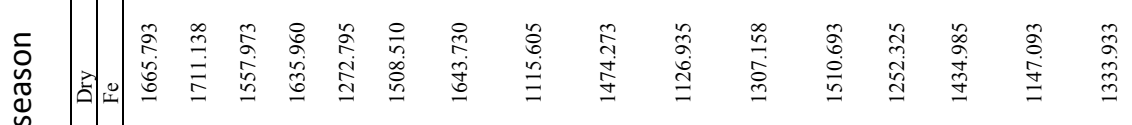

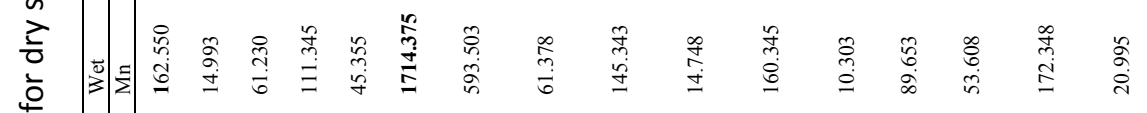

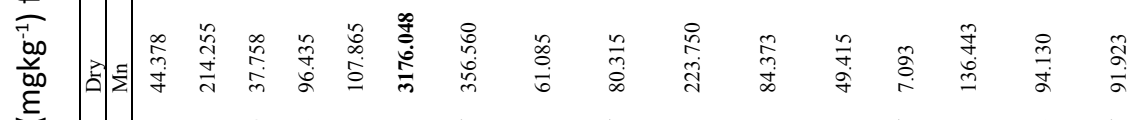

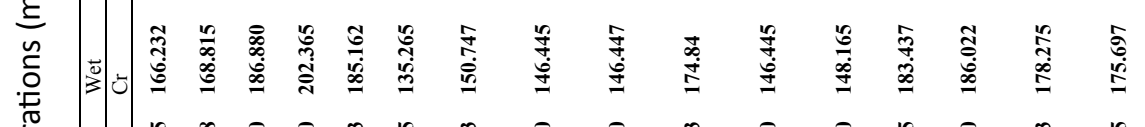

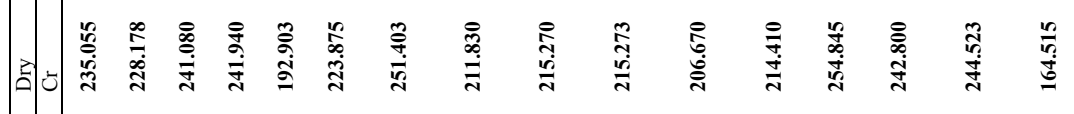

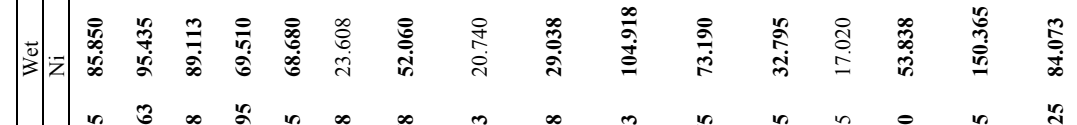

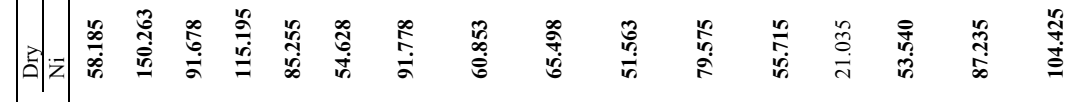

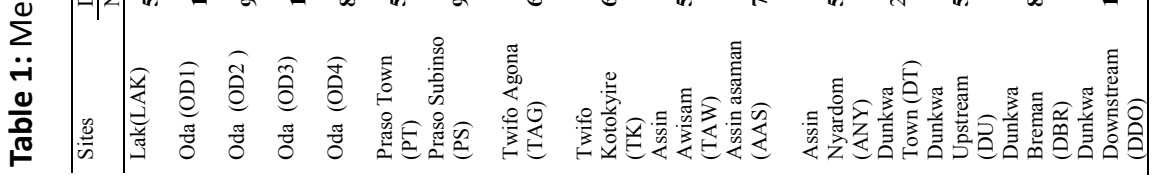




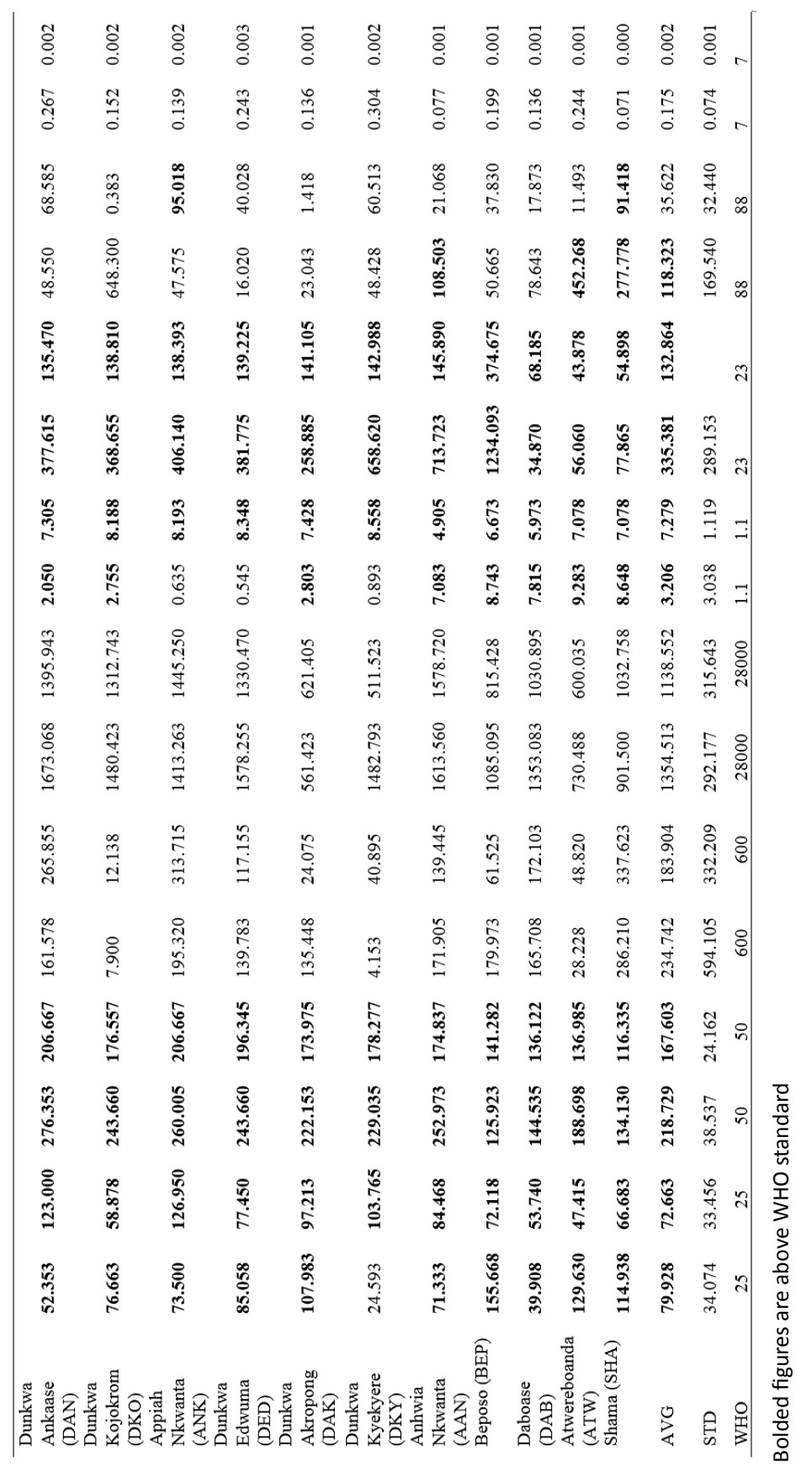




\section{Sediment pollution assessment}

The calculated enrichment factor (EF), pollution load index (PLI), and the background concentrations of metals in freshwater ecosystems are presented in table 2 . The EF ranged between $0-53.656$ during the dry season and $0.003-45$ during the wet season which indicates that the measured concentrations of four metals $(\mathrm{Mn}, \mathrm{Fe}$, $\mathrm{Zn} \& \mathrm{As}$ ) out of the eight in the studied area in both seasons were due to natural weathering process $(0.5 \leq \mathrm{EF} \leq 1.5)$ whereas the rest $(\mathrm{Pb}, \mathrm{Cd}, \mathrm{Cr} \& \mathrm{Ni})$ were due to anthropogenic activities ( $E F>2$ ). All the sites studied showed depletion to minimal enrichment for the metals $\mathrm{Mn}, \mathrm{Fe}, \mathrm{Zn}$ and As for the dry and wet seasons. All sites showed moderate enrichment $(E F=2-5)$ for $\mathrm{Cr}$ in both dry and wet seasons. Five (5) sites (TAG, TK, ANY, DT, \& ATW) out of the 27 recorded depletion to minimal enrichment for $\mathrm{Ni}$ in the wet season with 21 out of the 27 sites recording moderate enrichment and only 1 site (PT) recording extremely high enrichment. Unlike the wet season, only 3 sites (DT, DKY, and DAB) out of the 27 recorded depletion to minimal $\mathrm{Ni}$ enrichment for the dry season, the remaining 24 sites recorded values within the range of moderate enrichment to significant enrichment (table 2). However, there is no significant statistical difference in the dry season nickel enrichment $(M=3.19, S E=0.26)$ and wet season nickel enrichment $(M=4.53$, $\mathrm{SE}=1.57)$ in the basin. In the case of $\mathrm{Pb}$, there is a significant difference in the dry season enrichment $(M=14.58, S E=2.41)$ and wet season enrichment $(M=5.77, S E=$ 0.66). Four (4) out of the 27 sites recorded moderate $\mathrm{Pb}$ enrichment whereas 22 recorded significant enrichment with only 1 site Atweneboanda (ATW) recording depletion to minimum enrichment in the wet season. However, in the dry season, 8 sites recorded moderate $\mathrm{Pb}$ enrichment; 13 sites recorded significant enrichment; 4 recorded very high enrichment and 1 recorded extremely high enrichment. In the dry season, $\mathrm{Cd}$ recorded depletion to minimal enrichment in 12 sites; recorded moderate enrichment in 6 sites and recorded significant enrichment in 9 sites. However, it recorded moderate to significant enrichment for all the sites in the wet season (table 2). The seasonal influence on $\mathrm{Cd}$ enrichment in the sediment is very significant: dry season $C d$ enrichment $(M=2.76, S E=0.53)$ and wet season enrichment $(M=6.61, S E=0.19)$ (table 2). Irrespective of the high enrichment factors recorded for some sites, BEP was the only site polluted (PLI >1) (table 2) in both seasons. LAK which is upstream and served as the control site is the only sampling point which recorded excellent value for pollution $(\mathrm{PLI}=0$ ) in the dry season (table 2). Though LAK did not record zero in the wet season the value of 0.374 was still within the baseline level. The 0.374 is expected because in the wet season, the lake receives a lot of run off with high silt content from the surrounding mountains without any means of exiting such inflows. On the contrary, the calculated PLI for the remaining 26 sites though were within the baseline level are due to unregulated illegal mining in the area. 


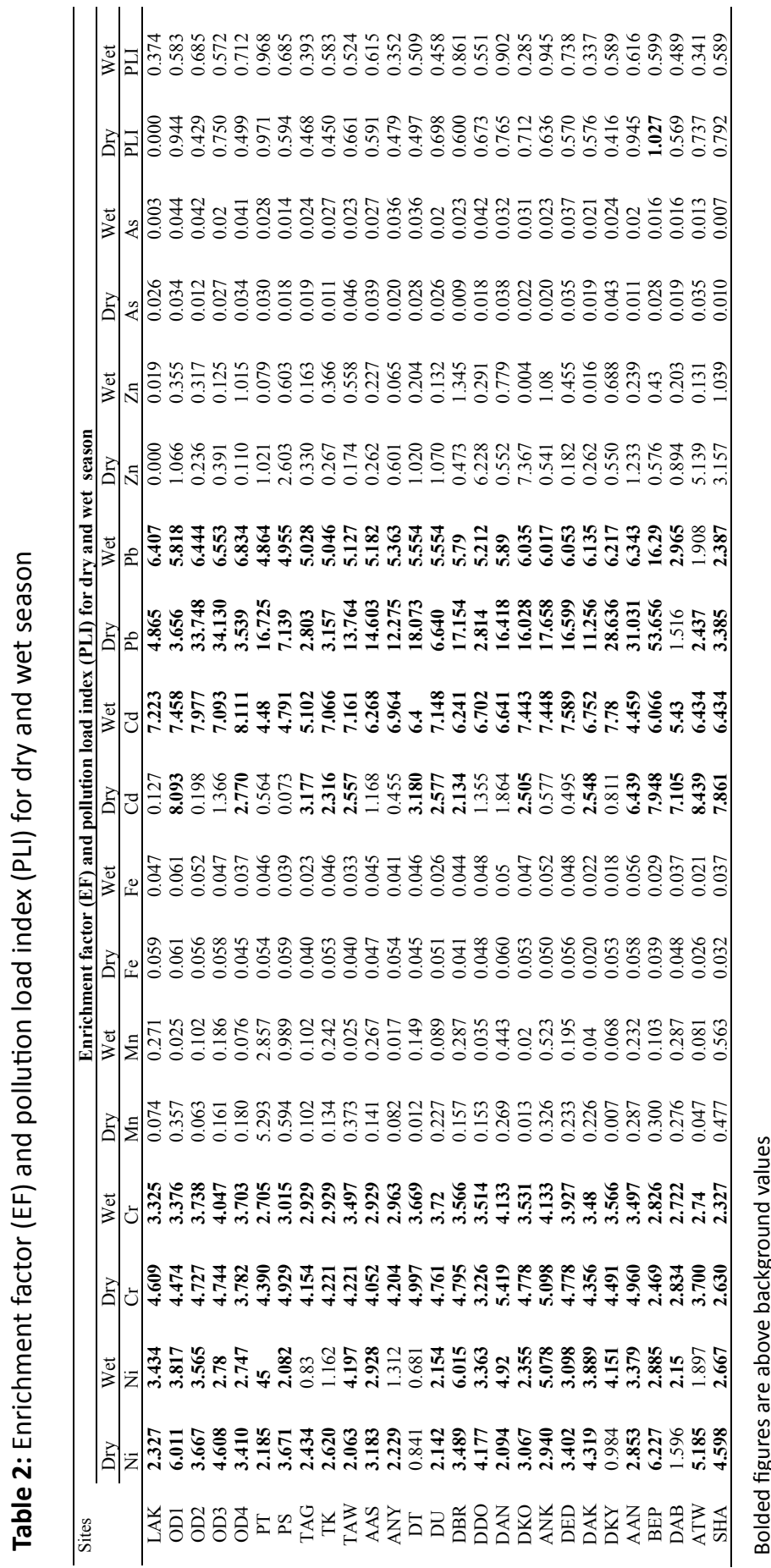


The calculated geo-accumulation indexes for the $4(\mathrm{~Pb}, \mathrm{Cd}, \mathrm{Cr}, \& \mathrm{Ni})$ enriching metals during the two seasons are presented in table 3 . In either the dry or wet season, all the non -enriching metals ( $\mathrm{Mn}, \mathrm{Fe}, \mathrm{Zn}$, and $\mathrm{As}$ ) did not contaminate (Igeo. $<0$ ) any of the sites studied except $\mathrm{Zn}$ which recorded a value of moderate contamination $(1<$ Igeo. $<2)$ at a site during the dry season. The result of the geo-accumulation index calculation for both seasons (table 3 ) shows that $\mathrm{Cr}$ and $\mathrm{Cd}$ values for all the 27 sites were within the uncontaminated to the moderately contamination class $(0 \geq$ Igeo. $<2)$. Only 1 out of the 27 sites was moderately to heavily contaminated (Igeo. $<3$ ) with $\mathrm{Pb}$ in the wet season whereas the rest recorded values within the uncontaminated to moderately contaminated range $(0<$ Igeo. $<2)$. Out of the 27 sites, only 2 were moderately to heavily contamination with $\mathrm{Ni}$ whereas the rest (25) were uncontaminated to moderately contamination in the wet season (table 3 ). The result (table 3 ) shows site DAB a drinking water intake point recording the highest contamination for $\mathrm{Ni}(11.140)$ and $\mathrm{Pb}$ (64.977) in the dry season. These high values could be attributed to the low flow rate at the time which aided the precipitation of these two metals.

The reason accounting for the difference in contamination across the seasons may be due to: 1) The washing away of the top sediments through the heavy downpour and high run-off in the wet season; 2) The low flow rate during the dry season which aids the process of precipitation and accumulation. The results of the geoaccumulation index shows the need for regular monitoring of the metals $\mathrm{Ni}$ and $\mathrm{Pb}$ and the illegal mining activities especially during the dry season at sampling site $\mathrm{DAB}$ to avoid further accumulation, contamination and the subsequent pollution of such metals at the intake. 


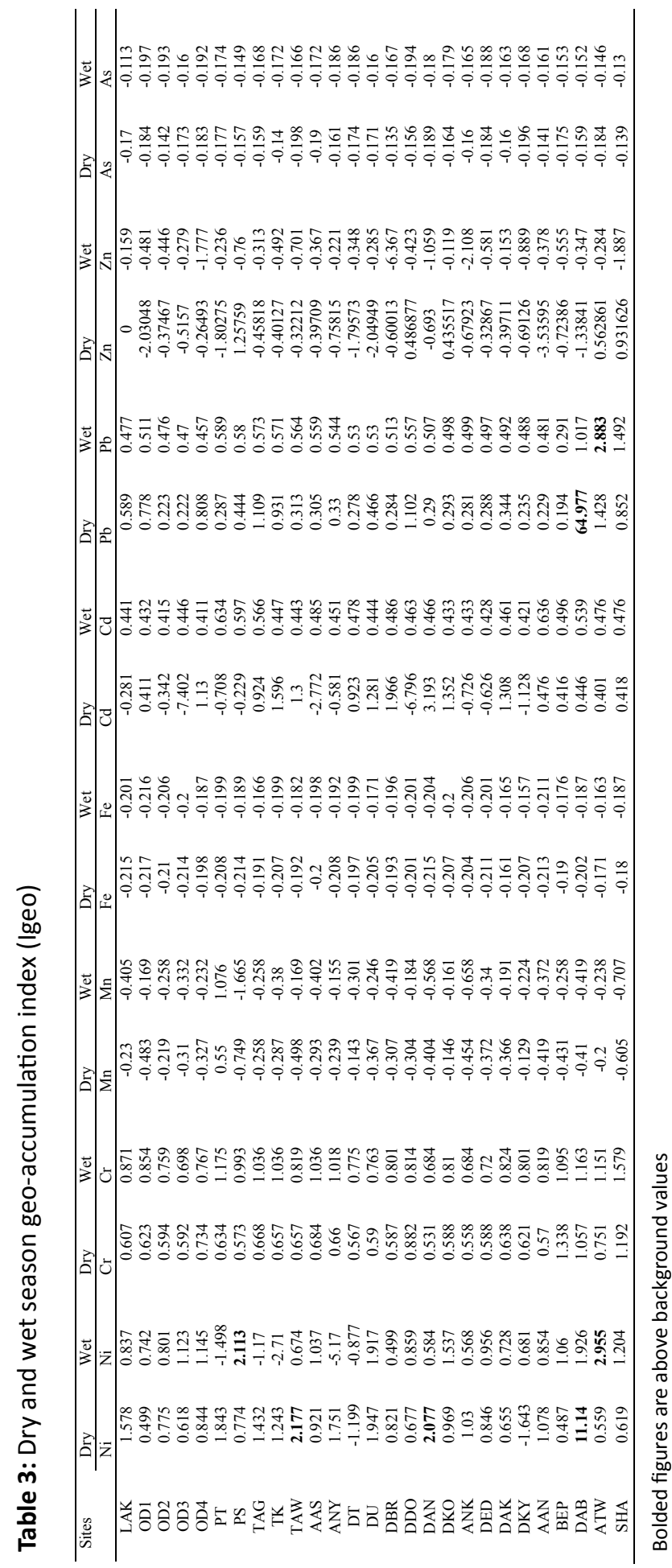




\section{Conclusions}

The river sediment in the Pra Basin is enriched and contaminated with $\mathrm{Ni}, \mathrm{Cr}, \mathrm{Cd}$, and $\mathrm{Pb}$, which is an indication of the human activities in the Basin. Generally, the mean concentrations of the metals were higher in the dry season than the wet season due to the low flow rate during the dry season which aids the process of precipitation and accumulation. It was only Beposo (BEP) which was found to be polluted (PLI < 1). Extreme contamination ( $\mathrm{Ni} \& \mathrm{~Pb}$ ) occurred at Daboase (DAB) which serves as an intake for the water treatment. This is due to the high illegal mining activities occurring in and around DAB and its environs. The result (figure 2) of the study shows the need for general monitoring of illegal mining activities as well as all 4 metals ( $\mathrm{Ni}, \mathrm{Cr}, \mathrm{Cd}$, and $\mathrm{Pb}$ ) especially $\mathrm{Ni}$, and $\mathrm{Pb}$ at $\mathrm{DAB}$. The monitoring will not only address the problem of further accumulation and pollution of these metals but it will also solve public health concerns which arise from the intake of these metals which are carcinogenic. Crop production on these soils is a potential route for these metals to enter the ecosystem hence the need for monitoring of activities in and around the river sediments, especially during the dry seasons. Finally, monitoring is required to reduce high-level siltation in the Basin Rivers which could lead to the drying of such rivers; a situation which threatens some rivers in some part of Ghana at the moment. 


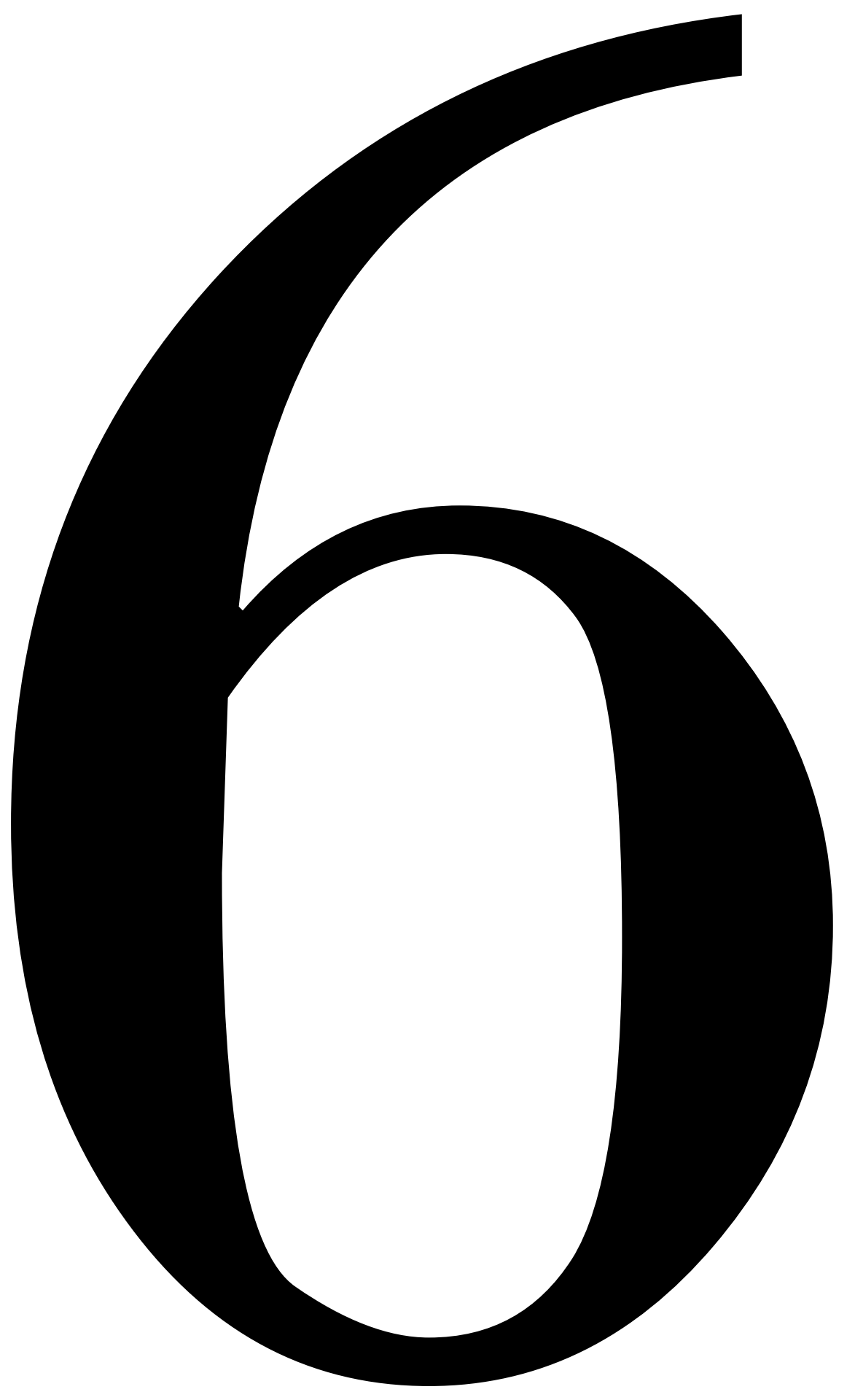




\section{Chapter 6}

\section{An Intervention to Address Deteriorating Water Quality: An Application of Ajzen's Theory of Planned Behavior}

\section{Submitted as:}

Albert Ebo Duncan, Nanne de Vries, Kwabena Biritwum Nyarko, An Intervention to Address Deteriorating Water Quality: An Application of Ajzen's Theory of Planned Behavior 


\section{Abstract}

This study investigates the factors which influence illegal miners' intention to choose an alternative job using the theory of planned behavior (TPB). Three hundred and thirtyeight (338) respondents from illegal mining communities in the Pra Basin completed a questionnaire on behavioral, social and demographic factors which might motivate an illegal miner to choose an alternative job. The findings from the structural equation analysis revealed that the model could predict illegal miners' intentions of choosing an alternative job. The attitude was found to be the only dominant significant antecedent of the behavioral intention. The findings from the study reveal that Perceived Behavioral Control (PBC) which has been the focus of the job intervention in the basin is not a predictor of their intention which is why miners are back to their sites working. 


\section{Introduction}

Unregulated illegal mining is posing a major threat to the security of most water resources in Ghana. All efforts by the Water Resources Commission (WRC) and other state institutions to mitigate the threat have failed to yield fruitful results. With the new government assuming office in January 2016 efforts to address the threat augmented. And barely a year and a few months after being in office, had the government of Ghana issued an edict for all illegal mining to be stopped by March 2017. This action reduced illegal mining activities in 2017 until January 2018 when illegal miners started going back to sites. One question many Ghanaians asked at the time was: can this government decision stand the test of time? As a way of addressing the plight of illegal miners that will be rendered unemployed, the government proposed roping them into their 'planting for food' project. The project is aimed at reducing migration of unemployed youth to the city centers and stopping the importation of foodstuff from neighboring countries. This is not the first-time efforts of such nature have been introduced to stop the illegal miners. It was, therefore, the expectation that more effort will be invested in finding out why illegal miners keep coming back to sites they are hunted out. Unfortunately, this was not done. On the $23^{\text {rd }}$ of March 2017, task forces were deployed all over the country to drive out illegal miners and constantly monitor the mining sites. It was indeed a very robust exercise which resulted in the seizure of some excavators. Barely a month after that, the planting for food program was launched on April 19, 2017, with a lot of promises. Indeed, the package was attractive: prices of fertilizers were reduced by $50 \%$ and farmers were provided with free seeds. Furthermore, the government promised to employ an additional 2000 agricultural extension officers and the construction of about 1000 metric ton capacity warehouse in each of the 216 districts. On the $1^{\text {st }}$ of March 2018, the Alliance for Green Revolution in Africa (AGRA) reported on their webpage: 715000 jobs were created in the planting for food projects in the rural areas in Ghana. Strangely, almost all illegal miners were back to site around the same period in the Pra Basin (field visit April \& March 2018). The question therefore remains whether planting for food proposes the best alternative jobs for the illegal miners? Were they even ready to change for an alternative job? What will influence their choice of an alternative job?

This paper argues that the approach adopted in dealing with the illegal miners was not sustainable. It, therefore, proposes that the behavior of the illegal miners requires empirical assessment instead of just proposing an alternative job. The empirical assessment, when done properly, will help to uncover the behavioral as well as the related social and economic issues to the pending challenge of illegal mining. It is only after this, that the right intervention needed to address the problem can be identified for proper solution design. Many behavioral theories do exist which have been successfully used in addressing human behavior; because the decision to quit mining and adopt alternative employment seems a reasoned one, 
the theory of planned behavior (TPB) seems the best option (Lee, 2010).

\section{Overview of Theory of Planned Behavior (TPB)}

The theory of planned behavior (TPB) as proposed by Ajzen (1985) has been used successfully in many ways to better understand a range of behaviors and why certain individuals behave in which way (Sommer, 2011). The theory is described as one of the best supported social psychological theories in predicting human behavior (Sommer, 2011). It has been used to predict a wide array of behaviors such as an enterprises' willingness to adopt/develop cleaner production technologies (Zhang, Yang, \& Bi, 2010); identify key behaviors underlying pro-environmental behaviors of high school students (De Leeuw, 2015), predict willingness to pay for the conservation of an urban park (López-Mosquera, 2014), to name just a few. TPB has been used successfully to predict human behaviors in business, health, energy, environment etc.

Ajzen (1991) proposes that behavior is driven by an individual's intention (I) to execute an action which in turn is determined by an individual's attitude (ATT), subjective norm (SN) and perceived behavioral control (PBC). The TPB framework, figure 1, specifies indirect determinants of these constructs. Belief about the likelihood of outcomes of a behavior (behavioral beliefs) multiplied by the evaluation of each outcome determine the attitude; beliefs about expectation of referent persons and organizations (normative beliefs) and the motivation to comply with such expectations constitute the subjective norm; the perceived power over the presence of factors which may facilitate or impede the performance of a behavior (control beliefs) make up the indirect determinant of PBC. Attitude is about the individual's positive or negative evaluation of a particular behavioral performance (Fishbein \& Ajzen, 1975). In this case, the attitude of the illegal miners towards the choice of an alternative job can also be defined by the illegal miner's positive or negative evaluation of choosing the alternative job. Individual's perception of what others think he should or should not do is the SN and it can be defined as illegal miners' perceptions of what friends, family etc. approve or disapprove concerning choosing an alternative job and his willingness to comply. PBC is about people's perception of the ease or difficulty of performing the behavior of interest (Ajzen, 1991). Similarly, the PBC will involve the illegal miner's difficulty or easy of choosing an alternative job. The relationship between the indirect determinants and the direct determinants is illustrated in figure 1. With a favorable attitude and subjective norm, and greater perceived control it is expected that a person's intention to engage in a behavior should be stronger. External variables (demographic, socioeconomic etc) are assumed to affect the basic variables in TPB. 


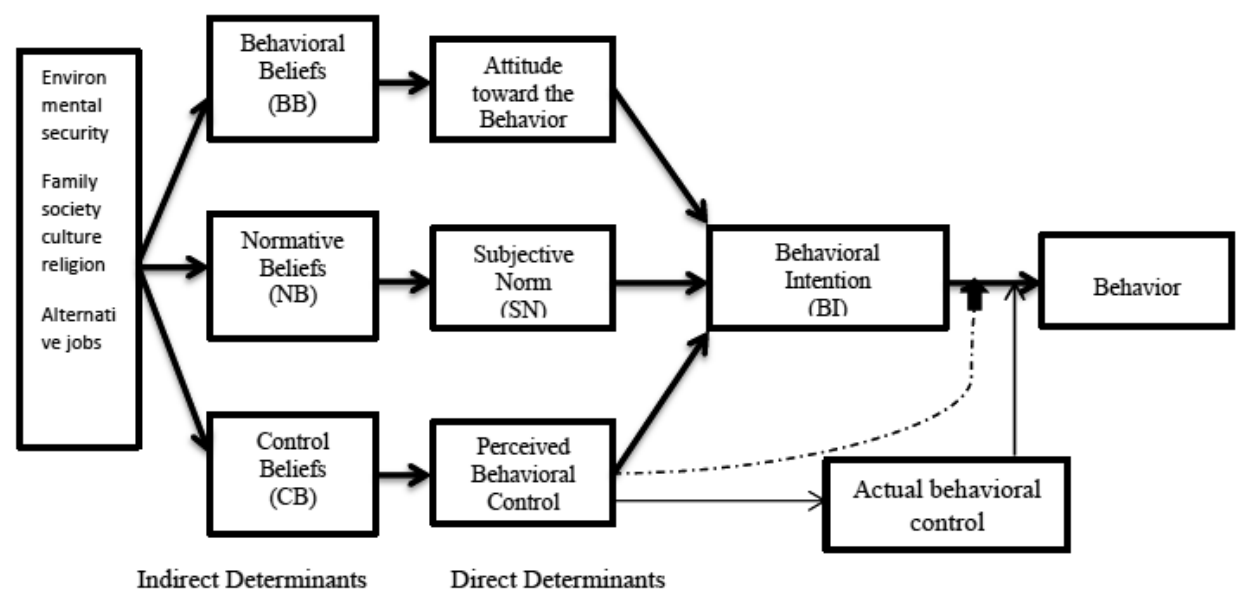

Figure 1. The conceptual framework of TPB

\section{Background and Method}

The Pra Basin is located between latitudes $5^{\circ} \mathrm{N}$ and $7^{0} 30^{\prime} \mathrm{N}$, and longitudes $2^{\circ} 30^{\prime} \mathrm{W}$, $0^{\circ} 30^{\prime} \mathrm{W}$, in south-central Ghana. It is the fourth basin to implement Integrated Water Resources Management in Ghana and the largest river basin among the three principal south-western basins of Ghana namely the Ankobra, Tano, and Pra. The total basin area is approximately $23200 \mathrm{~km}^{2}$. The basin houses one of the largest gold mining companies in Africa, AngloGold Ashanti, and many uncounted illegal mining sites. It also houses one of the largest crater lakes, Bosomtwe, with a maximum depth of nearly $80 \mathrm{~m}$ and a rim diameter of about $8 \mathrm{~km}$ across. Lake Bosomtwe is a major tourist attraction and fetches the country a lot of income from foreign and local tourists. The main river is the Pra with four tributaries: the Offin, Birim, Anum, and Oda.

In studies of this nature, the target behavior of the illegal miners at an appropriate level of specificity must be defined in order to obtain a more accurate insight into the factors that influence the illegal miners choice of an alternative job (Lee, 2010). Under this condition, the target behavior is defined as stopping illegal mining and adopting an alternative job with an available market for products. The aim of this study is to predict illegal miners' intention of choosing an alternative job. The overall aim was to assess the validity of a modified TPB model and to predict illegal miners' behavioral intention (BI). The specific objectives are to: 1 ) assess the validity of a modified TPB model 2) test the effect of the antecedents on attitudes, subjective norm, and perceived behavioral control 3) to examine the effect of SN, PBC, and attitude on BI. Eight hypotheses were developed to answer the specific objectives. 
Hypothesis 1: behavioral belief and its evaluative outcome $\left(B_{i} E_{i}\right)$ is a significant predictor of attitude (ATT)

Hypothesis 2: normative belief and the motivation to comply $\left(\mathrm{NB}_{\mathrm{i}} \mathrm{MC}_{\mathrm{i}}\right)$ is a significant predictor of subjective norm (SN)

Hypothesis 3: control belief and its evaluative outcome is a significant predictor of perceived behavioral control (PBC)

Hypothesis 4: $\mathrm{SN}_{\text {is }}$ a significant predictor of ATT

Hypothesis 5: $\mathrm{SN}$ is a significant predictor of PBC

Hypothesis 6: ATT is a significant predictor of behavioral intention (BI)

Hypothesis 7: $\mathrm{SN}$ is a significant predictor of $\mathrm{BI}$

Hypothesis 8: PBC is a significant predictor $\mathrm{BI}$.

Prior to the development of the final questionnaire, an elicitation study was conducted within four selected illegal mining communities in the Pra Basin in January 2017, to identify the set of relevant beliefs which underlie illegal miners' choice of alternative employment. Moving from house to house, facilitators explained to the respondents where they were coming from and their mission. This was very necessary because at the time there were rumors being circulated in the towns/villages about government's plan to arrest illegal miners. Strangers in the community could well be associated with such actions. With these measures in place, still some households refused to grant the facilitators audience. The target groups were the illegal miners and the youth: the potential illegal miners. To disabuse their fear, when explaining our purpose, we assured them of not revealing their identity however about 6 of the thirty respondents told us they are illegal miners. The subjective impression of interviewers, also based on their answers, was that almost all the respondents were illegal miners. One of the communities had an information center, so through the assemblyman, our presence was made known which made our work in that community easier.

Trained assistants were used in the administration of the questions to compensate for the educational level of most of the respondents. Open-ended questions were used in the study. In the administration of the questionnaire, the trained personnel read out the questions to the respondents and wrote down their responses. They were asked questions on how they feel about stopping illegal mining and what motivates people to engage in it. They were then asked about the advantages and disadvantages of illegal mining. We also asked about the factors which could influence someone to stop illegal mining for another job. They were then asked to provide a list of individuals or groups who are important in deciding what job to take. Fifty-six percent of the 30 respondents involved were between the ages of 15 to 30 and forty-four percent being between the ages of 31-35. The process is summarized in table 1. 


\section{Elicitation study}

Respondents who were engaged in the elicitation studies expressed a number of behavioral, normative and control beliefs regarding choosing an alternative job. Respondents' beliefs regarding choosing an alternative job can be summarized in water security and economic instability. There were varied opinions concerning the benefits and economic challenges that come with quitting illegal mining for another job. Whereas some complain that the alternative job may not pay well others spoke about the need to save the water resources before they get beyond recovery. The most relevant people/group/factors the respondents considered crucial to their choice of an alternative job are family, society, religion, culture and to some extent state institutions that enforce the law. Those who talked about the family explained that whatever decision they take also would have a strong influence on their immediate family. Example if they have their children in private school, then they have to consider if the alternative job can provide them with the means to pay their fees. When it came to the alternative job as a subject of choice, respondent argued extensively about these things: the kind of alternative job, the capital to start the job, the creation of a market for products, and the skills needed to start that alternative job. Below are some of the comments during the elicitation studies. The result of the elicitation is summarized in table 3.

I wouldn't want my pastor to know that I deal in illegal mining (Religion)

"What kind of job can pay at least 300 Ghana cedis a day?' (Economic instability)

"We did not get a good education but our children should attend good schools" (Economic instability).

"If we have to carry water in gallons to the farm today, then we should not only think about money but what will happen in future?" (Water security)

"Most of us are afraid to eat fish from the river" (Water security: pollution)

A job which comes with a capital to start will be worth considering (alternative job with capital)

Table 1: Summary of salient beliefs from elicitation study

\begin{tabular}{lll}
\hline Behavioral beliefs & Normative beliefs & Control beliefs \\
\hline Water security & Family & Alternative job \\
Economic challenge & Religion & Training and support \\
& Culture & Capital \\
& Society & Market \\
& State & \\
\hline
\end{tabular}




\section{Sample and scenario}

The participants for the main study were drawn from twenty-seven town/villages in the Pra Basin of Ghana using stratified sampling. In this regard, a purposive sample based on the characteristics of the population such as age, sex, religion, etc. and the objective of the study was used. In this study, the target group is mainly the youth who are known to be the affected population seriously engaging in illegal mining. And because the focus was on illegal miners (mostly youth) intention of choosing an alternative job the sample selection focused on them. Looking at the sizes in terms of population and area, a predetermined number of questionnaires was administered in each village or town with the help of trained assistance. In the same way as the elicitation studies, assistants read the questions to respondents and wrote their responses. An average of 15 to 18 minutes was spent in the administration of one questionnaire.

Out of the 338 respondents, 160 were aged between 20-25(47.3\%), 98 were aged between $26-30$ (29\%), 74 were of the age range $36-45(21.9 \%), 5$ were in the range of $36-40(1.5 \%)$ and 1 was in the range of $41-45(0.3 \%)$. What is interesting to this study was the educational background of the interviewee. Almost sixty percent $(59.8 \%)$ of the people interviewed have basic education as their highest form of education. Of the remaining 40.2\%, 13 (3.9\%) have tertiary education, 64 (19.2\%) have secondary education, 14 (4.2\%) have either commercial, vocational or technical education, 43 (12.9\%) have non-formal education. Of the total number sampled, only two were females indicating the dominance of males in the illegal mining business. About 95.9\% of the interviewee were Christians, 3.3\% were Muslims and the remaining $0.9 \%$ belong to other religion.

In all three hundred and thirty-eight questionnaires were successfully completed. A detailed description of the purpose of the research study, instructions and assurance of confidentiality was clearly written on the front page of the questionnaire and read out.

The information gathered from the elicitation study was used together with the guidelines recommended by Ajzen (2006) to develop the closed-ended questionnaire. The questionnaire used in this study was in four sections: The first part covered the respondent's behavioral beliefs and their evaluation (ATT). Section two focused on the normative beliefs and their evaluation (SN). The third part was on the control beliefs and their evaluation (PBC). The final part of the section looked at respondents' intentions of carrying out the behavior. Data collected was analyzed using structural equation model (SEM) to find the best-fitting model and to test causal relationships. SEM is a general model framework that integrates a number of different multivariate techniques into one model fitting framework. 


\section{Variables}

The behavioral belief towards the choice of an alternative job was measured by 5 items with a seven-point Likert scale (e.g., stopping illegal mining will help reduce the pollution of rivers.' $1=$ strongly disagree, 7 = strongly agree). To evaluate the outcomes, 5 items on a seven-point Likert scale was used (e.g. 'for me to reduce river pollution by stopping illegal mining is.' $1=$ extremely bad, $7=$ extremely good). To measure normative beliefs, 5 items with a seven-point Likert scale were employed (e.g. 'my family approves of illegal mining.' 1 definitely false =, $7=$ definitely true). To evaluate the motivation to comply, 5 items on the seven-point Likert scale were used (e.g. 'what my family thinks I should do is important to me.' 1= strongly disagree, 7 = strongly agree). To measure control beliefs, 5 items on a seven-point Likert scale were used (e.g. 'I will stop illegal mining if there is an alternative job.' $1=$ extremely bad, 7 = extremely good). Finally, 3 items on a seven-point Likert scale was used to assess the behavioral intention (e.g. 'I plan to stop illegal mining.' $1=$ very unlikely, $7=$ very likely). Before the administration of the questionnaire, it was first piloted among 30 respondents in Atwereboanda, a small town in the basin and further reviewed by the researcher before the final fieldwork.

Out of the 333 respondents sampled in this study.

\section{Measurement model}

Before testing the measurement model, screening was conducted on the collected data through the confirmatory factor analysis (CFA) using maximum likelihood estimation. From the results of the CFA variables $\mathrm{ATT}_{2}, \mathrm{SN}_{1}, \mathrm{PBC}_{1}, \mathrm{PBC}_{3}$ and $\mathrm{PBC}_{5}$ were deleted due to their low factor loading and their difficulty in causing the model to run. After the deletion of these variables which were unexplained empirically, the remaining variables were then subjected again to CFA to assess the underlying structure of the variables in the model. The CFA results show that the model fit the data well $\left(\chi^{2}=205.77, d f=59, \chi^{2} / d f=3.48, \mathrm{p}<0.001, \mathrm{NFI}=0.91, \mathrm{IFI}=0.93, \mathrm{TLI}=0.90\right.$, $\mathrm{CFI}=0.93, \mathrm{RMSEA}=0.073, \mathrm{R}^{2}=0.20$ ). The model gave very strong grand mean and a high path coefficient of the factor representing behavioral intentions $0.94(p<0.05)$. The very strong mean implies that the illegal miners' strong positive intentions towards performing the behavior which is also significant. There is a very strong positive mean towards the attitude. The path coefficient of the factor representing attitude was significant. This implies that the illegal miners do not show only strong positive behavioral beliefs towards the attitude but they are also significant in predicting the attitude. There is a very strong grand mean measured for the PBC, however, the path coefficient of the factor representing subjective norm was not significant. This implies that even though the illegal miners' have strong control over their control beliefs, it is not significant in predicting their PBC. There is positive but weak grand mean measured for the normative beliefs. This notwithstanding, the 
path coefficient shows, that the normative beliefs are predictors of the subjective norm. Cronbach's alpha and composite reliability were used to check the goodness of fit for the model. Item reliabilities ranged from 0.65 to 0.90 except for the behavioral control which fell below the range. Cronbach's alpha of the variables was between 0.65 and 0.94 which indicated internal consistency. Estimated composite reliability for all the constructs except that of perceived behavioral control was above 0.7 which signifies internal consistency among items for these constructs. The measurement properties of the measured construct and their reliabilities are presented in table 2.

Table 2: Measurement properties of latent constructs

\begin{tabular}{|c|c|c|c|c|c|c|c|c|}
\hline Factors & $\begin{array}{c}\text { Standardized } \\
\text { factor loadings }\end{array}$ & $\begin{array}{l}\text { Item }\left(\mathbf{r}^{2}\right) \\
\text { reliability }\end{array}$ & $\begin{array}{l}\text { Composite } \\
\text { reliability }\end{array}$ & $\begin{array}{c}\text { Beta } \\
\text { value }\end{array}$ & Significance & $\begin{array}{c}\text { Grand } \\
\text { mean }\end{array}$ & $\begin{array}{l}\text { Cronbach } \\
\text { alpha }\end{array}$ & SD \\
\hline ATT & & & 0.77 & 0.38 & 0.000 & 20.20 & 0.74 & 0.21 \\
\hline $\mathrm{BB}_{1} \mathrm{E}_{1}$ & 0.33 & 0.109 & & & & & & \\
\hline $\mathrm{BB}_{3} \mathrm{E}_{3}$ & 0.71 & 0.50 & & & & & & \\
\hline $\mathrm{BB}_{4} \mathrm{E}_{4}$ & 0.88 & 0.774 & & & & & & \\
\hline $\mathrm{BB}_{5} \mathrm{E}_{5}$ & 0.72 & 0.518 & & & & & & \\
\hline $\mathrm{SN}$ & & & 0.75 & 0.21 & 0.442 & 0.89 & 0.72 & 2.52 \\
\hline $\mathrm{NB}_{2} \mathrm{MC}_{2}$ & 0.44 & 0.194 & & & & & & \\
\hline $\mathrm{NB}_{3} \mathrm{MC}_{3}$ & 0.87 & 0.757 & & & & & & \\
\hline $\mathrm{NB}_{4} \mathrm{MC}_{4}$ & 1.023 & 1.047 & & & & & & \\
\hline $\mathrm{NB}_{5} \mathrm{MC}_{5}$ & 0.09 & 0.008 & & & & & & \\
\hline PBC & & & 0.13 & -0.33 & 0.519 & 17.92 & 0.65 & 2.06 \\
\hline $\mathrm{CB}_{2} \mathrm{E}_{2}$ & 0.10 & 0.01 & & & & & & \\
\hline $\mathrm{CB}_{4} \mathrm{E}_{4}$ & -0.42 & 0.176 & & & & & & \\
\hline I & & & 0.94 & & 0.000 & 6.73 & 0.94 & 0.00 \\
\hline $\mathrm{I}_{1}$ & 0.86 & 0.74 & & & & & & \\
\hline $\mathrm{I}_{2}$ & 0.93 & 0.87 & & & & & & \\
\hline $\mathrm{I}_{3}$ & 0.94 & 0.88 & & & & & & \\
\hline
\end{tabular}

$A T T=$ attitudes; $B B=$ behavioral beliefs; $E=$ evaluations of outcome; $N B=$ normative beliefs; $M C=$ motivation to comply; l= intention

\section{Structural equation model (SEM)}

A satisfactory fit is obtained when the RMSEA is less or equal to 0.08 , and $\mathrm{NFI}$, IFI, and TLI are equal to or above 0.9 (Bentler, 1990). The results of the SEM $(\chi 2=$ 205.77, $d f=59, \chi^{2} / d f=3.48, p<0.001, \mathrm{NFI}=0.91, \mathrm{IFI}=0.93, \mathrm{TLI}=0.90, \mathrm{CFI}=0.93$, RMSEA $=0.073, R^{2}=0.20$ ) shows a satisfactory data fit to the model (Fig.2) and hence the model is reasonably capable of predicting illegal miners' intention of choosing an alternative job. There are occasions when researchers modified the relation between attitude and the subjective norm in the TPB model in order to improve fit (Chang, 1998; Ryu \& Jang, 2006), however, in this model due to the beliefs elicited, the modification was done between subjective norm and intentions, and perceived behavioral control and intentions. The modified SEM (Fig. 3) results $\left(\chi 2=189, d f=556, \chi^{2} / d f=3.38, \mathrm{p}<0.01, \mathrm{NFI}=0.91, \mathrm{IFI}=0.94, \mathrm{TLI}=0.90, \mathrm{CFI}=0.94\right.$, RMSEA $=0.07, R^{2}=0.18$ ) shows a satisfactory data fit implying that the modified SEM could be used to predict illegal miner's intention of choosing an alternative job. The modified SEM which contains better fit chi-square $\left(\chi^{2} / d f=3.38,\right)$ is considered for the analysis. The results of the TPB model and the modified model (MTPB) are presented in table 3. 


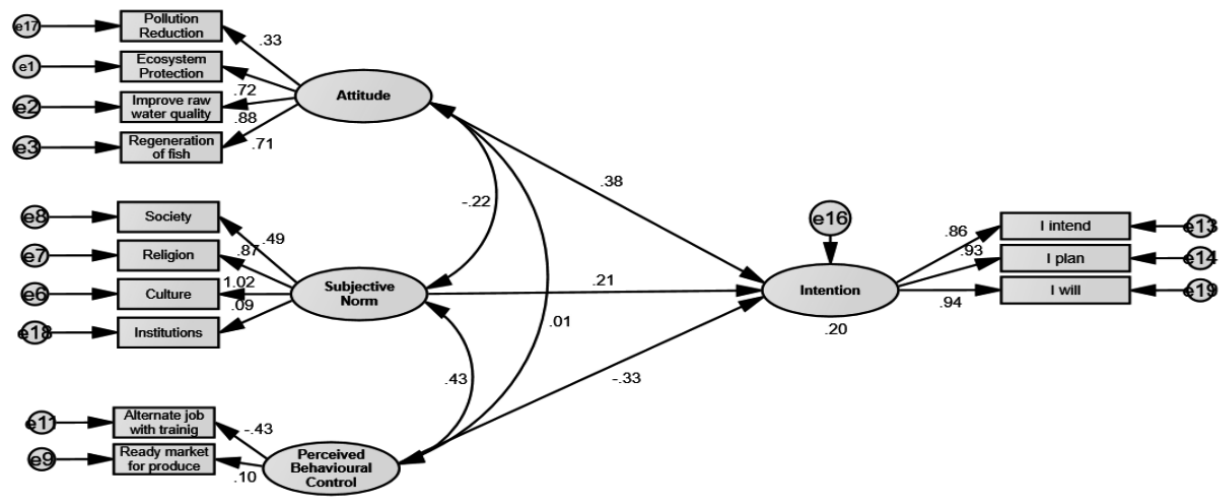

Fig. 2. The result of the structural equation model Chi-Square $=205.77, d f=59, p$-value $=0.000, R M S E A=0.073$

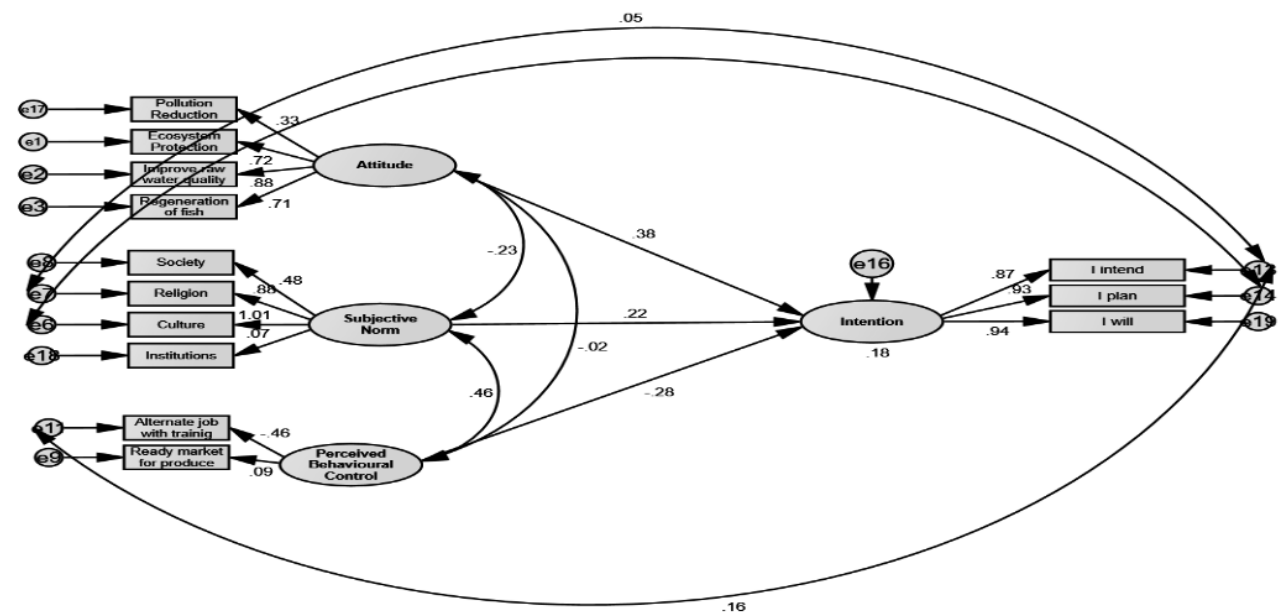

Fig. 3 Modified SEM Chi-square $=189, \mathrm{df}=56, \mathrm{p}$-value 0.000 RMSEA $=0.071$

Table 3: Explanatory power fit indices

\begin{tabular}{lcll}
\hline Fit indices & Recommended value & TPB & Modified TPB \\
\hline$\chi 2$ & -- & 205.77 & 189 \\
Df & -- & 59 & 56 \\
$\chi 2$ df & $\leq 2--\geq 5$ & 3.48 & 3.38 \\
RMSEA & $\leq 0.08$ & 0.073 & 0.071 \\
CFI & $\geq 0.90$ & 0.93 & 0.94 \\
NFI & $\geq 0.90$ & 0.91 & 0.91 \\
IFI & $\geq 0.90$ & 0.93 & 0.94 \\
TLI & $\geq 0.90$ & 0.9 & 0.90 \\
BI & -- & 0.20 & 0.18 \\
\hline
\end{tabular}




\section{Testing the hypothesis}

The estimate of the standardized coefficients indicate that the linkages between $\mathrm{BB}_{i} \mathrm{E}_{i}$ and ATT are significant $(\beta=0.77 ; p<0.05)$ and the path between $\mathrm{NB}_{i} \mathrm{MC}_{i}$ and SN was also significant $(\beta=0.75 ; p<0.05)$. Therefore, hypothesis 1 and 2 were supported. This implies that the illegal miner's attitude towards choosing an alternative job is influenced by his behavioral beliefs. From figure 3 all the behavioral belief variables predicting attitude all show positive, strong and significant predicting power except variable on pollution. Usually, individuals possess a favorable attitude when the outcomes are positively evaluated and he is potentially going to engage in that specific behavior(Han, 2010). In this regard, the illegal miner believes that choosing an alternative job will bring some environmental and health benefits such as improving raw water quality, protecting the ecosystem, helping regeneration of fishes and reducing pollution. Similarly, what others think he should or shouldn't do is also a significant predictor of the subjective norm. Hypothesis 3 was however not supported $(\beta=0.13 ; p>0.05$ ) which differs from previous studies (Lee, 2010; B. Zhang, Yang, \& Bi, 2010), indicating that the control beliefs are not the direct predictors of the PBC. Testing for the TPB assumption that predictive factors in the model are correlated show a correlation between ATT and SN $(\beta=-0.26 ; p<$ $0.05)$ but no correlation between SN and PBC $(\beta=0.46 ; p>0.05)$. The correlation between ATT and SN shows some level of interdependence between these direct determinants supporting hypothesis 4 . The assumptions being supported suggests that the attitude was not only influenced by the behavioral beliefs but may also be affected by the normative beliefs as well. This correlation can practically be exploited in addressing the problem of choosing an alternative job. The absence of correlation between the SN and PBC may imply the two constructs are independent (Ryu \& Jang, 2006). Hypothesis 5 (SN to PBC) was not supported. The estimate of the standardized coefficient shows attitude was significant $(\beta=0.38 ; p<0.05)$ in predicting illegal miner's behavioral intention (BI) of choosing an alternative job and explains $18 \%$ of the variance in $\mathrm{BI}$ (Fig. 3), supporting hypothesis 6 . Regarding hypothesis 7 and 8 , the subjective norm was positive in predicting the intention but not significant whereas the estimated standardized coefficient of perceived behavioral control was negative and not significant, hence both hypotheses were not supported. The positive values of coefficient of SN indicted that $\mathrm{SN}$ has some level of positive influence on illegal miner's choice of an alternative job, however, that level is not significant and the vice versa holds for the PBC. The non-significance of SN-BI may be due to the sample used. Most of respondents are youth who might have experience this kind of promises which never became a reality and as such maybe more concerned about their own beliefs (Vallerand, 1992 ). The findings in hypothesis 6, 7 and 8 suggests that of the three direct determinants, attitude towards the behavior had the most substantial influence $(\beta=0.38)$ on illegal miners intention to stopping illegal mining and adopt an alternative job, producing a change of 0.38 units of the behavioral intention for each unit change in attitude, positively 
insignificant by the opinion of others and negatively insignificant by factors such as provision of alternative jobs. The finding that $\mathrm{PBC}$ is not a predictor of illegal miner's intention of choosing an alternative job is a confirmation of why illegal miners are going back to their work sites. Figure 3 shows the direct influence of religion and alternative job on $\mathrm{BI}$. In both modifications, the path coefficient is positive showing that these two indirect determinants have a positive impact on the BI. This confirms the data gathered during the elicitation on how the indirect behaviors influence BI.

\section{Conclusion}

This study investigated the factors which influence illegal miner's decision in choosing an alternative job using the Theory of Planned Behavior (TPB). The findings revealed that the model could predict illegal miners intention of choosing an alternative job $(\beta=0.18)$ indicating that it is applicable to this environmental issue. The findings from the study reveal that PBC which has been the focus of facilitating illegal miner's choice of an alternative job is not a predictor of their intention $(\beta=0.13 ; p$ $>0.05$ ) explaining why miners are back to the site. The finding of the study suggests positive though not significant prediction from subjective norm (SN) on the BI of the illegal miners. Although SN and PBC were not significant predictors of illegal miner's BI of choosing an alternative job, the attitude was found to be the dominant significant antecedent of the behavioral intention. This empirical evidence can be used by the Water Resources Commission (WRC) to address the issue of choosing alternative job by illegal miners. WRC could achieve that by strategically directing all their expertise and resources in the sensitization and education of illegal miners' by focusing on the behavioral belief variables: improving raw water quality, protecting the ecosystem, helping regeneration of fishes and reducing water pollution. Because the study reveal a link between subjective norm and attitude, WRC may first establish ties with the communities' using focus group discussion by using the traditional/ opinion and religious leaders as facilitators. As time elapse, it could be expanded gradually into a form of a durbar with the focus on short sketches, demonstrations which will highlight on the behavioral beliefs. This can be enhanced with picture demonstration posters in the community and market centers. This can further be augmented by education in primary, junior and senior high schools, and on radio and, television. These processes have a lot of benefits. First, the illegal miners' will be well sensitization and educated for any possible change over. Second, the miners and the entire communities will have confidence and trust in the proposals that will be brought before them and be ready to own it. Third, community members or the youth who wished to join will now be educated, informed and unmotivated to engage in such act. The assumption that predicting factors in TPB are correlated was partially supported. The assumptions being supported suggests that the attitude was not only influenced by the behavioral beliefs but might be affected by the normative beliefs as well. The results did not support hypothesis 3, 7 and 8. The findings of this study call for the creation of a non-threatening platform or 
environment for a win-win situation where factors which are still unidentified but have a strong influence on the intentions of the illegal miners could be unearthed instead of putting so many resources into areas which have no empirical evidence to yield results. The study has some limitations which should be pointed out. There were certain areas where questionnaires could not be administered due to the risky nature of the area. The respondents in the research even though are from illegal mining communities or towns may not necessarily all be illegal miners which could affect the level of judgment in the answering of the questions. It will be interesting to conduct this research in all the other existing basins since most of the conditions such as the presence of the task force are no longer present. It will also be interesting to carry out this research in the same area but provide the option for respondents to choose their preferred alternative job themselves. 



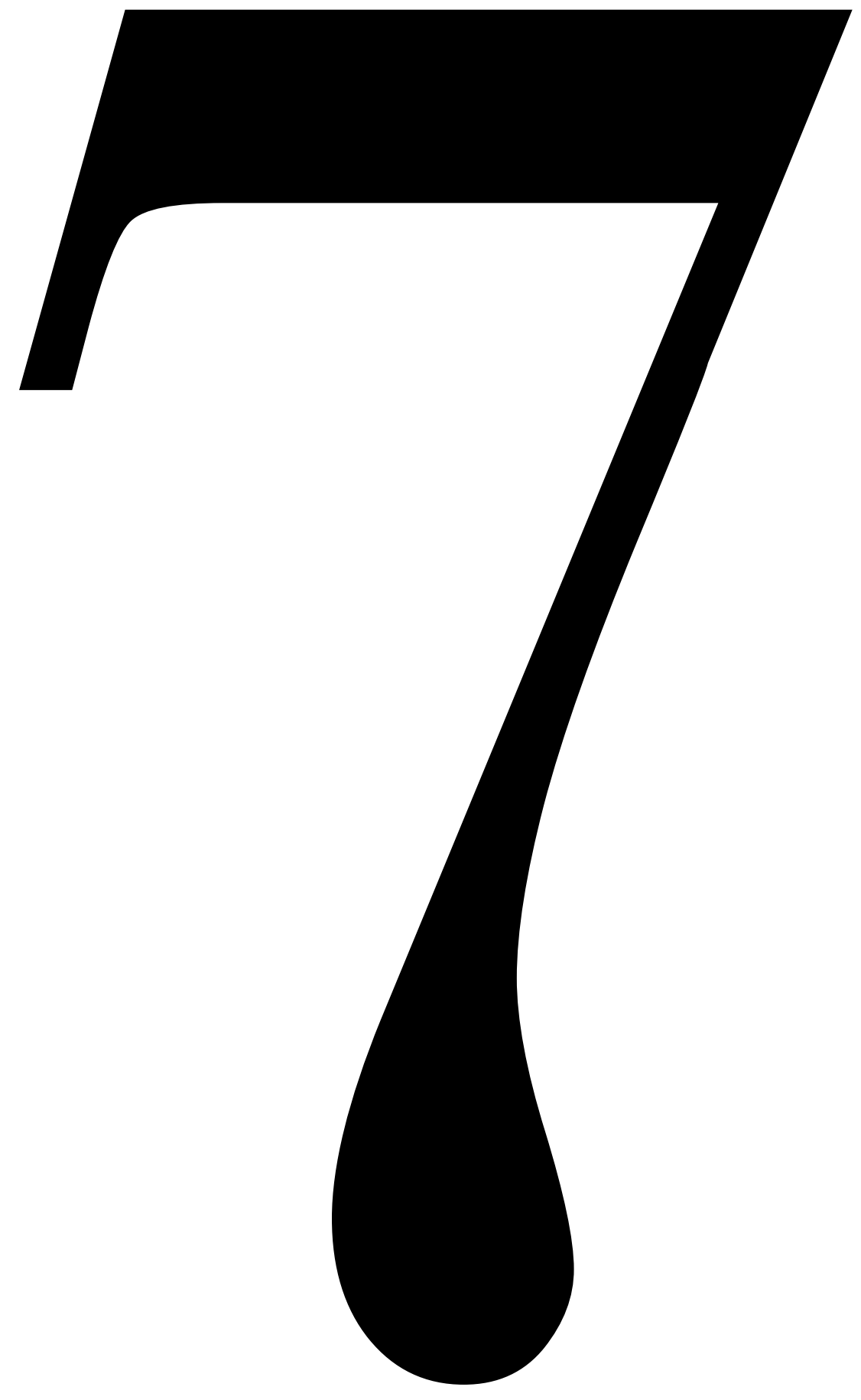




\section{Chapter 7}

General Discussion 

The aim of the research reported in this dissertation was to assess the effectiveness of integrated water resources management in the Pra Basin of Ghana, with a particular focus on its implementation, impact on water quality, and challenges to management intervention. This final chapter presents the main findings and discussion of methodological considerations to inform future research. The chapter addresses the following questions; What do we know about water management in the Pra Basin? What could be improved? How do we achieve that?

\section{Main findings}

\section{Implementation}

The water management system in the Pra Basin has strong government support which is clearly revealed in the creation of the enabling environment, institutional framework, and management instrument. Government commitment is further confirmed with the bold step taken to regulate artisanal mining with the introduction of an alternative livelihood to reduce pollution of the rivers despite the threat of losing vote in the next elections. Stakeholder involvement and actual participation in the planning and decision-making processes such as the identification and prioritization of problems in the basin is high and encouraging. Conflicts and overlapping roles and responsibilities are reduced with well-defined roles and responsibilities for institutions. To further strengthen this, the policies and laws are assigned to the appropriate institutions. The findings reveal the creation of a platform for data sharing and sector coordination. In addition, the identified problems in the basin were ranked in order of basin needs for redress by the basin planning group. According to the water resources act the basin board have the authority to address the illegal mining and any other issues that arise at the basin level.

These notwithstanding, there were still implementation drawbacks which impacted negatively on the management system. Similar to the findings in the implementation in Mozambique, the findings in this dissertation reveal that there is limited implementing capacity to translate the action plan on paper into practice ( $R$. Inguane, Gallego-Ayala, J., \& Juízo, D. ,2014). Certain platforms such as the Water Resources Information Services (WRIS) which were created to ensure data sharing and coordination are yet to be operational at the basin level. There are financial and logistical challenges because funding has been heavily dependent on the state that has been unreliable regarding funding of water resources management. This has affected the operations of related sectors such as the Environmental Protection Agency (EPA). These findings support previous implementation studies in South Africa, Mozambique, and Zimbabwe (Gallego-Ayala \& Juízo, 2011; R. Inguane, Gallego-Ayala, J., \& Juízo, D. , 2014). 
As reported in the case of Inguane et al. (2014), Nkhoma and Mulwafu (2004), and Ngana et al. (2003), the level of awareness in the basin is very low especially when it comes to education and training of Environmental Health Officers (EHOs): the focal point of the Water Resources Commission (WRC) at the district level. The limitations of using the river basin as the fundamental unit of operation (Saleth \& Dinar, 2004; Swatuk, 2005) has been supported by this studies. Most of the technical members of the River Basin Board such as the EPA, Hydrological Services Department (HSD), Meteorological Services Department (MSD), and Water Resources Information Services (WRIS) operate offices either at the national or regional level which does not favor the operations of the basin. Furthermore, there are no timelines in the plan of action, making it difficult for any meaningful evaluation. On paper the Pra Basin implementation framework to a large extent conforms to the proposed IWRM framework, however, there is great discrepancy in practice. For example, though the Pra Basin has the power to deal with the illegal artisanal miners, their authority is limited as the type of decentralization in the basin is the devolution type which have limitations in the governance authority. The discrepancy is shown in the required logistics and expertise for efficient running of the basin institutions (secretariat of PBB) and enforcement of regulations. Regarding the institutional operation, the basin is divided into three sub-basins for effective and efficient operation, however, only one sub-basin (Pra-Offin) is in operation. The other two are yet to start operation due to the absence of office space and logistical constraint. This is negatively affecting monitoring in the basin. The enforcement of regulations requires strengthening the technical capacities of the PBB and the relevant stakeholders, unfortunately there is absence of financial capacity to set up offices and recruit trained and skilled personnel for the two sub-basins. In addition, enforcement is to occur at the basin level yet most of the stakeholders for enforcement do not operate at the basin level. There is a clear sign of logistical and infrastructural deficit (Allan, 2003), the absence of human resource as well as unreliable and sustainable capital base to make implementation effective. This is contrary to what the framework proposed. Furthermore, there is strong physical evidence of illegal mining in the basin, yet the management plan does not capture it as a major determinant in the assessment of the quality of water.

\section{Effect of IWRM on the quality of water}

The quality of water resources and its immediate environment is one of the major factors that can be used to assess the strength of a water management system. Three different measurements relating to the quality of water was conducted to reflect the situation in the basin. First, the quality of water was assessed using physic-chemical and microbial parameters and compared with the baseline results. The results of the findings show a decline in the quality of water in almost all the study sites. Specifically, the Water Quality Index (WQI) findings indicate that as many as $50 \%$ of the sites moved from medium to bad, $25 \%$ moved from good to 
bad, and only $25 \%$ maintained their medium state. Even the $25 \%$ which maintained their status show a decline in the value of WQI. The deterioration is significantly high after implementation ( $M d n .=40.25)$ than before implementation (Mdn. = 72.19) $T=0, p=0.012, r=0.66$. The study findings identified suspended solids as the main cause of deterioration in the rivers. The study also reveals unregulated illegal mining as the main contributor of the suspended particles in the basin.

The presence of heavy metals could be influence by seasonal variations. Determining the seasonal variations provides a complete picture of their levels in the environment. Heavy metal presence in rivers is another determinant of water quality associated with illegal mining. The results from the study identify the metals $\mathrm{Pb}, \mathrm{Cd}, \mathrm{Cr}, \mathrm{Ni}, \mathrm{Fe}, \mathrm{Zn}$ as the principal metals polluting the rivers in both the dry and wet seasons whereas $\mathrm{Mn}, \mathrm{As}$, and $\mathrm{Cu}$, were found not to contribute to the pollution effect. The water quality index confirms that the water quality is marginal to fair in the dry season and poor for 26 out of the 27 sites in the wet season. The findings from the study, therefore, suggests the rivers (Pra, Offin, and Oda) are polluted and are unsafe for domestic activities.

River sediments serve as sinks for heavy metals when the $\mathrm{pH}$ of the river is high. At high $\mathrm{pH}$, the metals precipitate making them unavailable in water. However, at low $\mathrm{pH}$ or during high runoffs into the rivers, scouring occurs to introduce the metals into the water again. This, therefore, makes it prudent for the sediments to be assessed. The results of the findings show sediment enrichment with the metals $\mathrm{Pb}, \mathrm{Cd}$, and $\mathrm{Cr}$ at all study sites whereas $\mathrm{Ni}$ enrichment occurred in only 4 sites in the wet season. The sediments being enriched with these metals suggests that their presence in the sediments was caused by human action and not natural means. In the dry season, $\mathrm{Pb}$ and $\mathrm{Cd}$ enrich all the sites. The Igeo can generally be explained as the increasing levels of the metals over the years in the sediments. The results of the Igeo findings reveal that the sediments are contaminated with the metals $\mathrm{Zn}$ $<\mathrm{Cr}<\mathrm{Cd}<\mathrm{Ni}<\mathrm{Pb}$ in the dry season. The wet season recorded contamination of the metals $\mathrm{Cd}<\mathrm{Cr}<\mathrm{Ni}<\mathrm{Pb}$. The findings reveal increasing contamination levels of the metals $\mathrm{Cd}, \mathrm{Cr}, \mathrm{Ni}$, and $\mathrm{Pb}$ in the sediment. The high levels of $\mathrm{Cd}, \mathrm{Pb}$, and $\mathrm{Cr}$ in all the sites are due to unregulated illegal mining activities occurring in and around the study area. The first objective of the water management system was to address the inadequate water supply challenge in the basin; on the contrary, the quality of the water resources after implementation was rather deteriorating. The result from this finding is a clear indication of IWRM not fully implemented.

\section{Intervention challenges in the basin}

The rivers in the basin are aesthetically unattractive due to the high levels of suspended particles introduced into it by illegal mining. Interventions to stop the illegal mining activities by providing an alternative job to improve on the quality 
of the rivers have not been successful. The findings of the results indicate that the control behavior which has been the focus of government intervention is not a predictor of illegal miner's behavioral intention. The results further reveal the attitude as the only dominant significant antecedent of the behavioral intention. This, therefore, explains why the illegal miners are back to the sites. This situation occurred because there was insufficient preparation time to engage and discuss with the illegal miners other livelihood options which could have been of interest to them before the intervention study. The other reason is that the package was not designed for them but they were roped in for convenience purposes. Together these findings provide important insights into implementation gaps, water quality issues, and intervention failure: which raises questions about the effectiveness of the water management system in the Pra Basin.

\section{Future consideration to improve on IWRM}

To achieve effective water resources management is to ensure that the management framework can be practically translated into action. The identified challenges in the management system are multi-level and multi-sectorial and must be addressed with that caution to ensure practical and effective management system. Hence, future implementation processes that hope to achieve effective water resources management must target the identified gaps and design alternative intervention(s) that are empirically tested so that they will be accepted. Intervention mapping (IM) and the theory of planned behavior (TPB) can be used to address the implementation gaps and the intervention issues respectively. The IM approach is a theory and evidence-based approach that map the path from the recognition of a problem to the identification of a solution. The IM though designed for health education, its systematic approach can be tailored to address the implementation gaps identified in this study.

First, regarding the problem identification: The involvement of local components (local people) was not enough in the case of this study. However, this is very crucial for the implementation to enjoy the full support of the basin communities. The policy makers must therefore be careful in the setting up of a planning group. The planning group must be given the flexibility and the resources to co-opt other relevant sectors/stakeholders and invite them for identified problems for which the planning group lacks expertise. However, caution should be taken here as not all identified stakeholders may be operational at the basin level as in the case of this study. It is therefore prudent that the lowest operational levels of all identified stakeholders are established. Where they are absent at the basin level, efforts must be made to strategically create a pseudo office at the basin level where they can have representatives to link such stakeholders. The planning team together must identify the logistics, infrastructure human resources etc. that will enhance their capacity as institutions to function. In this regard, if there were institutions with 
logistical or human resource constraints, they will be properly equipped as in the case of Mexico (Muller, 2010) which work out very well. The second involves the process of developing the objectives based on the identified problems in the framework of national development. Meanwhile, the planning group must also know that the objectives will finally be implemented at the local level. As much as possible the objectives must be clearly outlined and the expected outcomes clearly stated. The roles of each sector /stakeholder should be specifically outlined and the expected outcomes clearly indicated. This helps to reduce conflicts to the minimum, eliminate overlapping roles and improves coordination and integration which enhances the implementation process and provides strong support to the national development framework as well. The identified parameters/indicators to measure/assess the expected outcomes should be ranked in order of priority at this level. This will help in the distribution of funds and resources. Third, focuses on how to develop innovative strategies to translate the plan on paper into practice. External or donor influence should be avoided or be reduced to the minimum to allow proper tailoring of innovations to the identified problems in the basin. Strong donor influences in similar situations in Tanzania and Zimbabwe did not yield any fruitful results (Dube \& Swatuk, 2002; Giordano, 2014).

In most cases, a long list of what to be done is provided without any evidence on how it will be done as in the case of this study. For example, a basin may be facing a low level of awareness creation for a new policy being introduced. This is how the solutions are usually proposed: the people will be educated. How is education going to be done? Will it be through radio and television announcement? Is it going to be a mobile van announcement? It is only when the 'how' to achieve the solution is clearly stated that a proper financial budget can be drawn. In addition to the above, the strategies should show the themes, the scope, the target group, the timelines and who is doing what. Fourth, making a conscious effort to and ensuring that the capacity of human resources and other physical facilities such as infrastructure are available as requested. Assumptions about the existence of these things before or during the implementation should be avoided. In areas where these things do exist empirical evidence should be gathered to ascertain whether improvement or upgrading is needed. Fifth, look at fine tuning the strategies and streamlining the action plan of the various stakeholders and synchronizing the activities of all the action plans through a brainstorming exercise. In the process of fine tuning, the planning group must be sensitive to the local environment where the implementation is taking place. For example Integrated Water Resources Management ( IWRM) considers the river basin as the lowest appropriate level for operation, however, in areas which are predominantly made of informal economies like 'black' South Africa, and India (Shah, 2006) it is advisable to adopt a hybrid of formal and informal normative framework which the people are familiar with (Meinzen-Dick, 2002) to ensure actual participation and ownership. The synchronization is very crucial in eliminating any hidden overlapping roles, reduce conflicts, enhance coordination, 
and create a platform for easy sharing of information among the sectors. Sixth deals with an evaluation plan to assess the determinants in relation to the expected outcome during and after each stage of implementation. This must also be done with timelines, a budget, and source of funding. There are usually feedbacks which come during the evaluation for adjustment and reshaping operations. These feedbacks are mostly underestimated by policy makers, basin officers, and engineers (PahlWostl, 2006) but they are very critical for the progress of the implementation and as such must be addressed with the serious it deserves.

There is the need to improve awareness creation, education, and training programs. The IWRM implementation is a process and not a one-time action. However, the result of the findings suggests that efforts invested in awareness creation, etc. before the implementation has not been sustained. To ensure sustainability, an awareness creation plans for the year, indicating what they intend to do when, who to do it, where to do it, how to do it; the target group, a budget and a source of funding must be clearly documented and planned for. In the same way, training programs should be planned with the district assemblies for their incorporation into the assembly plan. One of the major anticipated challenges with this training program is the expertise to carry out the training considering the staff size of WRC and the number of districts to cover. However, WRC can collaborate with institutions with the expertise like the University of Cape Coast Water and Sanitation Department. With the sustained awareness creation and training, gradually the ignorance of the management system among stakeholders and the citizens will be reduced or eliminated and citizens will become conscious of their actions in relation to water resources management. This will also equip the EHOs and give them a sense of responsibility for duties assigned them.

The mode of carrying out interventions in the basin needs improvement. Interventions should not be based on physical evidence but rather empirical. Thus, water resources management can be effective if the implementation focuses on the recommendations above.

\section{Methodological considerations}

This section describes the methodological approaches of the studies in this dissertation. It focuses on the study designs, strengths, and limitations. This study looked at the problem of water management from different angles and so employed different methodologies. As a result, the conclusions drawn are general conclusions. They are not based on one chapter or methodology but on the entire work. There were interviews, questionnaires, and measurements. The approaches used in this research have implications for research and practice. 


\section{Measurement instruments}

Three of the studies in this dissertation were measurements designed studies (chapters 3, 4 and 5). The second study, chapter 3 was on water quality assessment after the implementation of IWRM in the basin. This study measured the impact of the IWRM with reference to the baseline data in the basin. Water samples were collected from the 8 monitoring stations used for generating the baseline data. The 8 monitoring stations are located in the 5 main rivers in the basin. The measurement index showed deterioration in 6 out of the 8 sites. The study in chapter 4 though was on water quality focused on heavy metals because: 1 ) the baseline data did not cover that 2) of the unregulated illegal mining activities in the basin. The measurement was done for the dry and wet seasons from the upstream to the downstream of the basin. The results of the study findings exceeded the safe drinking water guidelines making the water unsafe for domestic activities like cooking. The findings further revealed that the rivers were polluted. Chapter 5 of the study also measured the heavy metal levels in the river sediments which are indirect contributors to metal pollution in rivers. This study was also used to confirm the source of heavy metals as natural or anthropogenic. Three measurement indexes namely geo-accumulation index, enrichment factor, and pollution load index were employed. The result of the study findings shows only 1 out of the 27 sites polluted. Even though only 1 site was polluted, all the sites were enriched and have accumulated some levels of heavy metals: an indication that implies the presence of the metals is due to human action. The number one priority of the basin management plan was to tackle the problem of inadequate water. Unfortunately, the quality of the water resources has neither improved nor maintained but rather deteriorated. The deteriorated quality of for example the Birim River resulted in the shutting down of the Kyebi water treatment plants. The studies presented thus far provide evidence that raises questions about the effectiveness of water resources management in the Pra Basin. Due to the constant excavation in and around the rivers, though we picked samples from the same site it was sometimes difficult to pick from the same spot. The threat posed by illegal miners in some areas restricted the sampling to 3 rivers. Future studies should assess the implementation in other operating basins. It should also measure the levels of heavy metals in the fishes in the river and crops grown close to the rivers. This will provide a complete picture of the ecosystem. Risk assessment on the fishes and the crops can then be conducted.

The studies from chapter 2 and 6 are in-depth design studies that used interviews, questionnaires, and literature to gather data. The questionnaire questions were based on the belief elicitation procedure proposed by Ajzen (1991) whereas the interview questions focused mainly on the gathered literature. The findings from these studies identify specific gaps in the intervention and implementation process which have negatively impacted on the effectiveness of the water management. Under implementation the affected areas include the inability to translate water 
management framework on paper into practice, absence of some major stakeholders at the district level, low staff strength and logistical constraints, absence of timelines in all the actions, opinion leaders not counting themselves as part of the board, absence of 'how' actions on management plan should be achieved. Finally, the use of the control belief as the focus for intervention change which was not a predictor of the behavioral intention. However, the study has some limitations which should be pointed out. There were certain areas where questionnaires could not be administered due to the risky nature of the area. The respondents in the research even though are from illegal mining communities or towns may not necessarily all be illegal miners which could affect the level of judgment in the answering of the questions. Some of the respondents complain of always answering questionnaires and this could influence their judgment in answering the questions.

A major strength of this research is the heterogeneous nature of the methods designed for the studies in this dissertation. The studies in this dissertation looked at the effect of water management from different angles using different methodologies. The methods included qualitative and quantitative techniques. For example, chapters 2 used interviews and existing literature whereas chapter 6 used the Theory of Planned Behavior (TPB) and the structural equation model (SEM). The chapters 3,4 , and 5 were quantitatively measured using the water quality index, enrichment factor, geo-accumulation index, and pollution indexes. These studies were together used to test the effectiveness of the water management system by particularly focusing on the process of implementation and its impact on water quality. By doing this we have been able to establish how adopting a water management system and not fully implementing it can seriously affect the quality of the water resources. The result of the findings from the studies listed above gives a vital proof which strongly connects to the effectiveness of water resources management and its impact on water quality. The heterogeneous nature of the methodology employed in these studies unites these findings. In addition to that, it has provided more insight into effective water resources management which couldn't have been achieved by a single approach.

\section{Implications and Recommendations}

\section{Implication for policy}

A new water management system should only be implemented when there is political will or commitment, reliable and sustainable funding, infrastructure and human resource capacity and an implementable framework. Policy makers must, therefore, ensure that what it takes to translate the action plan onto the ground is available but not assumed (refer to study 2). This can only be achieved if they target the gaps in the implementation process and the beliefs with influence on interventions and channel their resources in that direction. The regulators must 
enforce the laws.

Relevant stakeholders mandated to carry out some responsibilities should be well resourced; in logistics (e.g. nonfunctional laboratories in the case of EPA), human resources etc. to ensure the practical transfer of information and data. For full participation of all relevant stakeholders especially the technical stakeholders, efforts should be made to either create offices at the districts or provide means of robust transport and other logistics such as well-equipped laboratories, computers, laptops etc. One trademark of IWRM is the dissemination of information to the lowest appropriate level, this could be intensified by augmenting the education in the primary, Junior, and senior high schools with environmental debate and quiz competitions. This has a high potential of increasing awareness among the youth and the communities. However, how they intend to carry out the education i.e. either through debate or quiz must be clearly stated as indicated in the recommendations for proper budgeting and funding.

There should be a means to address feedbacks on identified gaps to improve the management system. A research and innovation network team can help in this direction. This should not be made up of only water resources engineers/managers but also inhabitants and expertise with sociology, psychology, etc. background to advise, guide and conduct research on issues and propose the appropriate interventions depending on the pending problem. All members of the network should be equipped with the communication device by which information can easily be displayed. Any problem identified can easily be assessed, by the team through communication on the platform for temporary measures to be taken through the basin board before gathering for the permanent solution later. This could be expensive though, but the benefits will be worth considering. In addition, the composition of the network team: from technical to behavioral etc. creates the versatility needed for this kind of job.

There is the need for the creation of water resources management desk at the district assemblies to purposely deal with water issues. The absence of this will continue to create a very big gap as the environmental officers at the district level are already overburdened. Additional EHOs or sanitation graduates must be employed to purposely take charge of water resources issues. Water resources management should be added to the training syllabus of the environmental health officers. This long-term project will eventually equip the EHOs and reduce the number of workshops and refresher courses which WRC would have to organize. There should be a means to augment the existing means of generating funds for example paying for abstracted water which are difficult to monitor and sustain. Other alternative long-term plans to raise funds to sustain the management system must be rolled on before implementation. For example, slumming huge sums of money as penalty on waters abstracted illegally by companies and individuals to serve as a deterrent. 
Improve technology should be employed to improve on the assessment of the actual volumes of water abstracted by the companies.

\section{Implications for practice}

An effective water management system that will ensure an adequate supply of water, ecological integrity, and economic development than the current system is needed. This research confirms that the only way to achieve this is to direct all investment and resources towards the gaps identified in the implementation process, and map interventions based on empirical evidence. Empirically established interventions to address the gaps identified in the implementation process are needed to ensure effective water resources management in the Pra Basin. The intervention mapping approach used under future consideration to improve on IWRM can serve as a guide.

\section{Conclusion}

The main objective of this study was to assess the effectiveness of water resources management in the Pra Basin with a particular focus on its implementation, impact on water quality, and challenges to management intervention. The findings from this study provide insight into how these determinants affect the effectiveness of the water resources management system. First, our research highlights six implementation challenges which impact negatively on the integrated water resources management. Second, these implementation gaps are found to cause the pollution of the water resources by introducing a high level of suspended particles and heavy metals making the water unsafe for those who still depend on them under water stress conditions and increase the cost of chemicals for water treatment. Third, the river sediments which is known to serve as sinks for heavy metals was found to be enriched and contaminated with heavy metals confirming the presence of these metals are from the anthropogenic source. Fourth, an effort to improve the quality of water resource management through the provision of an alternative livelihood was unsuccessful because the control belief which was used as the focus of the intervention was not a predictor of the behavioral intervention. The water management system can help improve on the quality of the water resources if it is fully implemented and monitored with the measurable determinants and taking appropriate action on the feedback from these determinants. 



\section{References}




\section{References}

Abdel-Ghani, N. T., \& Elchaghaby, G.A. (2007). Influence of operating conditions on the removal of $\mathrm{Cu}, \mathrm{Zn}, \mathrm{Cd}$, and $\mathrm{Pb}$ ions from wastewater by adsorption Int. J. Environ. Sci. Technol., 4, 451-456.

Afum, B. O., \& Owusu, C. (2016). Heavy metal pollution in the Birim River of Ghana. International Journal of Environmental Monitoring and Analysis, 4(3), 65-74.

Afrasiab, K. T., Imrana, N. S., Pramuk, P., Mohammad, S., Ashraf, K., Mohammad W. K. \& Sadat H. (2014). Detection of heavy metals (Pb, Sb, Al, As) through atomic absorption spectroscopy from drinking water of District Pishin, Balochistan, Pakistan International Journal of Current Microbiology and Applied Science, 3(1), 299-308.

Agyenim, J. B., \& Gupta, J. (2012). IWRM and developing countries: Implementation challenges in Ghana. Physics and Chemistry of the Earth, Parts $A / B / C, 47,46-57$.

Ajzen, I. (1991). The theory of planned behavior. Organizational behavior and human decision processes, 50(2), 179-211.

Alabaster, J. S., \& Lloyd. R. (1980). Water quality criteria for freshwater fish. Retrieved from Buttersworth, London-Boston:

Ali, M. M., Ali, M. L., Islam, Md. S., \& Rahman, Md. Z. (2016). Preliminary assessment of heavy metals in water and sediment of Karnaphuli River, Bangladesh. Environmental Nanotechnology, Monitoring \& Management, 5, 27-35.

Ali, M. M., Ali, M. L., Islam, Md. S., I., \& Rahman, Md Z. (2016). Preliminary assessment of heavy metals in water and sediment of Karnaphuli River, Bangladesh. Environmental Nanotechnology, Monitoring, and Management, 5, 27-35.

Allan, T. (2003). [IWRM/IWRAM: A new sanctioned discourse? SOAS Water Issues Study Group Occasional paper 50].

Atkinson, C. A., Jolley, D. F., \& Simpson, S. L. (2007). Effect of overlying water pH, dissolved oxygen, salinity and sediment disturbances on metal release and sequestration from contaminated marine sediments Chemosphere, vol. 69(no. 9), 1428-1437.

Akpabio, E. M. (2008). Integrated water resources management in the cross river basin, Nigeria: How can we reconcile institutional boundaries and interests?. International journal of river basin management, 6(3), 267-276.

Attuaquayefio, D., \& Folib, J. (2005). An overview of biodiversity conservation in Ghana: challenges and prospects. West African Journal of Applied Ecology, 7(1).

Bentler, P. M. (1990). Comparative fit indexes in structural models. Psychological Bulletin, 107(2), 238.

Bilotta, G. S., \& Brazier, R. E. (2008). Understanding the influence of suspended solids on water quality and aquatic biota. Water research, 42(12), 2849-2861.

Biswas, A. K. (2004). Integrated Water Resources Management: A Reassessment. Water International, 29(2), 248-256.

Biswas, A.K., 2008. Integrated water resources management: is it working? Water Resources Development 24, 5-22

Brian Oram, P. (2014). Phosphates in the environment.

Butterworth, J., Warner, J., Moriarty, P., Smits S., \& Batchelor, C. (2010). Finding practical approaches to integrated water resources management. Water Alternatives, 3(1), 68-81.

Carpenter, S. R., \& Lathrop, R. C. (2008). Probabilistic estimate of a threshold for eutrophication. Ecosystems, 11(4), 601-613. 
Carr, G. M., \& Neary, J. P. (2008). Water quality for ecosystem and human health: UNEP/ Earthprint.

Chang, M. K. (1998). Predicting unethical behavior: a comparison of the theory of reasoned action and the theory of planned behavior. Journal of Business Ethics, 17(16), 18251834.

Davis, J. C. (1975). Minimal dissolved oxygen requirements of aquatic life with emphasis on Canadian species: a review. Journal of Fisheries Research Board Canada, 32(12), 2295-2332.

Dawson, E., \& Macklin, M. (1998). Speciation of heavy metals on suspended sediment under high flow conditions in the River Aire, West Yorkshire, UK. Hydrological Processes, 12(9), 1483-1494.

Deborah, C. (1996). Water quality assessments-A guide to use of biota, sediments and water in Environmental Monitoring. UNESCO/WHO/UNEP.

Debyle, N. B., \& Simco, B. A. (1976). Plant nutrient and soil losses in overland flow from burned forest clearcuts. (14), 296-307.

Donkor, A. K., Bonzongo, J. C., Nartey, V. K., \& Adotey, D. K. (2006). Mercury in different environmental compartments of the Pra River Basin, Ghana. Science of the Total Environment, 368(1), 164-176.

Dovers, S. (2001). Institutional barriers and opportunities: processes and arrangements for natural resource management in Australia. Water Science and Technology, 43(9), 215.

Dube, D., \& Swatuk, L. A. (2002). Stakeholder participation in the new water management approach: a case study of the Save catchment, Zimbabwe. Physics and Chemistry of the Earth, Parts $A / B / C, 27(11-22), 867-874$.

Falkenmark, M., \& Rockström, J. (2004). Balancing water for humans and nature: the new approach in ecohydrology: Earthscan.

Fatawu, N. A., \& Allan, A. (2014). Managing the impacts of mining on Ghana's water resources from a legal perspective. JENRM, I (3), 156-165.

Fishbein, M., \& Ajzen, I. (1975). Belief, attitude, intention and behavior: An introduction to theory and research.

Gallego-Ayala, J., \& Juízo, D. (2011). Strategic implementation of integrated water resources management in Mozambique: An A'WOT analysis. Physics and Chemistry of the Earth, Parts $A / B / C, 36(14-15), 1103-1111$.

Gangwar, R. K., Khare, P., Singh, J., \& Singh, A. P. (2012). Assessment of physico-chemical properties of water: River Ramganga at Bareilly, UP. Journal of Chemical and Pharmaceutical Research, 4(9), 4231-4234.

Giordano, M., \& Shah, T. (2014). From IWRM back to integrated water resources management. International Journal Water Resources Management, 30(3), 364-376.

Gumbo, B., \& Van der Zaag, P. (2002). Water losses and the political constraints to demand management: the case of the City of Mutare, Zimbabwe. Physics and Chemistry of the Earth, Parts A/B/C, 27(11-22), 805-813.

GWP, G. W. P. (2000). Towards Water Security: A Framework for Action. Retrieved from

Haiyan L., A., S., Mingyi, L., \& Xiaoran, Z. (2013). Effect of pH, temperature, dissolved oxygen, and flow rate on overlaying water on heavy metals released from the storm sewer sediments. Journal of Chemistry, 11.

Han, H., Hsu, L. T. J., \& Sheu, C. ( 2010). Application of the theory of planned behavior to green hotel choice: Testing the effect of environmental friendly activities. Tourism 
Management, 31(3), 325-334.

Hassan. (2011). Water history of out times (Vol. 2). France UNESCO.

Hassing, J. (2009). Integrated water resources management in action: Dialogue paper: UNESCO.

Haygarth, P., Bilotta, G., Bol, R., Brazier, R., Butler, P., Freer, J., \& Macleod, C. (2006). Processes affecting transfer of sediment and colloids, with associated phosphorus, from intensively farmed grasslands: an overview of key issues. Hydrological Processes, 20(20), 4407-4413.

Hilemana, J., Hicksb, P., \& Jonesb, R. (2015). An alternative framework for analysing and managing conflicts in integrated water resources management (IWRM): linking theory and practice. International Journal of Water Resources Development, 32(5), 675-691. http://www.gwcl.com.gh/gwcl history.pdf.

Inguane, B. (2010). political, institutional, and socioeconomic factors constraining the performance of decentralized water management in Mozambique: From the major perspective of government functions. (MSc thesis), University of Queensland,

Inguane, R., Gallego-Ayala, J., \& Juízo, D. (2014). Decentralized water resources management in Mozambique: Challenges of implementation at the river basin level Physics and Chemistry of the Earth(67-69), 214-225.

Islam, M. S., Ahmed, M. K., Raknuzzaman, M., Habibullah-Al-Mamun, M., \& Islam, M. K. (2015). Heavy metal pollution in surface water and sediment: a preliminary assessment of an urban river in a developing country Ecol. Indic., 48, 282-291.

Ismaeel, W., \& Kusag, A. (2015). Enrichment factor and geo-accumulation index for heavy metals at industrial zone in Iraq. IOSR J. Appl. Geol. Geophys., 3, 26-32.

Jeffrey, P., \& Gearey, M. (2006). Integrated water resources management: lost on the road from ambition to realisation? Water Sci Technol, 53(1), 1-8.

Jønch-Clausen, T., \& Fugl, J. (2001). Firming up the conceptual basis of integrated water resources management. International Journal of Water Resources Development, 17(4), 501-510.

Jung, M. C. (2001). Heavy metal contaminiation of soils and waters in and around the Imcheon Au-Ag mine, Korea. Appl. Geochem., 16, 1369-1375.

Kennedy, K., Simonovic, S., Tejada-Guibert, A., de França Doria, M., \& Martin, J. L. (2009). IWRM implementation in basins, sub-basins and aquifers: state of the art review. The United Nations World Water Development Report, 3.

Klerks, P. L., \& Levinton, J. S. (1989). Rapid evolution of metal resistance in a benthic oligochaete inhabiting a metal-polluted site Biol Bull, 176, 135-141.

Kizha, A. R., Balachandran, S., Madurapperuma, B., \& Lima, H. (2016). Environmental impacts of accidental black liquor discharge into the Pearl River, Louisiana: a geospatial evaluation. Int. J. Environ. Sci, 6, 922-933.

Lee, J., Cerreto, F. A., \& Lee, J. (2010). Theory of planned behavior and teachers' decisions regarding use of educational technology. Journal of Educational Technology \& Society, 13(1).

Lenton, R., \& Muller, M. (2012). Integrated water resources management in practice: Better water management for development.

Lloyd, D. S., Koenings, J. P., \& Laperriere, J. D. (1987). Effects of turbidity in fresh waters of Alaska. North American Journal of Fisheries Management, 7(1), 18-33.

Louati, M. E. H., \& Bucknall, J. (2009). Tunisia's experience in water resource mobilization and management. Water in the Arab World, 157. 
Maurizio, B. (2016). The importance of enrichment factor (EF) and geoaccumulation index (Igeo) to evaluate the soil contamination. Geology and Geophysics, 5(1), 1-4.

Meinzen-Dick, R., \& Pradhan, R. (2002). Legal pluralism and dynamic property rights. Retrieved from

Merrey, D. J. (2008). Is integrated water resources management implementable? Journal of Physics and Chemistry of the Earth, 33, 899-905.

Miller, J. R., Hudson-Edwards, K. A., Lechler, P. I., Preston, D., \& Macklin, M. G. (2004). Heavy metal contamination of water soil and produce within riverine communities of the Rio Pilcomayo Basin. Sci. Total Environ, 320, 189-209.

Mitchell, B. (2005). Integrated water resource management, institutional arrangements, and land-use planning. Environment and Planning A, 37(8), 1335-1352.

Montuelle, B., \& Graillot, D. (2017). Fate and effect of pollutants in rivers: from analysis to modeling. In: Springer.

Moriarty, P., Batchelor, C., Laban, P., \& Fahmy, H. (2010). Developing a practical approach to 'light IWRM' in the middle east. Water Alternatives, 3(1), 122-136.

Mortimer, C. H. (1956.). [The oxygen content of air-saturated fresh waters, and aids in calculating percentage saturation].

Müller, G. (1979). Schwermetalle in den sedimenten des Rheinse Veranderrungen seitt 1971. Umschau, 79, 778-783.

Muller, M. (2010). Fit for purpose: taking integrated water resource management back to basics. Irrigation and drainage systems, 24(3-4), 161-175.

Nasirudeen, A. F., \& Allan A. (2014). Managing the impacts of mining on Ghana's water resources from the legal perspective. JERM, 1(3), 156-165.

Ololade, I. A., Lajide, L., \& Amoo, I. A. (2008). Seasonal metal distribution in Ondo Coastal Sediment, Nigeria. J. Appl. Sci. Environ. Mgmt., 12(4), 11-18.

Pahl-Wostl, C. (2006). The implications of complexity for integrated resources management. Environmental Modelling \& Software, 22(5), 561-569.

Pra Basin. (2012). Pra Basin IWRM Plan

Radiff, A. A. (1999). Integrated water resources management (IWRM): an approach to face the challenges of the next century and avert future crises. Journal of Desalination, $124,145-153$.

Rahaman, M. M., \& Varis, O. (2005). Integrated water resources management: evolution, prospects and future challenges Sustainability: Science, Practice, \& Policy, 1(1), $15-21$.

Rajendran, P., Muthukrishnan J., \& Gunasekaran P. (2003). Microbes in heavy metal remediation. Indian J. Exp. Biol., 41(9), 935-944.

Rathod, S. D., Mohsin, M., \& Farooqui, M. (2011). Water Quality Index In \& Around WalujShendra Industrial Area Aurangabad. (MS). Asian J. Biochem. Pharmaceut. Res, 1(2).

Ribot, J. (2004). Waiting for Democracy: The Politics of Choice in Natural Resources Decentralization. World Resource Institute, Washington DC.

Robertson-Bryan, I. (2004). pH Requirement of Freshwater Aquatic Life. Retrieved from Robinson, P. B. (2002). "All for some": water inequity in Zambia and Zimbabwe. Physics and Chemistry of the Earth, Parts A/B/C, 27(11-22), 851-857.

Ryu, K., \& Jang, S. (2006). Intention to experience local cuisine in a travel destination: The modified theory of reasoned action. Journal of Hospitality \& Tourism Research, 30(4), 507-516.

Saleth, R. M., \& Dinar, A. (2004). The institutional economics of water: a cross-country 
analysis of institutions and performance: The World Bank.

Salman, S., \& Bradlow, D. (2006). Regulatory frameworks for water resources management: A comparative study: Washington, DC: World Bank.

Saravanan, V., S. (2009). Decentralization and water resources management in India Himalayas: the contribution of new institutional theories. Consev. Soc., 7, 176-191.

Sekabira, K., Origa, H. O., Basamba, TA., Mutumba, G., \& Kakudidi, E. (2010). Assessment of heavy metal pollution in the urban stream sediments and its tributaries. International Journal of Environmental Science \& Technology, 7(3), 435-446.

Shah, T., \& Van Koppen., B. (2006). Is India ripe for integrated water resources management? Fitting water policy to national development context. Economic and Political Weekly, 3413-3421.

Shazili, M. N. A., Yunus, K., Ahmad, A. S., Avdullah, N., \& Abd Rashid, M. K (2006). Heavy metal pollution in the Malaysian aquatic environment. Aqua Ecosyst. Health Mgmt, 9(2), 137-145.

Simpson, S. L., Angel, B. M., \& Jolley, D. F. (2004). “ Metal equilibration in laboratorycontaminated ( spiked) sediments used for the development of whole-sediment toxicity tests". Chemosphere, vol. 54(no. 5), 597-609.

Smaya, T. J. ( 2008.). Complexity in the eutrophication-harmful algal bloom relationship, with comment on the importance of grazing. Harmful Algae 8(1), 140-151.

Smith, V. H. (2003.). Eutrophication of freshwater and coastal marine ecosystems: a global problem. Environmental Science and Pollution Research, 10, 126-139.

Swatuk, L. A. (2005). Political challenges to implementing IWRM in Southern Africa Physics and Chemistry of the Earth, 30, 872-880.

Tapela, B. N. (2002). The challenge of integration in the implementation of Zimbabwe's new water policy: case study of the catchment level institutions surrounding the Pungwe-Mutare water supply project. Physics and Chemistry of the Earth, Parts $A / B / C, 27(11-22)$, 993-1004.

Taylor, M. P., Mackay, A. K., Hudson-Edwards, K. A., \& Holz, E. (2010). Soil Cd, Cu, Pb and Zn contaminant around, around Isa city, Queensland, Australia: Potential sources and risks to human health Appl. Geochem., 25, 841-855.

Tomilson, M.J. (1980). Foundation design and construction. 4th Edn. Pitman Publishing Inc., London.

Vallerand, R. J., Deshaies, P., Cuerrier, J. P., Pelletier, L. G., \& Mongeau, C. (1992 ). Ajzen and Fishbein's theory of reasoned action as applied to moral behavior: A confirmatory analysis. Journal of Personality and Social Psychology, 62(1), 98.

van der Zaag, P. (2005). Integrated Water Resources Management: Relevant concept or irrelevant buzzword? A capacity building and research agenda for Southern Africa.

Physics and Chemistry of the Earth, Parts A/B/C, 30(11), 867-871.

WRC, (2011). Annual Report of the Water Resources Commission Accra.

WRC. (2012). National Integrated Water Resources Management Plan

Yi, Y., Yang, Z., \& Zhang, S. (2011). Ecological risk assessment of heavy metals in sediment and human health risk assessment of heavy metals in fishes in the middle and lower reaches of the Yangtze river Environ. Pollut., 169, 2575-2585.

Yu, G. B., Liu, Y., Yu, S., Wu, S. C., Leug, A. O. W., Luo, X. S., Xu, B. Li, H. B., \& Wong, M. H. (2011). Inconsistency and comprehensiveness of risk assessments for heavy metals in urban surface sediments. Chemosphere, 85, 1080-1057.

Zhang, B., Yang, S., \& Bi, J. (2010). Enterprises' willingness to adopt/develop cleaner 
production technologies: an empirical study in Changshu, China. Journal of Cleaner Production, 40, 62-70.

Zhang, J., \& Liu, C. L. (2002). Riverine composition and estuarine geochemistry of particulate metals in China-weathering feature, anthropogenic impact and chemical fluxes. Estuary Coast Shelf Sci., 54, 1051-1070. 

Summary 
The findings in this study assess the effectiveness of Integrated Water Resources Management (IWRM) in the Pra Basin of Ghana by looking at the implementation process and how it has impacted on the quality of the water resources. Using the implementation to assess the effectiveness of IWRM will help trace the root cause of any weakness identified, in other to propose appropriate measures to address them and improve on the management system.

Water resources management from the global level to the local level has undergone a series of historical transformations with the aim of getting an effective water management system (Hassan, 2011). Unfortunately, the earlier management reforms were said to be un-integrated and insensitive to the ecosystem and the environment (Merrey, 2008). The system is said to be fragmented with conflicting roles among stakeholders resulting in challenges in the management system. The Rio conference on the environment recommended that water should now be managed in an integrated manner. The integrated approach is projected to address the gaps in the un-integrated and achieve an effective water management system. Full and practical implementation of IWRM is very important to ensure effective water resources management. However, IWRM is criticized on the basis that it is not fully implemented and therefore the benefits are not realized. Ghana has been implementing IWRM since 2011 in the Pra Basin. The main aim of this study is to examine the gaps in the process of implementation and how it has impacted on the water quality in order to propose interventions that can help improve future implementation process and ensure effective water resources management.

Chapter 2 examines the effectiveness of Water Resources Management in the Pra Basin by assessing how it has been implemented to address the needs by addressing the following questions: 1 ) is the IWRM the appropriate management option? 2) Does the Pra Basin framework conform to the proposed IWRM framework? 3) What is working well? 4) What is not working well? 5) What is not happening but should have? The IWRM implementation in the Pra Basin on paper conforms to the proposed framework however, they are far apart in practice. Generally, the creation of the enabling environment, the institutional framework, the management instrument, and the problem identification in the basin was well conducted. However, there are questions when it comes to the appropriateness of the IWRM for the Pra Basin. The questions center on 1) the translation of framework on paper into practice; 2) some major stakeholders still not operating at the district level; 3) staff strength and logistical constraints; 4) absence of timelines in all the actions; $5)$ opinion leaders not seeing themselves as part of the board though they are represented; 6) 'how' the plan of actions will be achieved. Regarding what is not happening but should have, although Illegal mining (Galamsey) is very prevalent in the basin; the management framework is silent on it. The current framework needs improvement in the areas where questions have been raised if it needs to function well. To assess the effectiveness of the IWRM framework we assess the quality of 
the water resources from different dimensions.

Chapter 3 assesses the quality of the water resources after the implementation of the IWRM framework using water quality index (WQI). Eight (8) water sampling points from upstream to the downstream of the Basin were selected for sampling. Eight (8) physico-chemical and microbial parameters were used for the water quality measurement. Those sampling sites were chosen because the baseline data were measured using samples from those sites. The result generally shows significant deterioration in the quality of the water resources after the implementation, of IWRM. The level of suspended solids in the water was found to be a major contributor to the observed water quality deterioration. The high levels of suspended particles are due to illegal mining activities in and around the rivers. The worrying situation was that all the study sites failed to maintain their baseline water quality indexes. The study recommended the assessment of heavy metals in the water in addition to the parameters already assessed due to the illegal mining activities going on in the basin.

Chapter 4: assesses the levels of heavy metals from upstream to the downstream of the Pra Basin Rivers. The heavy metal assessment was based on two indices, the Canadian Council of Ministers of the Environment (CCME) Water Quality Index (WQI) and Nemerow's Pollution Index (NPI). The metal contamination measurement is very necessary because these rivers aside serving as the raw water sources for drinking water treatment plants in the basin is also used by some inhabitants along these rivers for domestic activities under water stress conditions. In all nine (9) metals were assessed and out of these five (5) metals exceeded the safe drinking water guidelines making the water unsafe for domestic activities like cooking. The pollution index reveals six metals namely $\mathrm{Pb}, \mathrm{Cd}, \mathrm{Cr}, \mathrm{Ni}, \mathrm{Fe}, \mathrm{Zn}$ as the principal metal pollutants in both the dry and wet seasons whereas $\mathrm{Mn}, \mathrm{As}$, and $\mathrm{Cu}$, were found not to contribute to the pollution effect. The water quality index confirms that the water quality is marginal to fair in the dry season and poor for 26 out of the 27 sites in the wet season. Generally, the studied rivers (Pra, Offin, and Oda) are polluted which is a serious threat to the health of inhabitants in the villages which still use the water for cooking activities.

Chapter 5: assesses the levels of heavy metals in the sediments of the Pra Basin Rivers from the upstream to the downstream for dry and wet seasons. River sediments have the potential of serving as sinks for heavy metals at high $\mathrm{pH}$ and releasing them into the water again under low $\mathrm{pH}$ or during scouring. Knowing the pollution status gives the overall picture of the pollution status of the water. In addition, certain benthic fishes feed on the sediments so may serve as a possible route into the food chain. In all 8 metals namely arsenic $(\mathrm{As})$, lead $(\mathrm{Pb})$, cadmium $(\mathrm{Cd})$, zinc $(\mathrm{Zn})$, manganese $(\mathrm{Mn})$, total chromium ( $\mathrm{Cr}$ ), nickel (Ni) and iron (Fe) were studied from 27 sampling sites. The result reveals enrichment at all site for the metals $\mathrm{Cr}, \mathrm{Pb}$, and $\mathrm{Cd}$ in the 
wet seasons. However, only 4 out of the 27 sites showed $\mathrm{Ni}$ enrichment in the wet season. Contrary to the wet season, only $\mathrm{Pb}$ and $\mathrm{Cr}$ recorded enrichment at all sites during the dry season. Fifteen (15) out of the 27 sites recorded Cd enrichment and 24 out of the 27 sites recorded $\mathrm{Ni}$ enriched during the dry season. For both dry and wet seasons, the pollution load index for all the sites except one was at the background levels which is a sign of non-deterioration of the sites studied. In the wet season, the calculated Igeo reveals that the study area is not contaminated with respect to $\mathrm{As}, \mathrm{Zn}, \mathrm{Fe}$, and $\mathrm{Mn}$; uncontaminated to moderately contaminated with $\mathrm{Cd}$; moderately contaminated with $\mathrm{Cr}$; uncontaminated to moderately to heavily contaminated with $\mathrm{Ni}$, and moderately to heavily contaminated with $\mathrm{Pb}$. The dry season Igeo results reveal non-contamination of the study area with respect to $\mathrm{As}$, Fe, and $\mathrm{Mn}$; uncontaminated to moderately contamination with $\mathrm{Zn}$; moderately contaminated with $\mathrm{Cr}$; uncontaminated to heavily contaminated with $\mathrm{Cd}$; uncontaminated to extremely contaminated with $\mathrm{Ni}$; and moderately to extremely contaminated with $\mathrm{Pb}$. The high levels of $\mathrm{Cd}, \mathrm{Pb}$, and $\mathrm{Cr}$ in all the sites are due to unregulated illegal mining activities occurring in and around the study area. It is hoped that this study will prompt the basin management board to improve their management strategies in controlling unregulated illegal mining in the basin.

Chapter 6: reports on a behavioral study using the Theory of Planned Behavior (TPB) to assess the behavioral factors which influence illegal miner's choice of an alternative job. This study was motivated by the fact that effort by the government to stop illegal mining failed despite the provision of an alternative job. The findings from the structural equation analysis revealed that the model could predict illegal miner's intention of choosing an alternative job. The attitude was found to be the only dominant significant antecedent of the behavioral intention. The findings from the study reveal that Perceived Behavioral Control (PBC) which has been the focus of the job intervention in the basin is not a predictor of intention which confirms why miners are back to site working.

Chapter 7: summarizes the main findings from the various studies, methodologies involved and the implications of this study on future research. From the main findings of this study, it can be concluded that there are gaps in the implementation process which have negatively affected the effectiveness of water resources management in the basin. First, our research highlights six implementation challenges which impact negatively on the integrated water resources management. Second, these implementation gaps are found to cause the pollution of the water resources by introducing a high level of suspended particles and heavy metals making the water unsafe for those who still depend on them under water stress conditions. Third, the river sediments which is known to serve as sinks for heavy metals was found to be enriched and contaminated with heavy metals. Fourth, an effort to improve the water management through the provision of an alternative job to reduce failed because the control belief which was used as the focus of the intervention was not 
a predictor of the behavioral intervention. The water management system can be effective if it is fully implemented and monitored with the measurable determinants and taking appropriate action on the feedback from these determinants. 



\section{Acknowledgements}


First and foremost, I have to thank my research supervisors, Professor Nanne de Vries, and Professor Kwabena Biritwum Nyarko. Without their assistance and dedicated involvement in every step throughout the process, this Ph.D. study would have never been accomplished. I would like to thank you very much for your support and understanding over these past four years. I would also like to show gratitude to the evaluation committee, who made very insightful inputs into the thesis to bring it to its current form. Even though I have not had the opportunity to work with you, the impact of your contribution to the work is much appreciated.

I am particularly grateful to the Netherlands Organization for International Cooperation in Higher Education (NUFFIC) for the financial contribution to make this study a success. I also want to thank the University of Cape Coast Ghana for the support they offered throughout this study.

Getting through my dissertation required more than academic support, and I have many, many people to thank for listening to and, at times, having to tolerate me over the past four years. I cannot begin to express my gratitude and appreciation for their friendship. Mr. Adai of Abono community, Dr. Ofosu of the University of Energy Sunyani, Mr. Osei of Technology Village University of Cape Coast, Veronica Adu-Sei, Jonathan Oti and the Omanhene of Dunkwa On Ofin have been unwavering in their personal and professional support during the time I spent on the field. For many memorable days out and in, I must thank everyone above as well as Mr. Frimpong. I would also like to thank Pastor Benjamin Odetola who opened both her home and heart to me when I first arrived in the city.

Most importantly, none of this could have happened without my family. My wife, Roberta Duncan who offered her encouragement through phone calls and skype every day when I am in Maastricht despite my own limited devotion to correspondence. With her own brand of humor, Roberta has been kind and supportive to me over the last several years. To my children and my siblings - it would be an understatement to say that, as a family, we have experienced some ups and downs in the past four years. Every time I was in Maastricht there is always issues you had to battle with yet you encouraged me to hold on. I am forever grateful. This dissertation stands as a testament to your unconditional love and encouragement. 
Valorization 
This chapter discusses the importance of this dissertation to social, economic and environmental development. It also discusses how the findings can reach the target group. Partial implementation of integrated water resources management is a major setback for effective water resources management. Ineffective water management, therefore, has negative consequences on the environment and socio-economic developments. Thus, effective management of water resources is very important for today and future society. Unfortunately, little empirical evidence exists on extensive and regular assessment on how the water resources management in the basin have been effective. The findings in this dissertation provide an overview of water resources management in the Pra Basin of Ghana. It highlights the implementation gaps and its consequences on effective water resources management.

The main gaps identified in the effectiveness of water resources management centers on the implementation framework (Chapter 2). A good and practical implementation framework is very critical for effective water resources management (Hassan 2009). There are recommendations on how to implement fully IWRM to enjoy the full benefits. The empirical evidence in this dissertation shows the effort put in place in setting up the Pra Basin implementation framework. However, the state of the water resources in the Pra Basin raises a question about the effectiveness of the implementation framework: a suspicion this study has confirmed. Thus, policymakers must augment their effort to strengthen the existing inter-sectoral collaboration among water and its related sectors to improve on coordination, actual participation, and execution of roles by all stakeholders especially those who are not at the basin level. This inter-sectoral collaboration even though already exists on paper, there is the need for water resources commission (WRC) to either equip or help the related stakeholders mandated to carry out some responsibilities source for logistics, human resources, etc. to ensure the practical transfer of information and data. WRC must come together with especially the technical stakeholders who only operate at the regional and national offices to create offices at the districts.

The findings in this dissertation provide information on the gaps contributing to the continuous deterioration of the water resources due to ineffective water resources management in the Pra Basin and pointed out some specific areas of intervention for improvement. For instance, chapter 6 revealed the absence of empirical evidence as to the cause of intervention failure. This dissertation recommends the establishment of a research and innovation team to liaise between the field and policymakers. This team should be composed of people with the local, social and the psychological, etc. expertise to ensure versatility, efficiency, and effectiveness.

Chapter 2 emphasizes the lack of IWRM awareness and education and the absence of training for environmental health officers (EHO's). There is a need for regular IWRM education and awareness creation through radio, television, durbars, and schools (debates, symposium, etc.). The expectations are that policymakers will plan this 
outreach program with timelines, budget and source of funding clearly indicated. This, when properly executed, will help spread the benefits as well as addressing the challenges of water resources management. The environmental health officer knowing his duties and being equipped with the knowledge and skills to carry out his duties are important determinants of his/her expected output. Currently, the University of Cape Coast is offering diploma and post-diploma programs for EHO's and other related sectors. However, most EHO's are not patronizing because of financial difficulties, inability to secure study leave and the inability to upgrade after training. WRC and the environmental health directorate can collaborate and work out the modalities to help train the EHO's and also draft a policy to outline the modalities concerning how and when trained officers will benefit from such training mentally, socially, environmentally and economically through upgrading after training. They, WRC can also collaborate with the University, to run short courses for the EHO's who are already on the field.

In chapter 2, this study recommended that an effort is made to incorporate IWRM into the training of EHO's in the long-term plan. It also proposes the establishment of a desk in all the districts assemblies as a long-term project. It must be emphasized that even though EHO's have general training in water in their syllabus; it is woefully below the level of IWRM delivery. By introducing substantial component into the training syllabus, all EHO's will have the exposure and will be equipped with the knowledge for the work ahead. Furthermore, the workload for EHO's is also a big challenge if they are to combine it with IWRM roles. They are already over-burdened by the major role they play in sanitation monitoring and rural water supply. Additional responsibilities may render them ineffective and unproductive. Creation of a separate desk with trained water and sanitation graduate or an EHO solely to manage water-related issues at the district level is important in strengthening the water resources management framework and delivery.

Concerning the beliefs and attitude of miners towards saving the deteriorating water quality and the environment, the perceived behavioral control (PBC) which was made the main focus of the intervention by the government was found not to be true in this study: a wrong selection of PBC was due to lack of empirical evidence. Gathering of empirical evidence and full or practical involvement of all stakeholders at all levels from the planning to implementation is very critical for introducing interventions successfully. Although PBC was not a significant predictor of illegal miner's behavioral intention (BI), the attitude was found to be the dominant significant antecedent of the behavioral intention. This empirical evidence can serve as a guide to interventions in basins of similar characteristics as well as being used by the Water Resources Commission (WRC) to strategize and reintroduce the intervention to save the water resources. WRC could achieve that by strategically directing all their expertise and resources in the sensitization and education of illegal miners' by focusing on the behavioral belief variables which 
were found to be reliable in addressing the beliefs in this study: improving raw water quality, protecting the ecosystem, helping regeneration of fishes and reducing water pollution. The link between subjective norm and attitude could be relied upon by WRC to first establish ties with the communities' using focus group discussion by using the traditional/ opinion and religious leaders as facilitators. As time elapses, this could be expanded gradually into a form of a durbar with the focus on short sketches, demonstrations which will highlight the behavioral beliefs. This can further be augmented by education in primary, junior and senior high schools, and on radio and, television. These processes have a lot of benefits. First, the illegal miners' will be well sensitization and educated for any possible change over. Second, the miners and the entire communities will have confidence and trust in the proposals that will be brought before them and be ready to own it. Third, community members or the youth who wished to join will now be educated, informed and unmotivated to engage in such activities.

The consequences of the polluted river on socioeconomic development and ecosystem stability cannot be underestimated. The continuous deterioration of the rivers as discussed in chapters 3,4 , and 5 are very big challenges which if not salvaged could seriously slow down economic growth and development. The effectiveness of the interventions to address pollution is strongly linked to recommendations made by the study. Introducing interventions without a proper empirical assessment of the situation will yield no fruitful results. There is, therefore, the need to use an approach that will unearth the facts concerning the pending situation before arriving at any intervention. In the last quarter of 2016, the Pra Basin officers together with the people of Abono and its surrounding villages piloted one of the recommendations of this dissertation: using intervention mapping in providing an alternative job. The approach has been very effective. For example, this intervention mapping approach can be piloted in the mining communities and monitored to improve on any weakness or gaps identified before it could be scaled up to address the illegal mining menace. 


\section{Curriculum Vitae}


Albert Ebo Duncan was born in Winneba in the Central Region of Ghana. He completed a Bachelor of Chemistry degree in University of Cape Coast (UCC) Ghana in 1999. He obtained a master degree in Water Supply and Environmental Sanitation from Kwame Nkrumah University of Science and Technology in 2008. He started his professional career as a chemistry tutor in St. Mary's Boys Senior Secondary School where he was involved with the organization of examination as well as serving as the chemistry resource person for the science resource center in the district. In 2009 Albert was employed as a lecturer into the chemistry department in UCC. He specifically works in the water and sanitation unit where he is involved with student teaching, perform and supervise student research, and coordinates master plan programs. In June 2012 to August 2013 Albert was appointed the academic advisor for first-year students in the department of chemistry. After his counseling role, he was appointed the department's examination officer a position he occupied until the commencement of his Ph.D. in late 2014. His main responsibility in that capacity was to coordinate examination results for departmental board meetings and represent the department at the faculty examination board. More importantly, he assists students in the department to resolve challenges in their examination results. He received a sponsorship as part of the capacity building project by NUFFIC in 2014 February to start his Ph.D. program. Though Albert got a study leave from UCC due to the issue of inadequate staff in his unit (water and sanitation) in the department of chemistry he had to opt for the split-site program where he spends part of the year in the Netherlands for intensive analysis and write up and part in Ghana for data collection and teaching. In April 2015, Albert was promoted from the rank of a lecturer to the rank of a senior lecturer. 


\section{Publications}


Duncan, A. E., de Vries, N., \& Nyarko, K. B. (2019). The effectiveness of water resources management in Pra Basin. Water Policy.

Albert Ebo Duncan, Nanne de Vries, Kwabena Nyarko. Assessing the Effect of Integrated Water Resources Management on Water Quality in Ghana, International Journal of Latest Research in Science and Technology: Vol. 5 Issue 6 Pages 60- 65 November - December 2016

Duncan, A. E., de Vries, N., \& Nyarko, K. B. (2018). Assessment of heavy metal pollution in the main Pra River and its tributaries in the Pra Basin of Ghana. Environmental nanotechnology, monitoring \& management, 10, 264-271.

Duncan, A. E., de Vries, N., \& Nyarko, K. B. (2018). Assessment of Heavy Metal Pollution in the Sediments of the River Pra and Its Tributaries. Water, Air, \& Soil Pollution, 229(8), 272.

A.E. Duncan, E. Awuah, D.K. Dodoo, A. Sam, Y. Ameyaw, Assessing The Potential of A Natural Wetland in Grey Water Treatment (A Case Study in Cape Coast - Central Region of Ghana), International Journal of Applied Environmental Sciences ISSN 0973-6077 Volume 5, Number 5 (2010), pp. 699-705 @ Research India Publications

R.K. Yankey, T.T Akiti, S. Osae, J.R. Fianko, A.E. Duncan, E.O. Amartey, D.K. Essuman, and O. Agyemang, The Hydrochemical Characteristics of Groundwater in the Tarkwa Mining Area, Ghana, Research Journal of Environmental and Earth Sciences 3(5): 600-607, 2011 ISSN: 2041-0492 @ Maxwell Scientific Organization, 2011

A. Sam, F. Okai-Sam, Duncan A. E and Y Ameyaw, Assessment of the Cation Exchange Capacities and Elemental Compositions of Clay Samples from the Eastern Region of Ghana), International Journal of Applied Environmental Sciences ISSN 0973-6077 Volume 6, Number 2 (2011), pp. 201-208 @ Research India Publications

R.K. Yankey, J.R. Fianko, S. Osae, E.K. Ahialey, A. E Duncan, D.K. Essuman, J.K. Bentum Evaluation of heavy metal pollution index of groundwater in the Tarkwa mining area, Ghana. Elixir Pollution Science 54 (2013) 12663 - 12667

M.Oteng- Peprah, M.O. Marfo, A. Duncan and A. A Sitsofe, Rainwater harvesting potential of University of Cape Coast campus: a GIS approach Sustainable Water and Sanitation Services For All in Fast-Changing World, $37^{\text {th }}$ WEDC International Conference, Hanoi, Vietnam,2014

Duncan A. E., Peprah, M.O, Marfo M.O., Tetteh, G., Opoku, A. E. (2014). Groundwater Quality Analysis on Selected Hand-Dug Wells in the Cape Coast Metropolis, Ghana: A Case Study of Abura. Journal of Basic and Applied Sciences, 1 (2), 23-30 

